\title{
5 Fallstudien III: Romane der Gegenwart
}

In einer dritten Gruppe von Fallstudien wurde die Rezeption von Patrick Süskinds Das Parfum. Geschichte eines Mörders (1985), Bernhard Schlinks Der Vorleser (1995) und Daniel Kehlmanns Die Vermessung der Welt (2005) betrachtet. Romane der Gegenwartsliteratur zu wählen, hat seinen Grund vor allem darin, dass sie die Möglichkeit eröffnen, die zeitgenössische Rezeption nichtprofessioneller Rezipient/-innen außerhalb der Wissenschaft in einer Art und Weise zu untersuchen, die vor dem Entstehen literarischer Kommunikation im Internet nicht möglich war. Eine Plattform wie LovelyBooks, die einleitend kurz $\mathrm{zu}$ beschreiben sein wird, bietet eine Fülle an Rezeptionsdokumenten, welche darüber Aufschluss zu geben vermögen, ob und wie die genannten Romane appliziert werden. Die Wahl der drei Texte lag insofern nahe, als sie im zeitgeschichtlichen Rahmen, also ungefähr in den letzten dreißig Jahren, zu den Romanen gehörten, die beim deutschsprachigen und internationalen Publikum besonders erfolgreich waren.

\subsection{Literarische Kommunikation bei LovelyBooks}

Die Quellengrundlage bedarf einer knappen Einordnung und Erläuterung. Neben Rezensionen in Tageszeitungen und Zeitschriften gehören zu den Quellen Rezensionen, die bei LovelyBooks, einer deutschsprachigen Lesegemeinschaft im Internet, eingestellt wurden und somit in den Bereich digitaler literarischer Kommunikation gehören.

Literarische Kommunikation im Internet kann verschiedene Formen annehmen. ${ }^{1}$ Dazu zählen Kundenrezensionen bei einem Versandhändler, ${ }^{2}$ BuchBlogs, ${ }^{3}$ Video-Rezensionen bei einem Portal wie Youtube, ${ }^{4}$ social reading-

1 Vgl. zu den weiterreichenden medialen Implikationen der Digitalität für den Umgang mit Literatur z. B. Martin Doll: Lesen im Zeitalter der Digitalisierung. In: Alexander Honold/Rolf Parr (Hg.): Grundthemen der Literaturwissenschaft: Lesen. Berlin/Boston 2018, S. 469-489.

2 Vgl. z. B. Andrea Bachmann-Stein: Zur Praxis des Bewertens in Laienrezensionen. In: Heinrich Kaulen/Christina Gansel (Hg.): Literaturkritik heute. Tendenzen - Traditionen - Vermittlung. Göttingen 2015, S. 77-91.

3 Vgl. z. B. Dominik Achtermeier: Drei von fünf Sternen: Literaturkritik 2.0. Die Rezension in den neuen Medien und als Ausdrucksform heranwachsender Blogger. In: Andrea Bartl/Markus Behmer (Hg.): Die Rezension. Aktuelle Tendenzen der Literaturkritik. Würzburg 2017, S. 203224. 
Plattformen wie Goodreads im englischsprachigen Raum und eben LovelyBooks im deutschsprachigen. Daneben gibt es Plattformen, auf denen man selbst literarische Texte publizieren und von anderen Nutzer/-innen kommentieren lassen kann. ${ }^{5}$ Digitale literarische Kommunikation stelle seit einiger Zeit ein „Massenphänomen“ dar, sie habe sich „zu einer ernsthaften Alternative zur professionellen Kritik“ entwickelt und zeige, dass „das Bedürfnis, über Literatur zu kommunizieren, heute größer oder sichtbarer denn je“ ist. ${ }^{6}$ Die Frage, wie Literaturkritik von ,Laien' einzuschätzen ist, hat die Forschung bereits verschiedentlich beschäftigt. ${ }^{7}$ Auf der einen Seite seien durch das Internet Rezensionen stets und in großer Zahl verfügbar. Literaturkritik erfahre eine größere Verbreitung, es werden neue Gegenstände erschlossen und neue Verfasser/innen und Leser/-innen gewonnen. Auf der anderen Seite könne es, etwa im Falle von Kundenrezensionen bei Versandhändlern, eine nicht wünschenswerte Verquickung mit ökonomischen Interessen geben. Glaubwürdigkeit und Qualität seien nicht immer gewährleistet. Das traditionelle Rezensionswesen in den Print-Medien gerate durch die neuen Alternativen unter Druck. Es büße seine Funktionen in Teilen ein. ${ }^{8}$

Damit sind einige wichtige Rahmenbedingungen und Merkmale genannt, die diese Form der literarischen Kommunikation auszeichnen. Das Internet bietet eine niedrigschwellige Möglichkeit, sich auf verschiedene Weise aus einem großen Angebot über Literatur zu informieren gemäß den individuellen Interessen. Die Verfasser/-innen mögen Expert/-innen auf ihrem jeweiligen Gebiet (z. B. einem Genre) sein, in der Regel dürfte ihre Autorität jedoch auf anderem Wege zustande kommen als in der traditionellen Literaturkritik, wo

\footnotetext{
4 Ina Brendel-Perpina: Die Video-Rezension als kulturelle Praxis der Booktuber. Eine kulturwissenschaftlich-didaktische Perspektive. In: Andrea Bartl/Markus Behmer (Hg.): Die Rezension. Aktuelle Tendenzen der Literaturkritik. Würzburg 2017, S. 253-274.

5 Vgl. z. B. Gesine Boesken: Literaturplattformen. In: Christine Grond-Rigler/Wolfgang Straub (Hg.): Literatur und Digitalisierung. Berlin/Boston 2013, S. 21-42; zur Netzliteratur z. B. Jörgen Schäfer: Netzliteratur. In: Natalie Binczek/Till Dembeck/Jörgen Schäfer (Hg.): Handbuch Medien der Literatur. Berlin/Boston 2013, S. 481-501.

6 Oliver Pfohlmann: Literaturkritik in der Bundesrepublik. In: Thomas Anz/Rainer Baasner (Hg.): Literaturkritik. Geschichte - Theorie - Praxis. München 2004, S. 169-191, hier S. 188.

7 Das im Folgenden Angeführte stammt aus Thomas Anz: Kontinuitäten und Veränderungen der Literaturkritik in Zeiten des Internets: Fünf Thesen und einige Bedenken. In: Renate Giacomuzzi/Stefan Neuhaus/Christiane Zintzen (Hg.): Digitale Literaturvermittlung. Praxis Forschung - Archivierung. Innsbruck/Wien/Bozen 2010, S. 48-59.

8 Von einem Geltungsverlust der traditionellen Literaturkritik spricht Barbara Basting: Das Ende der Literaturkritik, wie wir sie kannten. In: Philipp Theison/Christine Weder (Hg.): Literaturbetrieb. Zur Poetik einer Produktionsgemeinschaft. München 2013, S. 49-62.
} 
davon ausgegangen werden kann, dass die Verfasser/-innen professionelle Vermittler/-innen sind und das Medium Funktionen wie Filterung und Qualitätssicherung erfüllt. Bei der Literaturkritik im Internet könnte stattdessen zum Beispiel der Umstand eine Rolle spielen, dass die Texte von Gleichgesinnten verfasst werden. Der Schritt von der Rezeption literaturkritischer Texte zur aktiven Partizipation ist einfach und prinzipiell jedermann möglich. Nicht zuletzt aufgrund der Akteur/-innen und der medialen Gegebenheiten ist die nichtprofessionelle Kommunikation über Literatur im Internet eine spezifische Form, bei der sich Gemeinsamkeiten mit traditioneller Literaturkritik feststellen lassen. ${ }^{9}$

Anders als zum Beispiel Kundenrezensionen hat die Forschung bisher, soweit sich das sagen lässt, LovelyBooks eher selten wahrgenommen. ${ }^{10}$ LovelyBooks ist, so die Erläuterung in der Wikipedia, „ein webbasiertes soziales Netzwerk mit Web-2.0-Funktionalität für Literaturinteressierte“. ${ }^{11}$ Es wird betrieben

9 Vgl. zur Literaturkritik im Internet allgemein bzw. in Sozialen Medien Christoph SchmittMaaß: Gespräch oder Geschwätzigkeit? Salonkultur im WorldWideWeb - InternetLiteraturkritik als Form der (Selbst-)Verständigung. Mit einem Seitenblick auf Friedrich Schleiermacher und Friedrich Schlegel. In: Sylvie Grimm-Hamen/Françoise Willmann (Hg.): Die Kunst geht auch nach Brot! Wahrnehmung und Wertschätzung von Literatur. Berlin 2010, S. 89-106; Thomas Wegmann: Warentest und Selbstmanagement. Literaturkritik im Web 2.0 als Teil bürgerlicher Wissens- und Beurteilungskulturen. In: Matthias Beilein/Claudia Stockinger/Simone Winko (Hg.): Kanon, Wertung, Vermittlung. Boston/Berlin 2012, S. 279-291; Karin S. Wozonig: Literaturkritik im Medienwechsel. In: Christine Grond-Rigler/Wolfgang Straub (Hg.): Literatur und Digitalisierung. Berlin/Boston 2013, S. 43-68; Stefan Neuhaus: „Leeres, auf Intellektualität zielendes Abrakadabra“. Veränderungen von Literaturkritik und Literaturrezeption im 21. Jahrhundert. In: Heinrich Kaulen/Christina Gansel (Hg.): Literaturkritik heute. Tendenzen - Traditionen - Vermittlung. Göttingen 2015, S. 43-57; Thomas Ernst: ,User Generated Content' und der Leser-Autor als ,Prosumer'. Potenziale und Probleme der Literaturkritik in Sozialen Medien. In: Heinrich Kaulen/Christina Gansel (Hg.): Literaturkritik heute. Tendenzen - Traditionen - Vermittlung. Göttingen 2015, S. 93-111; Renate Giacomuzzi: Die Veränderung des Kanons durch die digitalen Medien oder: Formen der literarischen Wertung im Internet. In: Stefan Neuhaus/Uta Schaffers (Hg.): Was wir lesen sollen. Kanon und literarische Wertung am Beginn des 21. Jahrhunderts. Würzburg 2016, S. 193-203.

10 Vgl. aber Raphaela Knipp: Gemeinsam lesen. Zur Kollektivität des Lesens in analogen und digitalen Kontexten (LovelyBooks). In: Sebastian Böck u. a. (Hg.): Lesen X.0. Rezeptionsprozesse in der digitalen Gegenwart. Göttingen 2017, S.171-190, hier S. 179-186; Katharina Lukoschek: „Ich liebe den Austausch mit euch!“ Austausch über und anhand von Literatur in Social-Reading-Communities und auf Bücherblogs. In: Andrea Bartl/Markus Behmer (Hg.): Die Rezension. Aktuelle Tendenzen der Literaturkritik. Würzburg 2017, S. 225-252, hier S. 245-250. 11 https://de.wikipedia.org/wiki/LovelyBooks (01.07.2020). Daneben sei auf die journalistische Berichterstattung verwiesen, exemplarisch etwa Oliver Jungen: Die ungeschlagene Schlacht. In: Frankfurter Allgemeine Zeitung. Nr. 50, 28. Februar 2015, S. 18; Melanie Mühl: Ein 
von der aboutbooks $\mathrm{GmbH}$, welche der Verlagsgruppe Georg von Holtzbrinck gehört. ${ }^{12}$ Die Seite gibt es seit 2006. Die Nutzung des Angebotes ist kostenlos, manche Formen der Partizipation setzen eine Registrierung voraus. Es ist nicht erforderlich, den Klarnamen zu verwenden. In der überwiegenden Zahl der Fälle wählen die Nutzer/-innen Pseudonyme.

Den Nutzer/-innen stehen verschiedene Möglichkeiten der Information und aktiven Partizipation zur Verfügung: Sie können Bewertungen von Büchern (auf einer Skala von ein bis fünf Sterne) ansehen und abgeben, Rezensionen lesen, kommentieren, als hilfreich beurteilen und schreiben, zu Genres, Autor/-innen und Themen recherchieren, Bücherregale, thematische oder anlassbezogene Bücherlisten einsehen und erstellen, Ranglisten einsehen und für Bücher abstimmen, Bücher teilen und empfehlen, sich Empfehlungen geben und (per Rundschreiben) Informationen zuschicken lassen, Kontakt $\mathrm{zu}$ anderen Nutzer/innen mit ähnlichen Lektüreinteressen knüpfen, Kontakt zu Autor/-innen aufnehmen, etwa in Form von Fragerunden und Livestream-Lesungen, an Buchverlosungen und Leserunden teilnehmen, Leserunden initiieren. Es gibt Aktionswochen, Veranstaltungen und einen Publikumspreis mit verschiedenen Kategorien. Die gelesene und besprochene Literatur lässt sich überwiegend den Gattungen Kriminalroman und Thriller, Fantasy und Science-Fiction, historischer Roman, Liebesroman und erotische Literatur zuordnen. Schon allein hieran lässt sich erkennen, dass die beim Publikum beliebte, kommerziell erfolgreiche Literatur im Vordergrund steht, nicht diejenige, welche überwiegend im Feuilleton rezipiert wird. Daneben werden Sachbücher sowie Kinder- und Jugendbücher behandelt. ,Klassiker` der deutschsprachigen und der Weltliteratur sind ebenfalls vertreten, spielen aber eine untergeordnete Rolle.

Stand Juni 2018 wird die Seite nach Angaben der Betreiber im Monat 1,5 Millionen Mal aufgerufen. LovelyBooks hat 320.000 registrierte Mitglieder und 7.000 registrierte Autor/-innen, 6.000 aktive Blogger und Multiplikatoren und 500 Partnerverlage. ${ }^{13}$ Es bestehen Verbindungen mit Facebook, Twitter, Instagram und Youtube, letzterer Kanal wird für die Livestream-Lesungen genutzt. Auf Grundlage einer Nutzerbefragung von 2015 mit rund 6.000 Teilnehmer/-

Herzchen für die faire Rezi. In: Frankfurter Allgemeine Zeitung. Nr. 24, 28. Januar 2017, S. 18; und bereits Julia Roebke: Spione in Lokis und Saris Buchregalen. In: Frankfurter Allgemeine Zeitung. Nr. 141, 19. Juni 2008, S. 46.

12 Alle im Folgenden angeführten Informationen sind der Selbstbeschreibung der Plattform entnommen, vgl. dazu https://www.lovelybooks.de/info/presse/ (01.07.2020), oder sie wurden aus eigenen Beobachtungen der Seite gewonnen.

13 Vgl. https://s3-eu-west-1.amazonaws.com/media.lovelybooks.de/LovelyBooks_2018.pdf (01.07.2020), hier auch die folgenden Angaben. 
innen wirbt der Anbieter unter anderem damit, dass Nutzer-/innen von LovelyBooks im Durchschnitt rund 40 Bücher im Jahr lesen und 24 kaufen. 70\% kaufen regelmäßig Bücher, auf die sie auf dieser Plattform gestoßen sind; $62 \%$ haben im letzten Monat mindestens ein Buch weiterempfohlen, das sie auf der Plattform gefunden haben. Daran lässt sich das Geschäftsmodell erkennen. ${ }^{14}$ Es ist für Verlage attraktiv, auf der Seite Anzeigen zu schalten und über Produkte zu informieren, Exemplare für Leserunden zur Verfügung zu stellen und Lesungen mit Autor/-innen anzubieten, weil LovelyBooks den zum Teil wohl passgenauen Kontakt zu einem wichtigen Segment der Zielgruppe ermöglicht, zumal der Kerngruppe der Vielleser/-innen und Expert/-innen (im Genre-Bereich). Es wird jedenfalls damit geworben, dass Verlage und Autor/-innen auf der Plattform einen guten Zugang zu ihrer jeweiligen Zielgruppe aufbauen, pflegen und erweitern können. Die Nutzer/-innen dürften eine wichtige Funktion als Multiplikatoren haben, da, so die Annahme, das Urteil und die Empfehlung von Gleichgesinnten für die Kaufentscheidung ausgesprochen relevant sind. Wie auf dem Buchmarkt allgemein, geht es also darum, Bücher zu verkaufen. ${ }^{15} \mathrm{Ne}$ ben diesem konkreten Ziel kann man bei den Betreibern, Verlagen und Autor/innen das Kalkül vermuten, auf zeitgemäße Weise die Lesekultur zu pflegen und so dazu beizutragen, dass das Lesepublikum mittelfristig stabil bleibt und unter Umständen vergrößert werden kann.

Die wohl bisher umfangreichste Studie zu literarischer Kommunikation im Internet, die auf der Auswertung einer großen Menge an Texten beruht, wurde zu Kundenrezensionen bei Amazon durchgeführt. Die Studie erbrachte zahlreiche Ergebnisse, die im Rahmen dieser Arbeit aufschlussreich sind. ${ }^{16}$ Typischer-

14 Vgl. zum Folgenden die Ergebnisse einer Online-Studie, die Mitte 2012 bei LovelyBooks stattfand und an der sich rund 2.3000 Nutzer/-innen beteiligten: Vielleser \& Multiplikatoren. Wer sind die Multiplikatoren im Netz und wie wertvoll sind ihre Rezensionen und Empfehlungen für Verlage? http://media.lovelybooks.de.s3.amazonaws.com/lb_vielleserund multiplikatoren_studie2012.pdf (01.07.2020).

15 Der Weg zum Bestellen bei einem Versandhändler ist sehr kurz. Jedes Buch hat eine eigene Seite, auf der sich neben den Rezensionen, Bewertungen usw., gut sichtbar unterhalb des Covers und der Tasten für verschiedene Aktionen (Teilen, Bewerten, auf Wunschzettel setzen, in Bibliothek stellen, Buch folgen), Verknüpfungen finden zu den Seiten des Buches bei Amazon, Hugendubel und Thalia.

16 Vgl. zum Folgenden insbesondere Holger Kellermann/Gabriele Mehling: Laienrezensionen auf amazon.de im Spannungsfeld zwischen Alltagskommunikation und professioneller Literaturkritik. In: Andrea Bartl/Markus Behmer (Hg.): Die Rezension. Aktuelle Tendenzen der Literaturkritik. Würzburg 2017, S. 173-202, v. a. S. 188-196. Noch detailliertere Informationen zu einigen Aspekten bietet Gabriele Mehling/Axel Kellermann/Holger Kellermann/Martin Rehfeldt: Leserrezensionen auf amazon.de. Eine teilautomatisierte inhaltsanalytische Studie. 
weise seien Rezensionen bei Amazon kurz (mit einem Durchschnitt von 110 Wörtern bzw. 605 Zeichen und einem Median von 47 Wörtern und 264 Zeichen). Im Durchschnitt würden 4,1 Sterne vergeben; die Nutzer/-innen bewerten die Bücher also in der Regel sehr gut. Eine Mehrheit vergebe die Bestnote. Die Möglichkeit, Rezensionen als hilfreich $\mathrm{zu}$ bewerten und $\mathrm{zu}$ kommentieren, werde nur in einer Minderheit der Fälle genutzt. Wertungen kämen in so gut wie jeder Rezension vor, genauer in 91\% der Fälle (aus einer Stichprobe von 507 mit einer Grundgesamtheit von 19.407 Rezensionen, die 2012 und $2013 \mathrm{zu}$ insgesamt 24 Büchern verfasst wurden, welche vordere Plätze in der Bestsellerliste des Spiegel belegten). Durchschnittlich enthalte jede Rezension zwei Wertungen. 92\% wiesen Merkmale auf, die für Alltagsgespräche über Bücher typisch seien, im Durchschnitt seien es zwei. ${ }^{17}$ In 94\% der Texte finde sich ein Element, das als typisch angesehen werden könne für professionelle Literaturkritik, im Durchschnitt zwei. ${ }^{18}$ Es gebe Rezensionen, in welchen die Tendenz zur Alltagskommunikation stärker ausgeprägt sei, und solche, in denen Merkmale professioneller Literaturkritik überwögen. Aufs Ganze gesehen sei die Neigung zur Alltagskommunikation ausgeprägter.

Die Ergebnisse dieser Studie sind wohl nicht eins zu eins übertragbar auf LovelyBooks. Eine nur annähernd ähnlich detaillierte, quantifizierende Studie für die ausgewerteten Rezensionen bei LovelyBooks kann im Rahmen dieser Arbeit natürlich nicht geleistet werden. Sie wäre mit Blick auf die leitende Fragestellung nur von begrenztem Aussagewert. Auf Basis einer Lektüre von mehr als 1.000 Rezensionen lassen sich aber einige allgemeine Angaben machen, die

Bamberg 2018. Vgl. bereits Holger Kellermann/Gabriele Mehling/Martin Rehfeldt: Wie bewerten Laienrezensenten? Ausgewählte Ergebnisse einer inhaltsanalytischen Studie. In: Stefan Neuhaus/Uta Schaffers (Hg.): Was wir lesen sollen. Kanon und literarische Wertung am Beginn des 21. Jahrhunderts. Würzburg 2016, S. 229-238.

17 „Zu den Inhalten von Alltagsgesprächen über Bücher gehören, (1) wie man zum Buch gekommen ist (Aufmerksamkeit/Erwerb/Empfehlung), (2) auf welche Weise man das Buch gelesen hat (Tempo, Unterbrechungen, Abbruch), (3) welche Gratifikation die Lektüre verschafft hat, (4) ob und welche Formen der Identifikation angestoßen wurden, (4) [!] ob und welche Veränderungen die Lektüre ausgelöst hat und (5) [!] was einen veranlasst, über das Buch zu sprechen.“ - Kellermann/Mehling: Laienrezensionen auf amazon.de im Spannungsfeld zwischen Alltagskommunikation und professioneller Literaturkritik, S. 189 f.

18 Dazu zählen die Verfasser Angaben zum Inhalt, bibliographische Informationen und Kaufempfehlungen, Wertungen, Bezugnahmen auf andere literarische Texte und kulturelle Artefakte sowie auf gesellschaftliche Gegebenheiten, ferner Aussagen zur sprachlichen Qualität, vgl. Kellermann/Mehling: Laienrezensionen auf amazon.de im Spannungsfeld zwischen Alltagskommunikation und professioneller Literaturkritik, S. 180-185. 
geeignet sind, in Umrissen zu verdeutlichen, wie die Rezensionen beschaffen sind. ${ }^{19}$ Dabei ergeben sich Ähnlichkeiten mit Kundenrezensionen bei Amazon.

In den Rezensionen finden sich üblicherweise Aussagen zum Inhalt, also zu Figuren, Handlung und Schauplatz, Angaben zu emotionalen Reaktionen und ästhetischen Eindrücken (Unterhaltung und Spannung, Mitleid, Immersion, Entsetzen, Ekel usw.) und Bewertungen. Die Wertungen sind häufig explizit und stark, Gefallen und Missfallen werden deutlich artikuliert. Es gibt eine Tendenz zur positiven bis sehr positiven Beurteilung, was zumindest zum Teil wohl darauf zurückgeführt werden kann, dass die Motivation, eine Rezension zu schreiben, dann besonders hoch ist, wenn einem das Buch gefällt, da man manchen Nutzer/-innen wohl eine Neigung unterstellen darf, gerne insbesondere über das zu reden, was sie mögen. Es werden Lektüreempfehlungen ausgesprochen. Aspekte der formalen Beschaffenheit wie der Schreibstil werden seltener beachtet und dann in der Regel eher allgemein beschrieben und vor allem beurteilt. Einen großen Stellenwert können hingegen der Lektüreaufwand und die Textverständlichkeit haben. Es wird von einigen als der Mitteilung wert erachtet, festzustellen, ob der Text einfach oder schwierig zu lesen ist, wie kurz oder lang er ist, als wie lang (oder langatmig) einzelne Schilderungen oder Kapitel wahrgenommen werden, ob das Buch lange Sätze und unvertraute Wörter enthält oder zum Beispiel aufgrund des historischen Abstandes zusätzliche Verstehensvoraussetzungen macht. Generische und literaturgeschichtliche Einordnungen sowie Einordnungen in das Werk des Autors werden selten vorgenommen. Bezüge zur Gegenwart werden in der Regel nicht hergestellt. Es scheint aber eine Neigung zu geben, eine etwaige Verfilmung zu thematisieren und Buch und Film zu vergleichen. Die Materialität des Mediums wird bisweilen erwähnt und beurteilt, zum Beispiel das Umschlag- bzw. Titelbild.

Außerdem werden Aussagen dazu gemacht, wann und wo man das Buch wie und warum gelesen hat. Ob das Buch Schullektüre war, man es auf Empfehlung kaufte oder geschenkt bekam, die Lektüre lange vor sich herschob, es einem zufällig in die Hände fiel, man es aus Anlass der Verfilmung las, mit in den Urlaub genommen hat und andere Informationen mehr erscheinen manchen Nutzer/-innen als so bedeutsam, dass sie davon berichten. Sie mögen nicht von

19 Zwei Einschränkungen sind allerdings zu machen: Gesichtet wurden Rezensionen zu Büchern, die auf dieser Plattform eher am Rande interessieren und kaum als aktuelle Neuerscheinung rezensiert werden konnten, da der jüngste Roman, Kehlmanns Die Vermessung der Welt, bekanntlich 2005 erschien und damit ein Jahr bevor die Internetseite aufgesetzt wurde. Beides dürfte dazu führen, dass die folgenden Aussagen nicht einfach für Rezensionen bei LovelyBooks allgemein gelten. 
sachlicher Relevanz sein, dafür aber von sozialer. Die Nutzer/-innen schreiben häufig aus ihrer eigenen Perspektive. Es sind ihre Erfahrungen, Gedanken und Eindrücke bei der Lektüre, ihre persönlichen Meinungen zum Buch, über die sie Auskunft geben. Einige Texte sind an konzeptioneller Mündlichkeit orientiert. Sie werden bisweilen unter Verwendung umgangssprachlicher Ausdrücke geschrieben und ohne dass in jedem Fall die Regeln der Orthographie, Grammatik und Interpunktion beachtet werden. ${ }^{20}$ In einigen Fällen dürften sie vermutlich spontan, situativ und unmittelbar anlassbezogen geschrieben worden sein und ohne eingehendere Durchsicht, worauf nicht zuletzt manche weniger gelungene Ausdrücke und Formulierungen schließen lassen. Die Länge der Texte variiert von wenigen Sätzen (im Extremfall gar nur ein bis zwei) bis hin zu mehreren Absätzen. Der Aufbau ist unterschiedlich. Neben sehr freien Formen gibt es klar strukturierte Texte, die sich an einem Muster zu orientieren scheinen und, in einigen Fällen durch Zwischenüberschriften optisch untergliedert, erst den Inhalt wiedergeben, dann ausgewählte Aspekte bewerten, die Bewertung begründen und schließlich zu einer Gesamtbeurteilung kommen. ${ }^{21}$

Allgemein gesprochen, kann man zwei Typen unterscheiden, auf der einen Seite die (sehr) kurzen, ganz überwiegend aus Gefallensbekundungen und der Schilderung subjektiver Eindrücke bestehenden Rezensionen, ${ }^{22}$ und auf der anderen Seite diejenigen, die in einem bestimmten Umfang Merkmale dessen aufweisen, was man landläufig unter einer Rezension versteht. Viele, vielleicht sogar die meisten Nutzer/-innen dürften aufgrund ihres Textsortenwissens eine Vorstellung davon haben, wie eine ,traditionelle‘ Rezension üblicherweise gestaltet ist. Ein solches Wissen scheint in einigen Fällen beim Schreiben einzufließen und dürfte in anderen Fällen bewusst missachtet werden zugunsten dessen, was man als auf dieser Plattform angemessen und zulässig ansieht. Dialogische Kommunikation scheint bei LovelyBooks vor allem in anderen Formaten wie den Leserunden stattzufinden, die Möglichkeiten bei Rezensio-

20 Solche Abweichungen wurden bei den Zitaten in den folgenden Unterkapiteln in der Regel stillschweigend korrigiert.

21 Die Plattform stellt einen unverbindlichen Leitfaden bereit, vgl. https://s3-eu-west1.amazonaws.com/media.lovelybooks.de/Rezensionsleitfaden_2016.pdf (01.07.2020).

22 Das mag ein Grund dafür sein, warum es mittlerweile die Rubrik „Kurzmeinung“ gibt. Nicht wenige der Rezensionen, die zum in diesem Kapitel untersuchten Korpus gehören und aus früheren Jahren stammen, dürften auf der Plattform heute wohl nicht als Rezensionen eingestellt werden, sondern als eben solche Kurzmeinungen, die in ungefähr einem Satz eine Bewertung des jeweiligen Textes vornehmen. Allgemein lässt sich eine Tendenz von kürzeren zu längeren Texten beobachten. Sind viele Rezensionen in den ersten Jahren nach 2006 eher kurz, so werden zunehmend längere Texte verfasst, je näher man dem Jahr 2020 kommt. 
nen werden kaum genutzt. $\mathrm{Zu}$ wenigen Rezensionen gibt es überhaupt Kommentare, und dann nur in begrenzter Zahl. Von der Möglichkeit, Rezensionen als hilfreich zu bewerten, wird nur in geringem Umfang Gebrauch gemacht. Neben den Funktionen, die man üblicherweise einer Rezension zuschreiben kann und die zumindest teilweise oder in einem gewissen Grade von denen bei LovelyBooks erfüllt werden, gibt es weitere, die auf die eigene Person bezogen sind oder auf die Beziehung der Nutzer/-innen untereinander. Es steht zu vermuten, dass es als sozial relevant angesehen wird und mit persönlichen Gratifikationen verbunden ist, sich vor und für Gleichgesinnte über Vorlieben zu äußern, und ferner, dass für literarische Kommunikation auf der Plattform und für die dort zu findenden Rezensionen eine Funktion einschlägig ist, die seit jeher für den Umgang mit Literatur wichtig war, nämlich die gesellige Funktion. ${ }^{23}$

Die Quellen, um die es gehen wird, werden von den Betreibern und den Nutzer/-innen der Seite als ,Rezensionen“ bezeichnet. Inwiefern ist das eine zutreffende Klassifikation, wie bisher stillschweigend unterstellt wurde? Prototypisch für das Verständnis der Textsorte dürfte wohl die Zeitungsrezension sein, weniger die wissenschaftliche. Eine Definition lautet: „Rezension heißt der Beitrag in einem öffentlichen Medium, mit dem ein Journalist ein von ihm rezipiertes Kulturereignis unter anderem beschreibt, erklärt, einordnet, deutet und/oder bewertet.“24,Öffentliches Medium“ ist weit genug, um digitale Formen miteinzubeziehen, die beschriebenen Handlungen kommen gleichfalls bei den fraglichen Texten im Internet vor, allerdings mit Unterschieden, da gerade das Einordnen und Deuten weniger stark ausgeprägt sein dürfte. Unterschiede ergeben sich des Weiteren hinsichtlich der Verfasserschaft: nicht-professionelle Nutzer/-innen statt Journalisten. Außerdem muss man wohl bedenken, dass Zeitungsrezensionen nur zu aktuellen Publikationen geschrieben werden, die Internettexte hingegen zu beliebig alten verfasst werden können. Beides schei-

23 Vgl. dazu Lukoschek: „Ich liebe den Austausch mit euch!“, wo anhand von Blogs und Leserunden bei LovelyBooks gezeigt wird, dass partizipatorische Formen in sozialen Medien geeignet sind, ein Bedürfnis bei der Kommunikation über Literatur zu befriedigen, welches die traditionellen Formen der Literaturkritik nicht bedienen, nämlich das Bedürfnis nach Austausch. Vgl. zu dem, was die Mitglieder von digitalen Lesegemeinschaften motiviert und was sie erwarten, Axel Kuhn: Lesen in digitalen Netzwerken. In: Ursula Rautenberg/Ute Schneider (Hg.): Lesen. Ein interdisziplinäres Handbuch. Berlin/Boston 2016, S. 427-444, hier S. 438 f.

24 Gernot Stegert: Kommunikative Funktionen der Zeitungsrezensionen. In: Joachim-Felix Leonhard/Hans-Werner Ludwig/Dietrich Schwarze (Hg.): Medienwissenschaft. Ein Handbuch zur Entwicklung der Medien und Kommunikationsformen. 2. Teilbd. Berlin 2001, S. 1725-1729, hier S. 1725. 
nen aber die für die Textsorte weniger zentralen Merkmale zu sein. In dem bereits zitierten Handbuchartikel heißt es weiter: „Die wenigen vorfindlichen Definitionen gehen nicht über die Feststellung hinaus, daß in Rezensionen informiert, unterrichtet und beurteilt wird.“"25 Der Fokus scheint also vor allem auf den Sprechakten zu liegen und, wie ein Blick in diesen Artikel und in weitere Forschung zeigt, auf den Funktionen der Textsorte. Deswegen heißt es zu den Sprechakten etwas ausführlicher:

Konstitutive Handlungen des Rezensierens sind das Vorstellen einer Person (Künstler oder Figur im Kunstwerk), das Skizzieren einer Exposition (bei Roman, Theater oder Film), das Zusammenfassen des Inhalts (einer Handlung bei Romanen oder Spielfilmen), das Zitieren und andere Formen der Redewiedergabe, das Schildern und (Nach-)Erzählen von Ereignissen, das Beschreiben und Erklären der formalen Mittel (nicht nur das schlagwortartige Nennen), das Vergleichen mit anderen Kunstwerken (der Zeit, des Landes, der Person), das Erläutern von Hintergründen, das Einordnen in unterschiedliche Zusammenhänge, das Interpretieren, das Argumentieren, das Illustrieren einer Behauptung mit Beispielen und das Bewerten in seinen verschiedenen Spielarten von Feiern oder Spotten bis zum nüchternen Abwägen. ${ }^{26}$

Es fällt auf, dass die Rezension als Textsorte nicht allzu weitgehend festgelegt zu sein scheint. Über die genannten Merkmale wird gesagt, dass sie sich allesamt auch in anderen Beitragsformen fänden. Konstitutiv für eine Rezension werde erst eine von mehreren möglichen Zusammenstellungen aus diesen Merkmalen, verbunden mit fakultativen Sprechakten wie „Abraten oder Empfehlen, Vorwerfen oder Danken, Fiktionalisieren, Ironisieren““. ${ }^{27}$ Das hat zur Konsequenz, dass man sich die Textsorte ,Rezension“ wohl am ehesten als Gruppe von Typen vorzustellen hat. $\mathrm{Zu}$ den Funktionen, die Rezensionen erfüllen sollen, werden die folgenden gezählt: Rezensionen orientieren über Neuerscheinungen, helfen bei der Entscheidung, was gekauft und gelesen wird, vermitteln Verständnishilfen, helfen dabei, die Qualität zukünftiger Buchproduktion $\mathrm{zu}$ verbessern, leiten zur Reflexion und Kommunikation über Literatur an und dienen der Unterhaltung. ${ }^{28}$

25 Stegert: Kommunikative Funktionen der Zeitungsrezensionen, S. 1726.

26 Stegert: Kommunikative Funktionen der Zeitungsrezensionen, S. 1726.

27 Stegert: Kommunikative Funktionen der Zeitungsrezensionen, S. 1726. Dort auch das vorangehend Gesagte.

28 Vgl. dazu Thomas Anz: Theorien und Analysen zur Literaturkritik und zur Wertung. In: T.A./Rainer Baasner (Hg.): Literaturkritik. Geschichte - Theorie - Praxis. München 2004, S. 194-219, hier S. 195 f. Eine Studie konnte zeigen, dass Video-Rezensionen im Internet im Prinzip diese Funktionen gleichermaßen erfüllen, wenn auch mit gewissen Einschränkungen, vgl. Nicolai Glasenapp/Timo Rouget: ,BookTube‘ - Digitale Literaturkritik auf YouTube. In: 
Die Selbstbeschreibung der Plattform-Betreiber legt nahe, dass man dort ein weites Verständnis der Textsorte ,Rezension“ hat und vermitteln möchte. Sie geben den Nutzer/-innen die folgende Bestimmung an die Hand: „Rezensionen sind persönliche, ausführliche Beurteilungen von Büchern, die du gelesen hast. Hier kannst du alles eintragen, was dir zu dem Buch einfällt. Du gibst damit anderen Mitgliedern die Möglichkeit, ein Buch besser einschätzen zu können oder sogar erst zu entdecken.“29 Im Zentrum steht die bewusst subjektive Bewertung, wie auch ein dort zu findender Leitfaden verdeutlicht, aus dem hervorgeht, dass die Bewertung aussagekräftig, persönlich und begründet sein soll. ${ }^{30}$ Die Texte sollen andere Nutzer/-innen über das Buch informieren und orientieren, also Funktionen erfüllen, die typisch sind für Rezensionen. Darüber hinaus werden im Rezensionsleitfaden weitere Hinweise gegeben, die unverbindlich sind. Informationen zum Inhalt, zur Einordnung (Angaben zum Autor, zur Aufnahme des Buches, der Vergleich mit anderen literarischen Texten) und zu formalen Qualitäten der besprochenen Bücher werden als fakultativ bezeichnet.

Es erscheint plausibel, dass die fraglichen Internettexte die genannten Funktionen erfüllen können, zum Teil wohl sogar in gesteigertem Maße. Man kann also durchaus davon ausgehen, dass die Texte auf LovelyBooks, mit den erforderlichen Präzisierungen, als Exemplare einer Form der Textsorte ,Rezension` zu klassifizieren sind. Von den professionellen Rezensionen im Feuilleton sind sie ebenso $\mathrm{zu}$ unterscheiden wie von ,Kundenrezensionen“ bei Amazon. Letzteres schon allein deswegen, weil sie, anders als die dem Format nach eher in Richtung Warentest gehenden Texte bei Amazon, unabhängig sind vom Kauf des Produktes. Man wird den Rezensionen wohl am ehesten gerecht, wenn man sie als Texte von Liebhaber/-innen auffasst. Da ,Laienrezension“ die Sache nicht ganz trifft und keine Alternative vorhanden ist, werden die Texte im Folgenden schlicht ,Rezensionen“ genannt. Ihre Verfasser/-innen werden, wie bereits getan, neutral als ,Nutzer/-innen“ bezeichnet.

Im Folgenden interessiert nicht das Phänomen der literarischen Kommunikation im Internet als solches oder bei LovelyBooks. Aus dem bisher Gesagten dürfte deutlich geworden sein, dass die dort $\mathrm{zu}$ findenden Rezensionen sich ausgesprochen gut dazu eignen, literarische Kommunikation unter außerwis-

Stefan Neuhaus/Uta Schaffers (Hg.): Was wir lesen sollen. Kanon und literarische Wertung am Beginn des 21. Jahrhunderts. Würzburg 2016, S. 205-228. Vgl. zu den Funktionen von Rezensionen ferner Stegert: Kommunikative Funktionen der Zeitungsrezensionen, S. 1726-1728.

29 https://www.lovelybooks.de/info/faq/ (01.07.2020).

$30 \mathrm{Vgl}$. https://s3-eu-west-1.amazonaws.com/media.lovelybooks.de/Rezensionsleitfaden_ 2016.pdf (01.07.2020). Dort heißt es gleich zu Beginn: „Der wichtigste Teil einer Rezension ist die eigene Meinung.“ 
senschaftlichen, nicht-professionellen Leser/-innen $\mathrm{zu}$ beobachten. ${ }^{31}$ Dies geschieht im Folgenden mit Fokus auf der leitenden Fragestellung. Die Erwartung kann nicht sein, einen gleichsam ,natürlichen' Umgang mit Literatur zu beobachten, frei von jeglichen Einflüssen und historischen Kontinuitäten, oder auch die ganz neue und andere literarische Kommunikation, die sich fundamental von der Literaturkritik in den Print-Medien unterscheidet. ${ }^{32}$ Im Gegenteil: Es ist davon auszugehen, dass schulische Sozialisation, eventuell sogar ein literaturwissenschaftliches Universitätsstudium, und medial und kulturell geprägte, historisch gewordene Vorstellungen davon, was Literatur ist und wie man mit ihr umgeht, in einem gewissen Maße die Kommunikation in dieser Lesegemeinschaft beeinflussen. Es kommen die Möglichkeiten und Einschränkungen des Mediums hinzu sowie der potenzielle Einfluss anderer auf der Plattform oder in anderen Formaten digitaler Literaturkritik zu findender Rezensionen. Das niedrigschwellige Angebot zum partizipatorischen, an der Alltagskommunikation über Literatur angelehnten Schreiben über die eigene Lektüre, motiviert durch Liebhaberei, dürfte jedoch ein in Teilen authentisches Bild davon vermitteln, wie gelesen wird und wie darüber gedacht und gesprochen wird. Das ist natürlich nicht der nicht-professionelle Umgang mit Literatur schlechthin, aber eben einer und ein zunehmend wichtiger, dessen Untersuchung im Rahmen dieser Arbeit eine wichtige Ergänzung darstellt zu den sonst fast ausnahmslos von professionellen außerwissenschaftlichen Rezipienten stammenden Quellen.

\subsection{Patrick Süskind: Das Parfum (1985)}

Die Buchausgabe von Patrick Süskinds Das Parfum kam 1985 auf den Markt, nachdem der Roman zuvor (ab Oktober 1984) als Vorabdruck in der Frankfurter Allgemeinen Zeitung erschienen war. Millionen von verkauften Exemplaren und Übersetzungen in Dutzende von Sprachen machen ihn zu einem der wohl größ-

31 Vgl. zum Aussagewert von Kundenrezensionen Martin Rehfeldt: Leserrezensionen als Rezeptionsdokumente. Zum Nutzen nicht-professioneller Literaturkritiken für die Literaturwissenschaft. In: Andrea Bartl/Markus Behmer (Hg.): Die Rezension. Aktuelle Tendenzen der Literaturkritik. Würzburg 2017, S. 275-289.

32 Vgl. dazu auch Erika Thomalla: Bücheremphase. Populäre Literaturkritik und Social Reading im Netz. In: Steffen Martus/Carlos Spoerhase (Hg.): Gelesene Literatur. Populäre Lektüre im Medienwandel. München 2018, S. 124-136. 
ten deutschsprachigen Bestseller. ${ }^{33}$ Die Forschung hat die Rezeption des Romans durchaus beachtet, allerdings unter anderen Perspektiven, zumal der Frage nach den Ursachen für den großen Erfolg. ${ }^{34}$ Applikationen wurden (der Sache nach) nicht untersucht. Die vermutlich einzige Ausnahme ist ein Aufsatz, der eine Erklärung gibt für den Publikumserfolg und auf „die Möglichkeit“ hinweist, „diesen zunächst von unserer aktuellen Lebenswelt so weit entfernt scheinenden Text dennoch in einem Akt der Normalisierung auf eben diese Lebenswelt $\mathrm{zu}$ beziehen, indem man ihn als Gleichnis auf diktatoriale Herrschaftsverhältnisse, das Computerzeitalter, den Künstler oder worauf immer noch zu verstehen suchte“. ${ }^{35}$

Die Sichtung der Rezensionen bei LovelyBooks ergibt Indizien für verschiedene Applikationen des Romans, die sich unterschiedlichen Gruppen zuordnen lassen (Kap. 5.2.1). Sie werden mit Applikationen verglichen, auf welche die Rezensionen in überregionalen Zeitungen hindeuten (Kap. 5.2.2). Es erweist sich hier ebenfalls als aufschlussreich, die Applikationen zur Beschaffenheit des Textes in Beziehung zu setzen (Kap. 5.2.3).

\subsubsection{Applikationen bei LovelyBooks}

$\mathrm{Zu}$ Süskinds Das Parfum gibt es bei LovelyBooks bisher rund 425 Rezensionen. In 45 davon, das heißt in etwas mehr als jeder zehnten, lassen sich Applikationen nachweisen oder zumindest Hinweise und Indizien ausmachen. Zum Roman liegen rund 10.000 Bewertungen vor, im Durchschnitt wird er mit 4,1 von 5

33 Bis 2003 sollen im deutschsprachigen Raum 3,5 Millionen Exemplare verkauft worden sein, international 12,5 Millionen. Der Roman wurde bisher in 41 Sprachen übersetzt (Stand 2014). Vgl. zu diesen Zahlen Saskia Bodemer: Bestsellermarketing: Erfolgsfaktoren auf dem literarischen Markt der Gegenwart. Süskind - Schlink - Kehlmann. Stuttgart 2014, S. 161 und 212.

34 Vgl. vor allem Bodemer: Bestsellermarketing, S. 159-224, zur Rezeption in der Literaturkritik S. 167-190, zur internationalen Rezeption S. 210-222; daneben Frank Degler: Aisthetische Reduktionen. Analysen zu Patrick Süskinds Der Kontrabaß, Das Parfum und Rossini. Berlin/New York 2003, S. 122-148; Ulrich Pokern: Der Kritiker als Zirku(lation)sagent. Literaturkritik am Beispiel von Patrick Süskinds Das Parfum. Die Geschichte eines Mörders. In: Heinz Ludwig Arnold (Hg.): Text + Kritik. Heft 100: Über Literaturkritik (1988), S. 70-76; David Wieblitz: Geniale Bestseller. Der „Genieroman“ als Erfolgsrezept. Marburg 2009, S. 49-88.

35 Matthias Prangel: Patrick Süskinds Roman Das Parfum. Überlegungen zu den Gründen seines Erfolgs. In: Dirk Jürgens (Hg.): Mutual Exchanges. Sheffield Münster Colloquium II. Frankfurt a. M. u. a. 1999, S. 262-272, hier S. 272, vgl. dazu S. 268-271. Einen Gegenwartsbezug identifiziert auch Wolfgang Hallet: Das Genie als Mörder. Über Patrick Süskinds Das Parfum. In: Literatur für Leser 3-4 (1989), S. 275-288. 
Sternen bewertet. Die neusten Rezensionen stammen von 2020, die ältesten von 2006 und 2007; sie dürften durch die Verfilmung mitveranlasst sein, die 2006 in die Kinos kam (Regie: Tom Tykwer). Seitdem werden dort kontinuierlich Rezensionen publiziert. ${ }^{36}$ Die wenigsten der Nutzer/-innen, die sich zum Roman äußern, dürften $1985 \mathrm{zu}$ den Erstrezipienten gehört haben. Sie sind jedoch durchaus noch als zeitgeschichtliche Rezipienten $\mathrm{zu}$ bezeichnen, da der Roman aufgrund seines kontinuierlichen Erfolges, der Verfilmung und seiner Verwendung als Schullektüre lebensweltlich präsent ist und zur Gegenwartsliteratur gehört. ${ }^{37}$

Mitunter lassen sich Aussagen ausmachen, die eher allgemein gehalten sind, aber dem Format nach auf Applikationen zumindest hindeuten oder Voraussetzungen dafür benennen. Das zeigt sich zum Beispiel an der Annahme, der Roman sei „einzigartig“, weil er „völlig neue Perspektiven“ eröffne. ${ }^{38}$ Was konkret gemeint ist, dürfte potenziell neue Einsichten ermöglichen, die angenommen oder verworfen und folglich appliziert werden können. Eine Nutzerin war überzeugt, dass „[w]ir alle von diesem Buch etwas lernen“ können. ${ }^{39}$ Die Lernbereitschaft erfordert die Bereitschaft zur Applikation. In einer Rezension

36 Vgl. zu diesen Angaben https://www.lovelybooks.de/autor/Patrick-Sueskind/Das-Parfum1248967547-w/ (01.07.2019). Der 1. Juli 2020 ist hier und im Folgenden bei allen Internetquellen der Stichtag. Veränderungen, die sich danach ergeben haben, konnten nicht mehr berücksichtigt werden.

37 Vgl. zur Verfilmung z. B. Charlotte Feldmann: Erzähltechniken in Literatur und Film medienspezifische Möglichkeiten und Grenzen. Das Parfum. Die Geschichte eines Mörders (Patrick Süskind, Tom Tykwer). Marburg 2012; Rita Morrien: Sentimental Journeys. Die Transformation der Heldenfigur in Tom Tykwers Das Parfum (Patrick Süskind) und Stephen Daldrys Der Vorleser (Bernhard Schlink). In: Weimarer Beiträge 58 (2012), S. 39-61, hier S. 42-50. Als Beispiele für die Behandlung des Romans unter literaturdidaktischen Gesichtspunkten vgl. etwa Klaus-Michael Bogdal: „Mein ganz persönlicher Duft“. Das Parfum, die Didaktik und der Deutschunterricht. In: Diskussion Deutsch 24 (1993), S. 124-133; Klaus-Michael Bogdal (Hg.): Lektüre-Praxis, Lektüre-Vielfalt am Beispiel von Süskinds Das Parfum. In: Der Deutschunterricht 48 (1996); Angelika Buß: Intertextualität als Herausforderung für den Literaturunterricht. Am Beispiel von Patrick Süskinds Das Parfum. Frankfurt a. M. u. a. 2005; Degler: Aisthetische Reduktionen, S. 148-158. In diesen Zusammenhang gehören die Bände mit Erläuterungen und die Interpretationshilfen, vgl. z. B. Wolfgang Delseit/Ralf Drost: Patrick Süskind: Das Parfum. Stuttgart 2000; Werner Frizen/Marilies Spancke: Patrick Süskind: Das Parfum. München 1996.

38 Lilstar88: Eine Schullektüre, die jeder mal gelesen haben sollte. 2017. https://www. lovelybooks.de/autor/Patrick-Sueskind/Das-Parfum-1248967547-w/rezension/1438722601/ (01.07.2020).

39 JanineT: Ein Protagonist, den man gleichzeitig liebt und hasst. 2016. https://www. lovelybooks.de/autor/Patrick-Sueskind/Das-Parfuem-1248967547-w/rezension/1218853884/ (01.07.2020). 
wurde mit Wortspiel gefragt, ob der Roman über „die Essenz des Menschseins oder Menschwerdens“ Aufschluss gebe, und auf eine mögliche anthropologische Dimension hingewiesen. ${ }^{40}$ Mit Lust an der metaphorischen Formulierung schrieb ein anderer Nutzer: „Ein ungeheuer spannender Kuchen gespickt mit gesellschaftskritischen Rosinen. “41 Wenn man sich diese vermeintlich kritische Sicht des Romans zu eigen macht oder wenn man sie ablehnt, liegt ein Fall von Applikation vor. In wiederkehrender Formulierung war davon die Rede, dass der Roman zur Reflexion Anlass geben könne: Das Buch „regt [...] zum Nachdenken an“; ${ }^{42}$ es „regt hin und wieder zum Nachdenken an“, etwa über die Frage, ob „man wirklich schon böse geboren sein“ könne. ${ }^{43}$ Von der Einsicht in die besonderen olfaktorischen Fähigkeiten des Protagonisten sagte eine Nutzerin, dass sie sie „zum Nachdenken anregte“.44 Ob und mit welchem Ergebnis eine solche Reflexion tatsächlich stattfindet oder Leser/-innen der Rezension dazu veranlasst, ist damit zwar nicht gesagt. Es kann aber festgehalten werden, dass dem Roman zumindest ein Potenzial zugeschrieben wird, welches zu Applikationen führen kann.

Eine erste Gruppe von Applikationen steht im Zusammenhang mit dem übermenschlichen Geruchssinn des Protagonisten. Die olfaktorische Wahrnehmung der Umwelt und die Funktion des Geruchssinns sind Anlass zu Applikationen. Es wurde zum einen hervorgehoben, dass sich durch die Lektüre die Wahrnehmung von Gerüchen verändert habe. Süskind gewähre „einen Einblick in eine andere Welt, die Welt der Gerüche“. ${ }^{45}$ Der Roman sei gerade darin besonders: „Ich habe selten erlebt, dass ein Schriftsteller so viele Sinne wecken kann. “46 Während man im Alltag nicht darüber nachdenke, lasse der Autor mit seinem Roman das Publikum ,den olfaktorischen Sinn von einer anderen Seite

40 Phil_Skurril: Der Wahnsinn ist ein flüchtiger Rausch. 2015. https://www.lovelybooks.de/ autor/Patrick-Sueskind/Das-Parfum-1248967547-w/rezension/1154965584/ (01.07.2020).

41 Zeuhlibatman: [Rezension von Süskind: Das Parfum]. 2010. https://www.lovelybooks.de/ autor/Patrick-Sueskind/Das-Parfum-1248967547-w/rezension/967294187/ (01.07.2020).

42 Lilstar88: Eine Schullektüre, die jeder mal gelesen haben sollte.

43 Kaetzin: Interessant und beeindruckend. 2017. https://www.lovelybooks.de/autor/PatrickSueskind/Das-Parfum-1248967547-w/rezension/1417774677/ (01.07.2020).

44 Anneja: Die mörderische Suche nach dem Duft der Düfte. 2018. https://www.lovelybooks. de/autor/Patrick-Sueskind/Das-Parfum-1248967547-w/ (01.07.2020). Vgl. für ein weiteres Beispiel Wortverzauberte: Genie und Wahnsinn ganz nah beieinander. 2018. https://www. lovelybooks.de/autor/Patrick-Sueskind/Das-Parfum-1248967547-w/ (01.07.2020).

45 Mahebe: Wie riecht die Welt? Süskind gibt die Antwort. 2016. https://www.lovelybooks.de/ autor/Patrick-Sueskind/Das-Parfum-1248967547-w/rezension/1225048953/ (01.07.2020).

46 Merlyn: Ein Meisterwerk. 2016. https://www.lovelybooks.de/autor/Patrick-Sueskind/DasParfum-1248967547-w/rezension/1220881175/ (01.07.2020). 
sehen“. ${ }^{47}$ Bei einer Nutzerin entstand der Eindruck, dass sie nach der Lektüre des Romans ,alles viel intensiver riecht“ und „Gerüchen und Düften bei weitem mehr Aufmerksamkeit“ widme als zuvor. ${ }^{48}$ In die gleiche Richtung ging die Frage in einer Rezension: „Wer hat nach diesem Buch auch mehr auf Düfte und Gerüche geachtet?“ Der Nutzer oder die Nutzerin nach eigener Aussage auf jeden Fall: „Ich habe noch nichts Vergleichbares gelesen, das so eine starke Wirkung auf meine Wahrnehmung hatte“.49

Zum anderen scheint der Roman Anlass zur Bildung entsprechender Überzeugungen zu sein, die unterschiedliche Formen annehmen. Das kann zum Beispiel bedeuten, dass die vermeintliche Relevanz des Geruchssinns erkannt wird: „Gerüche sind so wichtig in unserem Leben und erfahren häufig so wenig Beachtung. " ${ }^{50}$ Eine andere Nutzerin schrieb dem Text das Potenzial zu, dass man nach der Lektüre ,tatsächlich für einen kurzen Moment fast davon überzeugt ist, dass die Nase das stärkste Sinnesorgan ist und wir vor allem nach ihr handeln und nicht, wie angenommen werden könnte, vor allem nach den Augen“. ${ }^{51}$ Eine dritte Nutzerin meinte: „Wir übersehen es, wie wichtig Gerüche in unserem Leben sind. Das Parfum stößt uns direkt mit der Nase auf diesen Fakt, lädt uns dazu ein, uns Gedanken über Gerüche zu machen. “52 Demgegenüber sehr weitreichend ist die Auffassung, der Roman vermittle eine als ,allumfassend[]“ und „bestürzend[]“ bezeichnete „Wahrheit“: „Der Riecher bestimmt das Miteinander“. ${ }^{53}$ Dazu lässt sich eine Negativapplikation finden. Eine Nutzerin konnte sich „nicht vorstellen, dass Düfte uns Menschen so extrem beeinflussen - und dass wir dies laut Buch nicht mal bemerken““. ${ }^{54}$ In beiden Fällen lie-

47 HeikeG: [Rezension von Süskind: Das Parfum]. 2007. https://www.lovelybooks.de/autor/ Patrick-Sueskind/Das-Parfum-1248967547-w/rezension/986368237/ (01.07.2020).

48 Nana_what_else: [Rezension von Süskind: Das Parfum]. 2009. https://www.lovelybooks. de/autor/Patrick-Sueskind/Das-Parfum-1248967547-w/rezension/984594015/ (01.07.2020).

49 Northlight: Interessanter Protagonist. 2018. https://www.lovelybooks.de/autor/PatrickSueskind/Das-Parfum-1248967547-w/ (01.07.2020).

50 AnneA: [Rezension von Süskind: Das Parfum]. 2012. https://www.lovelybooks.de/autor/ Patrick-Sueskind/Das-Parfum-Die-Geschichte-eines-Moerders-Premium-Edition-1248967547-w/ rezension/948916247/ (01.07.2020).

51 SddSina: [Rezension von Süskind: Das Parfum]. 2012. https://www.lovelybooks.de/autor/ Patrick-Sueskind/Das-Parfum-1248967547-w/rezension/948047011/ (01.07.2020).

52 Kapitel7: Ein Genie, besessen bis in den Wahn. 2018. https://www.lovelybooks.de/autor/ Patrick-Sueskind/Das-Parfum-1248967547-w/ (01.07.2020).

53 Huebner: [Rezension von Süskind: Das Parfum]. 2011. https://www.lovelybooks.de/autor/ Patrick-Sueskind/Das-Parfum-1248967547-w/rezension/966886208/ (01.07.2020).

54 Ami Li Misaki: [Rezension von Süskind: Das Parfum]. 2011. https://www.lovelybooks.de/ autor/Patrick-Sueskind/Das-Parfum-1248967547-w/rezension/964443253/ (01.07.2020). 
gen Applikationen vor, da sich nach Auskunft mancher Nutzer/-innen die Wahrnehmung oder die Überzeugungen durch die Lektüre ändern können.

Zum Teil in Überschneidung mit der ersten Gruppe ist eine zweite Gruppe von Applikationen auf im weiteren Sinne kulturgeschichtliche Aspekte bezogen, genauer: auf populäre, lebensweltliche Auffassungen von geschichtlichen Gegebenheiten vergangener Zeiten. Das kann zunächst bedeuten, dass man die Thematik historisch spezifiziert: Der Roman erlaube „einen guten Einblick in die Welt der Gerüche des 18. Jahrhunderts“". ${ }^{55}$ Außerdem wurde der Überzeugung Ausdruck verliehen, dass der Roman einen zutreffenden Eindruck von historischen Gegebenheiten vermittle. Häufig wurde in diesem Zusammenhang davon gesprochen, dass man sich „gut in die damalige Zeit hineinversetzen“ könne. ${ }^{56}$ Das gelte zum Beispiel für „den unglaublichen Schmutz und die Verhältnisse, die dort herrschten“. ${ }^{57}$ In einer Rezension war davon mit Blick auf die „Zustände“ die Rede, welche „erschreckend“ seien..$^{58}$ Dem Autor wurde „Einfühlungsvermögen in die damalige Welt“ zugeschrieben, welches zur Konsequenz habe, dass eine Nutzerin meinte, einen besonders anschaulichen Eindruck von den damaligen Verhältnissen erhalten zu haben: „Bildlich konnte ich mir die stinkenden Straßen von Paris ausmalen, fühlte mich wie hineingezogen in diese Welt“. ${ }^{59}$ In einer weiteren Rezension wurde festgestellt: „Die beschriebene Atmosphäre ist einzigartig und versetzt den Leser in eine andere Welt“، ${ }^{60}$

Konkreter gefasst, wurde in manchen Fällen das im Roman geschilderte soziale Miteinander als historisch zutreffend angesehen. Über das Verhalten der Mutter des Protagonisten bei der Geburt wurde in einer Rezension festgestellt:

55 Dot: [Rezension von Süskind: Das Parfum]. 2016. https://www.lovelybooks.de/autor/ Patrick-Sueskind/Das-Parfum-1248967547-w/rezension/1288219039/ (01.07.2020). Ähnlich eine Rezension, in welcher positiv hervorgehoben wird, dass man aus dem Roman „einiges über die Arbeit des Parfumeurs und die damalige Zeit“ lernen könne - Buchgetoeber_: Das Parfum Patrick Süskind. 2020. https://www.lovelybooks.de/autor/Patrick-Sueskind/Das-Parfum1248967547-w/ (01.07.2020).

56 Juli.buecher: Eine grausame Geschichte. 2017. https://www.lovelybooks.de/autor/PatrickSueskind/Das-Parfum-1248967547-w/rezension/1440146903/ (01.07.2020).

57 Claire Cullen: [Rezension von Süskind: Das Parfum]. 2009. https://www.lovelybooks.de/ autor/Patrick-Sueskind/Das-Parfum-1248967547-w/rezension/984556235/ (01.07.2020).

58 Ein LovelyBooks-Nutzer: Mal eine ganz andere Geschichte, unfassbar gut! Ein echter Klassiker. 2016. https://www.lovelybooks.de/autor/Patrick-Sueskind/Das-Parfum-1248967547-w/ rezension/1246986225/(01.07.2020).

59 Anastasiahe: Das Parfum. 2015. https://www.lovelybooks.de/autor/Patrick-Sueskind/DasParfum-1248967547-w/rezension/1159542311/ (01.07.2020).

60 Sommerlese: Einzigartige Erzählkunst. 2015. https://www.lovelybooks.de/autor/PatrickSueskind/Das-Parfum-1248967547-w/rezension/1162141506/ (01.07.2020). 
„Wie gleichgültig diese Frau doch mit dem Leben umgegangen ist. Vermutlich keine Seltenheit damals, wenn man wirklich an der Grenze zum Hungertod lebte“ ${ }^{61}$ Im Zusammenhang mit der Bekundung von Antipathie gegenüber den Figuren wurde angedeutet, dass ihr Verhalten aus den historischen Gegebenheiten $\mathrm{zu}$ erklären sei, von denen also ebenfalls angenommen wird, dass sie korrekt wiedergegeben werden: „Die Personen an sich waren so unsympathisch. Klar, es war im 18. Jahrhundert. Trotzdem bekam ich regelrecht Ausschlag von den ,Lebensweisen“ und den Gefühlsregungen.“62 Ähnlich eine andere Nutzerin: „Allgemein ist die Beschreibung der Personen sehr gut, wobei ich sagen muss, dass die harten Zeiten ebenso harte Personen hervorbrachten. Niemand gönnt den anderen etwas, da Missgunst, Neid und Geldgier an oberster Stelle standen."63 Selten wurden solche Überlegungen direkt auf die eigene Person bezogen. Der Roman leite dazu an, zu „hinterfragen [...], welche Rolle wir im Gefüge der Welt rund um Jean-Baptiste hätten und ob unser Handeln nicht auch zeitweise unbewusst andere negativ beeinflusst“. ${ }^{64}$ Was hier aufgrund der Subjektivität der Aussage besonders deutlich als Applikation erkennbar wird, trifft auf die angeführten Aussagen allgemein zu. Es liegen Applikationen vor, insofern angenommen wird, dass das im Roman Geschilderte historisch zutrifft - und dass das eine relevante Einsicht ist. Die Lektüre führt zur Bildung neuer Überzeugungen oder bestärkt die Nutzer/-innen in bestehenden.

Im Einzelfall wurde das Romangeschehen politisch verstanden und auf die Zeitgeschichte bezogen: „Sollte mich jemand nach dem Kontext fragen“, so ein Nutzer, „würde ich sagen: ,Ein Buch mit vielen Facetten über praktizierten Faschismus.“ “ Er betonte zugleich in einer „Kurzmeinung“ die Relevanz des Romans für die Gegenwart: „[D]as Thema bleibt topaktuell“. ${ }^{65}$ Was man sich darunter im Einzelnen vorzustellen hat, bleibt offen. $\mathrm{Zu}$ denken ist vermutlich an den NS, und konkreter an dessen menschenverachtende Praktiken (Grenouilles Morde) oder die Genese totalitärer Herrschaft in Gestalt des charismatischen Führers (die Wirkung des Parfums auf Menschen und Menschenmengen). Un-

61 Ein LovelyBooks-Nutzer: Konnte mich nicht überzeugen. 2016. https://www.lovelybooks. de/autor/Patrick-Sueskind/Das-Parfum-1248967547-w/rezension/1234109995/ (01.07.2020).

62 Books-4ever: Nicht mein Fall. 2016. https://www.lovelybooks.de/autor/Patrick-Sueskind/ Das-Parfum-1248967547-w/rezension/1233381969/ (01.07.2020).

63 Anneja: Die mörderische Suche nach dem Duft der Düfte.

64 CorinaBock: Das Parfum. 2017. https://www.lovelybooks.de/autor/Patrick-Sueskind/DasParfum-1248967547-w/rezension/1457450074/ (01.07.2020).

65 Ein LovelyBooks-Nutzer: Das Parfum. 2018. https://www.lovelybooks.de/autor/PatrickSueskind/Das-Parfum-1248967547-w/ (01.07.2020). 
abhängig davon, was genau der Nutzer im Sinn hatte, scheint er eine Applikation vorgenommen zu haben. Die Romanlektüre war in seiner Wahrnehmung geeignet, Einsichten zu vermitteln beziehungsweise Überzeugungen zu bilden oder zu verstärken, die sich auf „praktizierten Faschismus“, also realweltliche Gegebenheiten beziehen.

Einzelfall bleibt des Weiteren die Betonung, dass der Roman „durch und durch ein negatives Welt- und Menschenbild vermittelt“; ein Umstand, der positiv hervorzuheben sei: „Aber gerade dieses Negative macht den Roman spannend. Es macht Spaß, sich die Abgründe des menschlichen Daseins zu Gemüte zu führen; der Tod, das Verbrechen und dies in Verbindung mit dem genialen Genie Grenouilles ist aufregend und faszinierend. "66 Die Zuschreibung ästhetischer Qualitäten (Lesevergnügen, Spannung, Faszination) hat zur Voraussetzung, dass das negative Welt- und Menschenbild des Romans als zumindest in Teilen realweltlich zutreffend eingeschätzt wird. Darin besteht eine Applikation.

Neben den auf Geruch und Geruchssinn bezogenen Applikationen und denen, die kulturgeschichtliche Gesichtspunkte hervorheben, sind es auf die Figur des Protagonisten abzielende, die als dritte Gruppe zahlenmäßig hervorstechen. In manchen Rezensionen wurden bei dem Protagonisten unbefriedigte emotionale oder psychische Bedürfnisse diagnostiziert. Es wurde zum Beispiel erklärt: „Wie oft liegt das so nah beisammen: Einsamkeit, Wahnsinn und Genie. “67 Der Protagonist sei „,auf der Suche nach Liebe und Anerkennung““ ${ }^{68}$ Alternativ hieß es: „Er sucht sein ganzes Leben lang nach einer Identität“. ${ }^{69}$ In anderen Rezensionen wurden die anthropologischen Einsichten in psychische Extreme herausgestellt. Der Roman biete „Einblick in die Welt eines Massenmörders“. ${ }^{70}$ Es sei „faszinierend, wie das Verlangen jemanden zu etwas treibt, was unvorstell-

66 Nadja_kropp: [Rezension von Süskind: Das Parfum]. 2013. https://www.lovelybooks.de/ autor/Patrick-Sueskind/Das-Parfum-1248967547-w/rezension/1013108370/ (01.07.2020).

67 De_schwob: Genie, Einsamkeit und Wahnsinn. 2017. https://www.lovelybooks.de/autor/ Patrick-Sueskind/Das-Parfum-1248967547-w/rezension/1481852662/ (01.07.2020).

68 ElkeK: [Rezension von Süskind: Das Parfum]. 2015. https://www.lovelybooks.de/autor/ Patrick-Sueskind/Das-Parfum-1248967547-w/rezension/1174223615/ (01.07.2020). Ähnlich Spagetti: Geruch. 2015. https://www.lovelybooks.de/autor/Patrick-Sueskind/Das-Parfum1248967547-w/rezension/1191793213/ (01.07.2020).

69 Elodie_k: Sehr geschmackvoll! 2016. https://www.lovelybooks.de/autor/Patrick-Sueskind/ Das-Parfum-1248967547-w/rezension/1241205876/ (01.07.2020).

70 CorinaBock: Das Parfum. 
bar ist“. ${ }^{71}$ Der Roman zeige „die Abgründe menschlicher Existenz“ “. ${ }^{72}$ Es würden „Obsessionen verständlich gemacht“. ${ }^{73}$ Der Text wurde sogar zur Persönlichkeitsstudie erklärt, die das Verhältnis von Genie und Wahnsinn erhelle: „Wir bekommen ein Psychogramm eines Mörders, eines Wahnsinnigen, einer genialen Persönlichkeit und merken: Genie und Wahnsinn liegen nah beieinander und sind schier untrennbar."74 Verschiedene Aspekte dieser Art verbindend, findet sich in einer Rezension die Aussage, dass der Roman „eine Geschichte über die Agonie fehlender Identität [sei] wie über Besessenheit, Genie, Wahnsinn und das Leben abseits einer Norm “. ${ }^{75}$ Im Einzelfall findet sich sogar die Einschätzung, man könne tatsächlich zu der Überzeugung gelangen, „dass es so jemanden wirklich einmal gegeben“ habe. ${ }^{76}$ In wieder anderen Rezensionen wurde der Protagonist zum Produkt der Verhältnisse erklärt, unter denen er aufgewachsen ist. Es sei „kein Wunder“, dass der Protagonist „,so geworden“ sei, da er als Waisenkind „einen schweren Start im Leben“ gehabt habe, „ohne jegliche Liebe und Zuneigung“; ${ }^{77}$ „,sein Hintergrund und Leiden“ sei die „Quelle seiner Grausamkeit““ ${ }^{78}$ So unterschiedlich diese Aussagen im Detail sein mögen, haben sie doch gemeinsam, dass sie Applikationen sind. Sie legen zumindest nahe, dass der Roman geeignet ist, Überzeugungen bezüglich der menschlichen Psyche und der Persönlichkeitsentwicklung zu bilden. Selbst wenn es der Fall sein sollte, dass hier lebensweltliche Vorstellungen einfach beim Verstehen einbezogen werden, scheint der Roman zumindest die entsprechenden Überzeugungen bestätigt und verstärkt zu haben; eine Applikation, die man in ihrer Wichtigkeit nicht unterschätzen sollte.

71 Janinezachariae: Vom Wahnsinn des Geruchs. 2017. https://www.lovelybooks.de/autor/ Patrick-Sueskind/Das-Parfum-1248967547-w/rezension/1413838493/ (01.07.2020).

72 Buchkritikerin: Abartigkeit mit Genialität gepaart. 2016. https://www.lovelybooks.de/ autor/Patrick-Sueskind/Das-Parfum-1248967547-w/rezension/1242757522/ (01.07.2020).

73 Kadiya: Mein allerliebstes Lieblingsbuch. 2015. https://www.lovelybooks.de/autor/PatrickSueskind/Das-Parfum-1248967547-w/rezension/1195474940/ (01.07.2020).

74 Sky: [Rezension von Süskind: Das Parfum]. 2012. https://www.lovelybooks.de/autor/ Patrick-Sueskind/Das-Parfum-1248967547-w/rezension/953975694/ (01.07.2020).

75 Kinskinski: Was gerne übersehen wird. 2020. https://www.lovelybooks.de/autor/PatrickSueskind/Das-Parfum-1248967547-w/ (01.07.2020).

76 SonnenBlume: [Rezension von Süskind: Das Parfum]. 2014. https://www.lovelybooks.de/ autor/Patrick-Sueskind/Das-Parfum-1248967547-w/rezension/1105764704/ (01.07.2020).

77 Ein LovelyBooks-Nutzer: Mal eine ganz andere Geschichte, unfassbar gut! Ein echter Klassiker.

78 Julo: Große Sprache, große Geschichte. 2016. https://www.lovelybooks.de/autor/PatrickSueskind/Das-Parfum-1248967547-w/rezension/1241981429/ (01.07.2020). 
Daneben gibt es in den Quellen Aussagen, die mittelbar mit Applikationen in Verbindung stehen können, insofern sie Applikationen begünstigen können, aber zugleich unabhängig davon aufschlussreich sind mit Blick darauf, wie der Roman von Nutzer/-innen der Internetseite wahrgenommen wurde. Es wurde, um ein Beispiel zu geben, beobachtet, dass der Roman keine moralische Botschaft vermittle: „Dieses Buch verrät seinen Protagonisten nicht, es gibt ihn nicht im Dienste irgendeiner Moral oder Ordnung preis, es bleibt ganz bei ihm. Grenouille erlebt die Welt nicht wie die anderen Menschen, deshalb wird im Buch auch nicht mehr als nötig gesprochen, deshalb braucht es auch keine moralischen Reflexionen über das Morden."79 Außerdem wurde etwa angegeben, dass der Roman Mitleid und Empathie mit dem Protagonisten hervorrufe. Es sei dem Autor gelungen, „dass man sich irgendwie doch gut in Grenouille hineinversetzen kann und ihn teilweise sogar auch versteht und mag“, sodass man „Mitleid“ mit ihm haben könne. ${ }^{80}$

Es lassen sich also durchaus Applikationen ausmachen oder vermuten. Allerdings sollte der Befund nicht den Blick dafür verstellen, dass in der Regel andere Aspekte im Vordergrund stehen oder zumindest gleich wichtig sind. Es überwiegen insgesamt Aussagen, die auf das Lesevergnügen und auf ästhetische Wirkungen (in einem weiten Sinne) abheben. Der Roman wurde als unterhaltend, spannend oder packend angesehen - oder es wurde moniert, dass er genau das nicht sei. Er rufe Ekel hervor oder sei gruselig, die Darstellung sei makaber und abscheulich, fesselnd und faszinierend und anderes mehr; Wahrnehmungen, die jeweils zu positiven oder negativen Wertungen Anlass geben können. Wie bei der Rezeption anderer Romane auf dieser Internetseite gibt es eine Tendenz zu stark positiven Bewertungen, die sich unter anderem darin niederschlagen, dass der Roman als „Meisterwerk“, „Klassiker“ oder „Weltliteratur“ bezeichnet wird. Zudem ist festzustellen, dass die Applikationen relativ einfach ausfallen oder nur im Ansatz vorgenommen werden. Das ist keine wertende Aussage über die Kompetenzen der Nutzer/-innen, sondern ergibt sich, wie weiter unten eingehender darzustellen sein wird, aus der Beschaffenheit des Textes, die erklären kann, warum dem Anschein nach andere Rezeptionsweisen als die Applikation bei diesem Roman eher im Vordergrund stehen und die Zahl der identifizierten Applikationen umso beachtlicher ist.

79 Berenstein: Wie es duftet. 2013. https://www.lovelybooks.de/autor/Patrick-Sueskind/DasParfum-1248967547-w/rezension/1073241761/ (01.07.2020).

80 Elix: [Rezension von Süskind: Das Parfum]. 2015. https://www.lovelybooks.de/autor/ Patrick-Sueskind/Das-Parfum-1248967547-w/rezension/1132522194/ (01.07.2020). 


\subsubsection{Professionelle Rezeption, Autor und Gegebenheiten}

Nicht zuletzt wohl aufgrund des Fortsetzungsabdrucks in der Frankfurter Allgemeinen Zeitung, der begeisterten Reaktionen erster Leserbriefschreiber oder erster Rezensenten wie Marcel Reich-Ranicki und des schnell einsetzenden, nationalen und internationalen Verkaufserfolgs der Buchausgabe wurde dem Roman bei seinem Erscheinen große Aufmerksamkeit und Resonanz zuteil. In zahlreichen Zeitungen und Zeitschriften wurde er besprochen.

Geruch als Thema des Romans und der übermenschliche Geruchssinn des Protagonisten wurden in den Rezensionen zwar bisweilen angesprochen, etwa, indem lebensweltliche Beobachtungen angestellt wurden, die der Konturierung des Themas dienen. Entsprechende Applikationen wurden jedoch in der Regel nicht vorgenommen. Das mag man erwartet haben. Umso überraschender ist dann jedoch der Befund in einer Rezension. Nachdem sie den Geruchssinn als zentrales Thema des Romans identifiziert und den historischen Unterschied zwischen damals und heute konstatiert hatte, fragte die Rezensentin rhetorisch: „Da wir aber unseren Geruchssinn so sträflich mißachten, was wären wir ohne ihn?“ Ihre Antwort lautete folgendermaßen:

Kennt nicht auch jeder von uns die Kehrseite des Sprichworts vom ,nicht mehr riechen können'? Diese Faszination, die vom Geruch eines Menschen ausgehen kann, diese magische Anziehungskraft, die Körperdüfte haben können? Meine Erfahrung jedenfalls ist, daß eine große Liebe auch das Bedürfnis nach Eintauchen in den Duft des anderen ist. Und das im Deo-Jahrhundert. ${ }^{81}$

Das im Roman über den Einfluss des Geruchssinns Gesagte nahm sie mithin zum Anlass, über die Bedeutung olfaktorischer Reize heutzutage und in der eigenen Erfahrungswelt nachzudenken. Die Rezensentin wies ihnen eine wichtige Funktion $\mathrm{zu}$ im menschlichen Miteinander und insbesondere in der Partnerschaft, zumal im „Deo-Jahrhundert“. Sie hob am Roman also etwas hervor, das als Bildung neuer Überzeugungen oder als Verstärkung bestehender aufgefasst werden kann. Der Applikationsvorgang ist deutlich genug: Im Text Gesagtes wird auf die subjektive Erfahrung bezogen und führt $\mathrm{zu}$ entsprechenden Einsichten. Die Applikation steht in einer überregionalen Tageszeitung, könnte in dieser Form allerdings ohne Weiteres in einer Rezension bei LovelyBooks vorkommen.

81 Gabriele Alings: Dufte. Patrick Süskinds Parfum - ein Mörder auf der Suche nach dem Duft der Düfte. In: die tageszeitung. Nr. 1578, 4. April 1985, S. 8. 
Was kulturgeschichtliche Bezüge betrifft, so verwies ein Rezensent darauf, dass das Geschilderte, sofern es den am Beginn des Romans beschriebenen Gestank in Paris und dergleichen betrifft, historiographisch verbürgt ist. In seiner 1984 in deutscher Übersetzung erschienenen Monographie Pesthauch und Blütenduft hatte der französische Mentalitätshistoriker Alain Corbin, so der Untertitel der deutschen Ausgabe, eine „Geschichte des Geruchs“ geschrieben. Am Beispiel von Paris im 18. und 19. Jahrhundert stellte er da, wie Geruch und Gestank zeitgenössisch wahrgenommen wurden, welche Vorstellungen sich damit verbanden und welche Maßnahmen man dagegen ergriff. ${ }^{82}$ Der Rezensent schrieb:

Paris war damals der allerdreckigste Ort im französischen Königreich, die Weltstadt des Gestanks. In seinem Buch Pesthauch und Blütenduft hat der französische Historiker Alain Corbin [...] zeitgenössische Chronisten zitiert, die sich über diesen „Schlupfwinkel aller nur denkbaren Laster und Übel“ ausließen. Die dreckige Luft sei im Paris des achtzehnten Jahrhunderts so dick gewesen, daß man die Atmosphäre auf mehr als drei Meilen riechen konnte. Corbins historische Dokumentation hat Süskind in einen deftigen Roman übersetzt. ${ }^{83}$

Unabhängig von etwaigen Annahmen darüber, wovon der Autor beeinflusst war, kann festgestellt werden, dass der Rezensent annahm, der Roman sei in den fraglichen Hinsichten historisch korrekt, ja eine ,Übersetzung‘ gesicherten historiographischen Wissens in einen Roman. Daraus folgt, dass der Roman ein Applikationspotenzial besitzt. Nutzer/-innen von LovelyBooks, die, wie gesehen, der Auffassung waren, dass der Roman ,geruchsgeschichtlich“ verbürgt ist, befinden sich also in guter Gesellschaft.

Verschiedentlich wurde der Roman auf den NS bezogen. Der Roman sei ein „Gleichnis“, die Geschichte habe einen „gleichnishaften Charakter“. Im Zentrum stehe die „Sehnsucht nach dem Absoluten, ihre Ursachen und ihre Folgen“. Besonders deutlich werde das an der Szene, in welcher es dem Protagonisten kurz vor seiner Hinrichtung gelingt, mithilfe des von ihm kreierten Parfums die Masse der anwesenden Menschen in einen Zustand der Ekstase zu versetzen. Diese Szene sei

82 Vgl. Alain Corbin: Pesthauch und Blütenduft. Eine Geschichte des Geruchs. Berlin 1984. Zuerst frz. u. d. T. Le Miasme et la Jonquille. L'odorat et l'imaginaire social XVIIIe-XIXe siècles. Paris 1982.

83 Michael Fischer: Ein Stänkerer gegen die Deo-Zeit. In: Der Spiegel. Nr. 10, 4. März 1985, S. 237/240, hier S. 237. 
eine grandiose Darstellung des Massenwahns, der Verführbarkeit der Menschen; genauer: der kaum zu begreifenden Wirkung eines widerlichen und verabscheuungswürdigen Verbrechers auf ein zivilisiertes Volk inmitten Europas. Muß man sagen, welches Ungeheuer Patrick Süskind meint, auf welches Volk sein Gleichnis vor allem abzielt? ${ }^{84}$

Wenn der Roman also Aufschluss geben soll über die Beziehung des Diktators zum deutschen Volk, dann bedarf es zur Realisierung dieses Potentials der Applikation. Beim Protagonisten eine „Sehnsucht nach dem Absoluten“ zu diagnostizieren, ist ein Akt des Textverstehens. $\mathrm{Zu}$ dem Schluss zu kommen, dass damit etwas ausgesagt werden kann über historische Personen, ist eine Sache der Applikation, bei welcher das im Roman Dargestellte so aufgefasst werden muss, dass es Einsichten ermöglicht in realgeschichtliche Gegebenheiten.

Andere Rezensionen wiesen in die gleiche Richtung. Der Protagonist sei „ein totalitärer Übermensch, dem totalitäre Machtausübung mit dem Auslösen eines Massenwahns gelingt“". ${ }^{85}$ Neben diesem allgemeinen Hinweis auf Totalitarismus gab es weitere spezifischere Überlegungen. Grenouille sei „eine $Z u$ kunftsfigur: eine Vision, die mit dem Material der Vergangenheit (noch) ferne Schrecken beschwören und projizieren kann“. Er gehöre zur selben Sorte Mensch wie Reinhard Heydrich, der maßgeblich für die Organisation des Genozids an den europäischen Juden verantwortlich war: „Jean-Baptiste Grenouille, welcher mordet aus Gründen eines ,höheren Zwecks‘, gehört deshalb nicht zur Sorte ,Don Juan', er gehört eher zur Sorte ,Heydrich“ “" ${ }^{86}$ In einer anderen Rezension wurden Parallelen gezogen zum KZ-Arzt Josef Mengele, der in Auschwitz an ,Selektionen' und Ermordungen beteiligt war und Menschenexperimente durchführte. ${ }^{87}$ Der Bezug auf den NS scheint gerade im angloamerikanischen Raum hergestellt worden zu sein. In einem Artikel in der Süddeutschen Zeitung über die dortige Rezeption des Romans wurde auf den damaligen Korrespondenten der New York Times in Bonn verwiesen, der geschrieben habe, „daß die psychologische Story des Mädchenmörders Grenouille ohne die Folie des Drit-

84 Marcel Reich-Ranicki: Des Mörders betörender Duft. In: Frankfurter Allgemeine Zeitung. Nr. 52, 2. März 1985, Bilder und Zeiten, S. BuZ5.

85 Beatrice von Matt: Das Scheusal als Romanheld. Zum Roman Das Parfum von Patrick Süskind. In: Neue Zürcher Zeitung. Fernausgabe. Nr. 61, 15. März 1985, S. 43.

86 Gerhard Stadelmeier: Lebens-Riechlauf eines Duftmörders. Patrick Süskinds Roman Das Parfum. Die Geschichte eines Mörders. In: Die Zeit. Nr. 12, 15. März 1985, S. 55.

87 Vgl. Wolfram Schütte: ,Parfum‘ und Unmenschlichkeit. Mengele von Süskinds Roman aus gesehen. In: Frankfurter Rundschau. Nr. 152, 5. Juli 1985, S. 17. 
ten Reiches nicht zu verstehen sei“. Wörtlich habe es geheißen: „Für die PostHitler-Deutschen sollte die allegorische Botschaft deutlich genug sein.“88

In einer Rezension wurde das Fehlen eines utopischen Entwurfs beklagt oder genauer, dass der Roman, anders als Die Blechtrommel von Günter Grass, bei der Rezeption nicht zu utopischen Überlegungen Anlass gebe: „Im Blechtrommler spiegelt sich die Welt so verzerrt und fragwürdig traurig, dass der Leser allenthalben zu überlegen gedrängt ist, wie sie denn sein müsste. Im ,Parfum' fehlt auch die leiseste Spur eines utopischen Entwurfs. "89 Was die Rezensentin vermisste, ist ein Applikationspotenzial: Im literarischen Text negative realweltliche Verhältnisse erkennen zu können, soll in Verbindung mit anderen Teilen des Textes zur Reflexion anleiten, wie eine positive Alternative beschaffen sein könnte. Damit das möglich ist, bedarf es der Applikation. Das im Roman Geschilderte muss als lebensweltlich zutreffend angesehen und die darauf entwickelte negative Perspektive als richtig akzeptiert werden.

Der Protagonist wurde von einem Rezensenten als „Kunstfigur“ und „Phantasieprodukt“ bezeichnet; er lebe „nur auf dem Papier, auf das dieser Roman gedruckt ist “. ${ }^{90}$ Darin kann man eine Negativapplikation sehen. Der Protagonist kann gerade nicht Aufschluss geben über reale Menschen. Andere sahen in ihm „ein menschliches Exempel““.91 Es wurde betont, dass es ungewöhnlich sei, ein solches Leben zu thematisieren: „Es gibt Geschichten, die nie in Büchern stehen, weil die Literaten sich weigern, sich das Leben vorzustellen." ${ }^{2}$ Die Hauptfigur konnte im Zusammenhang mit den bereits erwähnten Formen totalitärer Herrschaft als Künstler betrachtet werden, sie konnte aber zugleich ,psychologisch' aufgefasst werden:

Grenouille, das ist: die Geburt und Existenz des Bösen als Ausgeschlossenes der Liebe; die Geschichte des Ressentiments und des Hasses als Verlangen nach der totalen Macht, die die Makel des ,Anormalen` tilgen soll; ist analog mythisierender Modelle [...] ein Spiegelbild politischer und religiöser ,Führung;; ist aber auch eine Reflexion über den Künstler, der ,sein inneres Imperium', das ,Reich der Seele‘ durch die spezialistische Verfeinerung seines imaginativen Sensoriums derart illusionistisch, imitatorisch der Welt vor Augen

88 Robert von Berg: Geruchs-Sonaten. In: Süddeutsche Zeitung. Nr. 256, 7. November 1986, S. 49.

89 Matt: Das Scheusal als Romanheld.

90 Günther Grack: Der Duft der Schönheit. Patrick Süskinds Roman Das Parfum. In: Der Tagesspiegel. Nr. 12021, 7. April 1985, S. 47.

91 Wolfram Schütte: Parabel und Gedankenspiel. In: Frankfurter Rundschau. Nr. 81, 6. April 1985, Zeit und Bild, S. ZB4.

92 Stadelmeier: Lebens-Riechlauf eines Duftmörders. 
zaubern kann, daß es die Wirklichkeit außer Kraft setzt - freilich um den Preis, es der Welt nur abnehmen zu können, wenn er ihre Schönheit zuvor getötet hat. ${ }^{93}$

Bezüge zum NS lassen sich in den Rezensionen bei LovelyBooks, wie gezeigt, kaum identifizieren. Die Künstlerproblematik kommt nicht vor. Die Tendenz mancher LovelyBooks-Rezensionen, dem Protagonisten eine psychische Entwicklung, Bedürfnisse und Defizite zuzuschreiben und den Roman diesbezüglich zu applizieren, hat jedoch in durchaus überraschender Weise eine Entsprechung in dieser Rezension, die in etwas komplexerer Form Vergleichbares tut.

Ähnlich wie im Falle der Rezensionen bei LovelyBooks stand in den Feuilleton-Rezensionen etwas Anderes als Applikation eher im Vordergrund, und dies, aufs Ganze gesehen, wohl noch stärker. Anlass zum Kommentar bot die Schreibweise. Süskind sei „ein milder Epigone“, welcher „im Duktus traditioneller Autoren“ schreibe; ${ }^{44}$ er verwende einen „Stil, wie er spätestens aus dem 19. Jahrhundert bekannt ist““95 in dem Roman trete ein „klassischer Erzähler“ auf. ${ }^{96}$ Bereits der Romananfang sei „ein vielleicht trotziges Bekenntnis zum traditionellen Erzählen“, wie es bei Balzac, Victor Hugo oder Marcel Proust zu finden ist. ${ }^{97}$ Der Autor schreibe ,,alles wie Fontane-Keller-Mann-Lenz-Grass-BöllHebel-Musil-Grimmelshausen-Dickens-usw.“. ${ }^{98}$ Die Schreibweise wurde mitunter negativ bewertet, etwa wenn der Roman als „ein Juwel an preziösem Stil“ beurteilt wurde. ${ }^{99}$ Aufschlussreich ist ferner die generische Zuordnung. Der Roman wurde als „ein Krimi der allerbesten Sorte“ bezeichnet, ${ }^{100}$ als „Mischung aus Kolportage, schwarzer Schelmen-Geschichte und fesselndem Künstlerroman“, ${ }^{101}$ als „Spektakelliteratur“ mit den „nötigen Zugaben von Trivialität“, ${ }^{102}$ als „ein - wenn auch glänzend formulierter - Dutzendroman“ ${ }^{103}$ Schließlich wurde das Wirkungspotenzial thematisiert. Ausnahme blieb die Vorstellung,

93 Schütte: Parabel und Gedankenspiel.

94 Fischer: Ein Stänkerer gegen die Deo-Zeit, S. 240.

95 Grack: Der Duft der Schönheit.

96 Schütte: Parabel und Gedankenspiel.

97 Reich-Ranicki: Des Mörders betörender Duft.

98 Stadelmeier: Lebens-Riechlauf eines Duftmörders.

99 Rudolf Krämer-Badoni: Neuer Vampir für den Film? Patrick Süskinds Romangeschichte eines Mörders. In: Die Welt. Nr. 40, 16. Februar 1985, S. 31.

100 Grack: Der Duft der Schönheit.

101 Joachim Kaiser: Viel Flottheit und Phantasie. Patrick Süskinds Geschichte eines Monsters. In: Süddeutsche Zeitung. Nr. 74, 28. März 1985, Literatur, S. V.

102 Matt: Das Scheusal als Romanheld.

103 Stadelmeier: Lebens-Riechlauf eines Duftmörders. 
der Roman erwecke „die Anteilnahme des Lesers“ für den Protagonisten. ${ }^{104}$ In einzelnen Fällen wurden ästhetische Qualitäten identifiziert, etwa wenn der Roman als ein „makabres Buch“ angesehen wurde, ${ }^{105}$ oder wenn angenommen wurde, dass er „morbides Amüsement und Stoff für Horrorfilme“ biete. ${ }^{106}$ Hervorgehoben wurde vor allem die Spannung, die mit der Lektüre verbunden sein kann. ${ }^{107}$

Süskind hat sich nicht oder kaum zu seinem Roman geäußert. Einem USamerikanischen Journalisten gegenüber habe er $\mathrm{zu}$ verstehen gegeben, dass „französische und angelsächsische Kritiker [...] die Allegorie besser als die deutschen [begriffen]“, und wörtlich gesagt: „Das Dritte Reich war für meine Generation im Geist stets gegenwärtig. Es ist egal, ob man Gedichte, Schauspiele oder Romane schreibt. Es ist immer das Thema.“108 Damit hat er ein Verständnis des Romans vor dem Hintergrund des NS nahegelegt, wie es in manchen Rezensionen vorkommt. Es hat aber den Anschein, als ob der Roman in erster Linie als ,innerliterarisches' Ereignis wahrgenommen und daher mit den geschichtlichen Gegebenheiten nur in einigen Fällen in einem relevanten Zusammenhang gesehen wurde. Er wurde als literarische Besonderheit betrachtet, insofern er sich in der Wahrnehmung der Rezensenten von der zeitgenössischen Literaturproduktion unterschied. So wurde zum Beispiel festgestellt: „Also das gibt es immer noch oder schon wieder: einen deutschen Schriftsteller, der des Deutschen mächtig ist; einen zeitgenössischen Erzähler, der dennoch erzählen kann; einen Romancier, der uns nicht mit dem Spiegelbild seines Bauchnabels belästigt; einen jungen Autor, der trotzdem kein Langweiler ist." ${ }^{109}$ Entworfen wurde mithin das Bild eines Sonderfalls in Form des stilistisch ansprechenden und unterhaltenden, erzählerisch gelungenen Romans, der auf den Ausdruck persönlicher Befindlichkeiten verzichtet zugunsten einer relevanten Geschichte. ${ }^{110}$

104 Grack: Der Duft der Schönheit.

105 Kaiser: Viel Flottheit und Phantasie.

106 Krämer-Badoni: Neuer Vampir für den Film?

107 Vgl. Grack: Der Duft der Schönheit; Kaiser: Viel Flottheit und Phantasie; Krämer-Badoni: Neuer Vampir für den Film?; Schütte: Parabel und Gedankenspiel.

108 Berg: Geruchs-Sonaten.

109 Reich-Ranicki: Des Mörders betörender Duft.

110 Vgl. dazu die literaturgeschichtliche Einordnung, wonach der Roman nicht zur Literatur mit politischem Engagement gehört habe oder zur Literatur der Neuen Subjektivität. Solche Literatur habe damals die deutschsprachige Nachkriegsliteratur bestimmt und $\mathrm{zu}$ einem „Überdruß breiter Leserschichten an historischer, politischer, moralischer, psychologischer und ästhetischer Herausforderung“ geführt (Prangel: Patrick Süskinds Roman Das Parfum, S. 265 f., das Zitat S. 266). 
Für die Applikationen in diesen Rezensionen, soweit sie ausgemacht oder vermutet werden konnten, gilt im Prinzip dasselbe wie für die Applikationen bei LovelyBooks. Sie sind relativ einfach und bleiben eher unbestimmt. Es kommt hinzu, dass man in manchen Fällen gezwungen ist, dem Roman, wie bereits am Rande erwähnt, eine Zweitbedeutung zuzuschreiben. Es handele sich, wie in einer Rezension explizit festgestellt wird, um „einen allegorischen Roman“. ${ }^{111}$ Dass es prinzipiell möglich ist, den Roman als Allegorie auf Gegebenheiten zur Zeit des Dritten Reiches zu lesen, muss nicht bestritten werden. Aber das ist häufig der Fall und zeigt nicht zuletzt, dass allegorische Lesarten schnell beliebig werden können. Sie lassen sich selten überzeugend am Text belegen und führen bei einem Roman wie dem von Süskind nur zu eher vagen Applikationen.

Vergleicht man die Befunde zu Rezensionen in Zeitungen und Zeitschriften mit denen zu Rezensionen bei LovelyBooks, so ergibt sich ein aufschlussreicher Befund: Applikationen gibt es in beiden Gruppen. Nicht darin unterscheiden sich die professionellen Rezensent/-innen von den nicht-professionellen. Es gibt mithin keinen prinzipiellen Unterschied. Wenn die Applikationen anders ausfallen, dann in quantitativer Hinsicht und qualitativen Details. Bei LovelyBooks gibt es mehr Applikationen, die mit der Geruchsthematik in Verbindung stehen oder auf die Figur des Protagonisten bezogen sind. Die Applikationen mit Blick auf den NS sind in den Feuilleton-Rezensionen häufiger und differenzierter. Eine Applikation in Bezug auf die kulturgeschichtlichen Gegebenheiten ist komplexer, wenn sie die aktuellen Ergebnisse der einschlägigen historiographischen Forschung zur Kenntnis genommen hat, und einfacher, wenn sie von populären und eher undifferenzierten Vorstellungen über die prekären sozialen Verhältnisse in der damaligen Zeit ausgeht. $\mathrm{Zu}$ bedenken wäre aber wohl in allen Fällen, dass die Nutzer/-innen bei LovelyBooks eben keine professionellen Rezipienten sind. Sofern sie Expert/-innen sind, sind sie es wohl eher für andere Genres (Kriminalroman, Fantasy und ähnliche). Gemessen an ihrem Kenntnisstand können die festgestellten Applikationen durchaus als Ausdruck relativer Kompetenz angesehen werden.

Was die Erklärung dieser Befunde angeht, wären verschiedene Hypothesen denkbar. Man könnte zum Beispiel vermuten, dass die Erstrezeption des Romans im Feuilleton die Art und Weise beeinflusst hat, in welcher er als Schullektüre unterrichtet wurde. Das Bild des Romans, welches Lektürehilfen und vergleichbare Formate vermitteln, dürfte ebenfalls mit dieser Erstrezeption in Verbindung stehen. Die literaturwissenschaftliche Forschung jedenfalls scheint

111 Schütte: ,Parfum‘ und Unmenschlichkeit. 
sie durchaus beeinflusst zu haben. Beides, Schulunterricht und Lektürehilfen, kommt bei manchen Nutzer/-innen von LovelyBooks wohl eher als Informationsquelle in Betracht als eine Lektüre der Feuilletons. Ein weiterer Faktor könnte die Berichterstattung über den Film sein, bei der es naheliegt, dass man sich an den Rezensionen der Erstrezipienten orientierte, sofern die literarische Vorlage betroffen war. Denkbar wäre ferner, dass es gar keinen Zusammenhang zwischen Feuilleton-Rezensionen und der Rezeption bei LovelyBooks gibt oder dass beide von etwas Drittem beeinflusst wurden - und anderes mehr. Eine Überprüfung dieser Hypothesen ist in der vorliegenden Arbeit weder möglich noch nötig. Entscheidend ist der Befund, dass Applikationen nicht allein ein Phänomen des professionellen außerwissenschaftlichen Umgangs mit Literatur sind, sondern auch beim nicht-professionellen $\mathrm{zu}$ beobachten sind, und dass sie sich bei allen Unterschieden doch in manchen relevanten Hinsichten gleichen oder zumindest ähneln. Wie sich zeigen wird, trifft das in vergleichbarer Weise auf die Rezeption der beiden anderen Romane zu, die in den folgenden Unterkapiteln untersucht werden.

\subsubsection{Beschaffenheit und Potenzial des Textes}

Die festgestellten Applikationen sollen nun mit der Beschaffenheit des Textes in Beziehung gesetzt werden. Es ist noch einmal daran zu erinnern, dass es nicht darum geht, an literarischer Kommunikation teilzunehmen und Empfehlungen abzugeben, ob und wie der Roman appliziert werden kann und soll. Es soll des Weiteren nicht erörtert werden, ob die Applikationen zulässig und gelungen sind. Das Ziel besteht darin, einen Sachverhalt literaturwissenschaftlich zu beschreiben, nämlich die Passung einer rezipientenseitigen Praktik mit dem literarischen Artefakt, mit welchem die Akteur/-innen umgehen. Es zeigt sich, dass der Roman zu keiner der identifizierten Applikationen wirklich Anlass gibt. Aufgrund seiner Beschaffenheit eignet er sich lediglich für Applikationen anhand des Textes oder für solche, die eher partiell bleiben.

Der wundersame Geruchssinn des Protagonisten wird verschiedentlich und ausführlich geschildert (vgl. allein S. 31-37, 43-49, 49-58). ${ }^{112}$ Er kann Dinge auf große Distanz und durch Wände riechen, feinste Unterscheidungen vornehmen und sich exakt an den Geruch erinnern. Der Erzähler berichtet an einer Stelle, um zumindest ein Beispiel anzuführen:

112 Patrick Süskind: Das Parfum. Die Geschichte eines Mörders. Zürich 1985. Nachweise im Folgenden unmittelbar im Anschluss an das Zitat. 


\begin{abstract}
Mit sechs Jahren hatte er seine Umgebung olfaktorisch vollständig erfaßt. Es gab im Hause der Madame Gaillard keinen Gegenstand, in der nördlichen Rue de Charonne keinen Ort, keinen Menschen, keinen Stein, Baum, Strauch oder Lattenzaun, keinen noch so kleinen Flecken, den er nicht geruchlich kannte, wiedererkannte und in der jeweiligen Einmaligkeit fest im Gedächtnis verwahrte. Zehntausend, hunderttausend spezifische Eigengerüchte hatte er gesammelt und hielt sie zu seiner Verfügung, so deutlich, so beliebig, daß er sich nicht nur ihrer erinnerte, wenn er sie wiederroch, sondern daß er sie tatsächlich roch, wenn er sich ihrer wiedererinnerte; ja, mehr noch, daß er sie sogar in seiner bloßen Phantasie untereinander neu zu kombinieren verstand und dergestalt in sich Gerüche erschuf, die es in der wirklichen Welt gar nicht gab. (S. 34)
\end{abstract}

Nur geleitet von seiner Nase kann er das Parfum eines Pariser Parfümeurs kopieren, im Handumdrehen ein besseres herstellen und beliebig viele weitere Parfums kreieren (vgl. S. 104-112, 114-122 und 122-127, ähnlich S. 190-194). Aus dem weiteren Verlauf der Handlung ließe sich eine Fülle weiterer Beispiele anführen. Stets wird gesagt und gezeigt, wie außergewöhnlich die Fähigkeit des Protagonisten ist. Es dürfte auf der Hand liegen, dass ein solcher Geruchssinn menschliches und tierisches Vermögen bei weitem übersteigt. In einer sonst zumeist prinzipiell realistischen erzählten Welt ist das ein Element des Wunderbaren.

Das, was über den Stellenwert des Geruchssinnes im menschlichen Miteinander gesagt wird, entspricht ebenfalls nicht den Tatsachen, sondern erweist sich als wunderbar. Olfaktorische Reize sind in der erzählten Welt so wichtig, dass sie menschliches Miteinander maßgeblich bestimmen. Grenouille kann ein Parfum herstellen, mit dem er, der eigentlich geruchlos ist, sich einen ,menschlichen' Duft verleiht. Erst dadurch wird er von seinem Mitmenschen überhaupt und zum Teil positiv wahrgenommen, nicht, wie zuvor, gar nicht oder lediglich mit Befremden (vgl. S. 194-200). Er kann verschiedene ,Parfums“ herstellen, je nachdem, wie er von Menschen behandelt werden will (vgl. S. 231-233). Sexuelle Attraktion beruhe maßgeblich auf dem Körpergeruch, nicht auf dem, was man landläufig annehme, etwa dem Äußeren (vgl. S. 217 f.). Mithilfe des aus dem Körpergeruch von 25 jungen Frauen hergestellten Parfums kann der Protagonist die Menschenmenge, die zusammengekommen war, um seiner Hinrichtung beizuwohnen, von seiner Unschuld überzeugen und sie dazu bringen, ihn $\mathrm{zu}$ bewundern und zu lieben. Die Wirkung des Parfums ist so stark, dass es zu einer kollektiven Ausübung von Sexualität kommt und der Vater der letzten Frau, die Grenouille ermordete, ihn wie einen Sohn liebt und adoptieren will (vgl. S. 296-308, 308-310). Es bringt schließlich eine Gruppe von Kriminellen in Paris dazu, Grenouille zu zerreißen und zu verspeisen (vgl. S. 318-320).

Sollte aus Rezipientenperspektive Unklarheit über den Realitätsbezug des Geschilderten bestehen, ließe sich davon sprechen, dass sie den Roman als 
phantastischen lesen. Es kommt hinzu, dass der Protagonist aufgrund seiner besonderen Fähigkeit Züge des Unheimlichen trägt. Die Amme, welche den Waisen eine Zeitlang stillt, meint, dass er „vom Teufel besessen“ sei, und führt als Grund an: „Er riecht überhaupt nicht.“ (S. 14) Der Pater, welcher den Säugling an die Amme vermittelt hatte, beobachtet ihn beim Erwachen und bei seiner anscheinend vor allem durch die Nase gesteuerten Wahrnehmung der Umwelt. Das hat zur Konsequenz, dass er alles daransetzt, das Kind loszuwerden (,weg mit diesem Unhold, weg mit diesem unerträglichen Kind“, S. 24, dazu S. 22-25). Den anderen Waisenkindern, mit denen er aufwächst, ist er „unheimlich“ (S. 30). Sie versuchen, ihn zu töten, verspüren Ekel und „Angst“ (ebd.).

Betrachtet man vor dem Hintergrund dieser Befunde, die den Charakter einer Beschreibung maßgeblicher Gehalte des Textes haben, die auf Geruch und Geruchssinn bezogenen Applikationen, so ist festzustellen, dass sie vom Text kaum gedeckt werden. Von den exorbitanten Fähigkeiten des Protagonisten und der wunderbaren Funktion des Geruchs ist es ein weiter Weg zur Erfahrungswirklichkeit des Publikums. Der Text schließt dergleichen aufgrund seiner Beschaffenheit zwar nicht aus, die übermenschlichen Fähigkeiten des Protagonisten und die letztlich nicht den Tatsachen entsprechenden Aussagen über den Einfluss olfaktorischer Reize verhindern jedoch eine weiterreichende, vom Text gedeckte Applikation. Wenn der Roman Anlass ist zu neuen oder modifizierten Wahrnehmungen oder Überzeugungen, dann liegt dem eine Applikation anhand des Textes zugrunde, nicht eine Applikation des Textes. Außerdem dürften die Applikationen nicht besonders aufschlussreich sein. Dass der Geruchssinn lebensweltlich eine gewisse Relevanz hat, liegt auf der Hand, ist aber eine eher einfache Einsicht. In einem stärkeren Sinne erkenntniserweiternd wäre die Einsicht erst, wenn die Wirkung des Geruchssinnes deutlich größer wäre. Das ist aber lebensweltlich unzutreffend. Außerdem ist ein Wirkungspotenzial des Textes zu berücksichtigen, welches eher im Vordergrund zu stehen scheint. Die Handlung, die Züge des Wunderbaren, Phantastischen und Unheimlichen trägt, eignet sich wohl eher für ästhetische Erfahrungen (Grusel, Ekel, Spannung) und eine Funktion wie die Unterhaltung. ${ }^{113}$

Applikationen des Textes, allerdings nur partielle, auf Details bezogene, sind die verschiedenen kulturgeschichtlichen. Gleich zu Beginn wird ausführlich der Gestank beschrieben, der im 18. Jahrhundert in einer Großstadt wie Paris geherrscht haben muss (vgl. S.5-7). Im weiteren Verlauf wird ver-

113 Vgl. dazu z. B. Christian Klein: „Dieser Geruch war eine Mischung aus beidem ...“. Lust und Ekel in Das Parfum. In: Andreas Blödorn/Christine Hummel (Hg.): Psychogramme der Postmoderne. Neue Untersuchungen zum Werk Patrick Süskinds. Trier 2008, S. 53-65. 
schiedentlich darüber berichtet, wie man zu der Zeit Parfum herstellte und welche Arbeitsschritte dazu gehörten. Beides dürfte historisch in weiten Teilen korrekt sein. Ebenso werden am Anfang die schlechten hygienischen Zustände geschildert, der Umgang mit einer ,Kindsmörderin“ wie der Mutter von Grenouille und die inhumane Behandlung von Waisenkindern (vgl. S. 7-11). Im weiteren Verlauf ist von dergleichen immer einmal wieder die Rede, unter anderem von mentalitätsgeschichtlichen Aspekten wie dem Nebeneinander christlicher und ,heidnischer', aufklärerischer und freigeistiger Vorstellungen. Solche Applikationen sind zwar vom Text veranlasst, beziehen sich allerdings auf Elemente der erzählten Welt, die letztlich im Hintergrund bleiben, vor allem auf den Schauplatz und die Zeit. Sie sind Applikationen des Textes, aber nur partielle. Der historische Schauplatz scheint in erster Linie dazu geeignet $\mathrm{zu}$ sein, den Eindruck historischer Alterität zu vermitteln, der schaudern macht in Anbetracht der damaligen Verhältnisse, die sich von der heutigen Erfahrungswirklichkeit stark unterscheiden.

Eine andere prinzipielle Möglichkeit der Applikation, die aber weder in den Rezensionen im Feuilleton noch in denen bei LovelyBooks identifiziert werden konnte, bezieht sich auf die (negative, satirische) Perspektive, welche im Roman auf die Aufklärung entwickelt wird. An verschiedenen Figuren wird jedenfalls ein Bezug auf die Geistesgeschichte der Zeit festgemacht, so an Pater Terrier (vgl. S.18f.), dem Parfümeur Baldini (vgl. S. 72-76) und dem dilettantischen Universalgelehrten Marquis de la Taillade-Espinasse (vgl. S. 177-186, 206-208). Eventuell denkbare Applikationen dieser Art würden ebenfalls recht partiell bleiben. Es dürfte die komische Wirkung überwiegen, die von den Figuren ausgeht. ${ }^{114}$

114 Vgl. für Forschungsbeiträge, die in dem Roman Vernunft- und Aufklärungskritik sehen, Richard T. Gray: The Dialectic of „Enscentment“. Patrick Süskind's Das Parfum as Critical History of Enlightenment Culture. In: PMLA 108 (1993), S. 489-505; Achim Küpper: Eine ,erlesene‘ Kreation. Patrick Süskinds Roman Das Parfum und die Selbstdarstellung der künstlerischen Schaffensweise im nachaufklärerischen Massenzeitalter. In: Wirkendes Wort 60 (2010), S. 85-100; Leilian Zhao: Über die Vernunftkritik im Roman Das Parfum. Die Geschichte eines Mörders von Patrick Süskind. In: Literaturstraße. Chinesisch-deutsches Jahrbuch für Sprache, Literatur und Kultur 5 (2004), S. 227-241. Eine Alternative formuliert Mirjam-Kerstin Holl: Grenouille, der unbewusste Materialist? Patrick Süskinds Das Parfum und seine Anspielungen auf Décadence und Monismus in der Figur des Grenouille. In: Wirkendes Wort 58 (2008), S. 351-371. Als Beispiel für die Klassifikation des Protagonisten als Genie vgl. Sebastian Zilles: Zwischen Bewunderung und Horror. Zur Genie-Konzeption in Patrick Süskinds Das Parfum, Robert Schneiders Schlafes Bruder und Marcel Beyers Flughunde. In: Zeitschrift für Literaturwissenschaft und Linguistik 166 (2012), S. 150-167, hier S. 151-155. 
Applikationen, welche auf den NS abheben, lassen sich am Text nicht hinreichend festmachen. ${ }^{115}$ Das hat nicht zuletzt mit den bei diesen Applikationen erforderlichen Allegorisierungen zu tun. ${ }^{116}$ Als entscheidender erweist sich etwas Anderes. Man kann ohne Weiteres zugestehen, dass eine derartige Applikation möglich ist - allein die Existenz solcher Applikationen weist ja darauf hin. Es stellt sich jedoch die Frage, wie spezifisch derlei Applikationen sind und was genau man auf diesem Wege eigentlich in Erfahrung bringen kann über deutsche Geschichte, NS-Verbrecher, die Genese totalitärer Herrschaft, Führerkult und Manipulation der Massen. Was man über den asozialen und menschenverachtenden, in einer Fähigkeit aber herausragenden Protagonisten erfährt, der fünfundzwanzig junge Frauen tötet, weil er ihre Körper benötigt, um einen vermeintlich höheren Zweck zu erreichen und die Masse der Mitmenschen zu manipulieren, wird, so scheint es, assoziativ mit dem in Beziehung gesetzt, was lebensweltlich zu Recht als Inbegriff von Menschenverachtung und Manipulation gilt. Der Text ist jedoch wenig dazu angetan, diesbezügliche Einsichten zu veranlassen oder Aufschlüsse zu gewähren. Als Illustration von lebensweltlich Gewusstem scheint er sich ebenfalls nur bedingt zu eignen. Es liegen also gleichfalls Applikationen anhand des Textes vor.

Wie in einer Rezension geschehen, $\mathrm{zu}$ beklagen, dass der Roman keine Möglichkeit biete, eine utopische Alternative $\mathrm{zu}$ formulieren, ist als Rezeptionserwartung vielleicht naheliegend und gewiss zulässig, verkennt aber die Beschaf-

115 Vgl. als Forschungsbeitrag zum NS-Bezug Adrian Brauneis: Geburt des Romans aus dem Geist der Mentalitätsgeschichte. Eine problemgeschichtliche Untersuchung von Patrick Süskinds Roman Das Parfum. In: Text \& Kontext 35 (2013), S. 165-181.

116 Vgl. dazu z. B. die Aussage, dass der Roman eine „Allegorie auf die Verführbarkeit des Menschen“ sei - Werner Frizen: Das gute Buch für jedermann oder Verus Prometheus. Patrick Süskinds Das Parfum. In: Deutsche Vierteljahrsschrift für Literaturwissenschaft und Geistesgeschichte 68 (1994), S. 757-786, hier S. 783, vgl. dazu S. 782-785. Eine allegorische Bedeutungsdimension müssen auch die psychoanalytisch orientierten Interpretationen des Romans annehmen, vgl. Edith H. Krause: In Search of the Maternal: Patrick Süskind's Perfume. In: The Germanic Review 87 (2012), S. 345-364; Tomasz Małyszek: Ästhetik der Psychoanalyse. Die Internalisierung der Psychoanalyse in den literarischen Gestalten von Patrick Süskind und Sten Nadolny. Wrocław 2000; Marc Pieber: Das Subjekt zwischen Begehren und Genießen. Psychoanalytische Interpretationen zu Süskinds Das Parfum. In: Gianluca Crepaldi/Andreas Kriwak/Simon Zangerle (Hg.): Lust im Spiegel von Literatur, Philosophie und Psychoanalyse. Innsbruck 2010, S. 59-74; Katja Schettler: Eros, Liebe und Lieblosigkeit in Das Parfum. In: Andreas Blödorn/Christine Hummel (Hg.): Psychogramme der Postmoderne. Neue Untersuchungen zum Werk Patrick Süskinds. Trier 2008, S. 53-66; Julia Splitt: Narzissmus in Patrick Süskinds Roman Das Parfum. In: Andrea Bartl (Hg.): Transitträume. Beiträge zur deutschsprachigen Gegenwartsliteratur. Augsburg 2009, S. 333-348. 
fenheit des Romans. Die Nutzerin bei LovelyBooks, die betont, dass der Roman vor allem auf negative Aspekte abhebe, und diesen Umstand begrüßt, hat jedenfalls auf etwas Wesentliches hingewiesen. Wenn soziale und hygienische Missstände geschildert werden, wenn makabre Details auf drastische Weise dargestellt werden, dann geschieht das um der ästhetischen Erfahrung willen. Der Roman ist wohl eher geeignet, ein als angenehm empfundenes Schaudern ob der damaligen Zustände hervorzurufen, als zur Reflexion Anlass zu geben. Er erzählt eine spannende und unterhaltsame Geschichte, die in keiner Weise über solche Wirkungen hinausweisen muss, damit die Lektüre als zufriedenstellend wahrgenommen werden kann. Nicht zuletzt der Erfolg des Buches dürfte in Teilen auf diesen Wirkungen beruhen und nicht etwa darauf, dass er besonders relevante Applikationen ermöglicht.

Betrachtet man die auf die Figur des Protagonisten bezogenen Applikationen, so könnte man unter Umständen den Eindruck haben, dass der Roman mithilfe der monströsen Figur des Protagonisten eine Parabel auf die eigentlich monströsen gesellschaftlichen und gemeinschaftlichen Verhältnisse erzählt: Der Protagonist, der in inhumanen Verhältnissen aufwächst, wird selbst inhuman. Gezeigt wird die Pathogenese einer Figur, die eigentlich nur will, was alle wollen: Liebe und Zuwendung, Zugehörigkeit und Identität. Dem steht allerdings die Konzeption der Figur entschieden entgegen. Seine Resilienz gegen Krankheiten und Mangelernährung vergleicht der Erzähler mit primitiven Lebewesen: „Er war zäh wie ein resistentes Bakterium und genügsam wie ein Zeck, der still auf dem Baum sitzt und von einem winzigen Blutströpfchen lebt, das er vor Jahren erbeutet hat.“ (S. 27) Als „Zeck“ wird er immer wieder bezeichnet (vgl. z. B. S. 29, 41 und 43, 114, 242 und 244). Aufgrund ihres Geruches kann er die Gemeinschaft von Menschen nicht ertragen und zieht sich, darin gleichfalls einer Zecke ähnlich, sieben Jahre an den am allerweitesten von allen menschlichen Gerüchen entfernten Ort des Landes zurück, den Gipfel eines erloschenen Vulkans im Zentralmassiv, wo er selbstgenügsam und größenwahnsinnig in Geruchserinnerungen schwelgt, die er beliebig hervorbringen kann. Er verlässt diesen Ort überhaupt nur, weil er entdeckt, dass er selbst geruchlos ist (vgl. S. 147-176).

Seine Geburt trägt Züge des Wunderbaren und vermittelt das Bild einer von Beginn an bösen Existenz, die sich „vegetativ“ (S. 29) für das Leben entschieden und bewusst auf alles Menschliche verzichtet hat:

Für seine Seele brauchte er nichts. Geborgenheit, Zuwendung, Zärtlichkeit, Liebe - oder wie die ganzen Dinge hießen, deren ein Kind angeblich bedurfte - waren dem Kinde Grenouille völlig entbehrlich. Vielmehr, so scheint uns, hatte er sie sich selbst entbehrlich gemacht, um überhaupt leben zu können, von Anfang an. Der Schrei nach seiner Geburt, 
der Schrei unter dem Schlachttisch hervor, mit dem er sich in Erinnerung und seine Mutter aufs Schafott gebracht hatte, war kein instinktiver Schrei nach Mitleid und Liebe gewesen. Es war ein wohlerwogener, fast möchte man sagen ein reiflich erwogener Schrei gewesen, mit dem sich das Neugeborene gegen die Liebe und dennoch für das Leben entschieden hatte. Unter den obwaltenden Umständen war dieses ja auch nur ohne jene möglich, und hätte das Kind beides gefordert, so wäre es zweifellos alsbald elend zugrunde gegangen. Es hätte damals allerdings auch die zweite ihm offenstehende Möglichkeit ergreifen und schweigen und den Weg von der Geburt zum Tode ohne den Umweg über das Leben wählen können, und es hätte damit der Welt und sich selbst eine Menge Unheil erspart. Um aber so bescheiden abzutreten, hätte es eines Mindestmaßes an eingeborener Freundlichkeit bedurft, und die besaß Grenouille nicht. Er war von Beginn an ein Scheusal. Er entschied sich für das Leben aus reinem Trotz und aus reiner Boshaftigkeit. (S. 28)

Der Erzähler lässt keinen Zweifel daran, dass der Protagonist eine negative Figur ist. Gleich im ersten Satz zählt er ihn zu den „genialsten“ und zugleich „abscheulichsten Gestalten“ des 18. Jahrhunderts (S. 5). Immer wieder wird er als „Scheusal“ bezeichnet (vgl. z. B. S. 57 und 242) oder als „Unmensch“ (ebd.) und einer „der verabscheuungswürdigsten Verbrecher seiner Zeit“ (S. 303). Außerdem ist er im Wortsinne asozial. Seine wundersame Fähigkeit verhindert, dass er unter Menschen leben kann, sie macht es ihm außerdem unmöglich, auf Dauer allein und abgeschieden zu leben. Es ist nicht nur der Fall, dass sich keine Hinweise im Text finden, die solche Applikationen zulassen; es ist vielmehr so, dass der Text ihnen in wesentlichen Punkten entgegensteht.

Manche der auf die Figur des Protagonisten bezogenen Applikationen erweisen sich noch in einer anderen Hinsicht als nicht hinreichend vom Text gedeckt, vor allem die Vorstellung, es handele sich um einen Künstlerroman, der etwas aussage über den Künstler, die Entstehung von Kunst und dergleichen. Es ist dazu erforderlich, das im Text Geschilderte zu allegorisieren. Das Geschilderte passt allerdings nicht wirklich zur vermeintlichen zweiten Bedeutungsschicht. Verantwortlich dafür sind wiederum Figurenkonzeption und Perspektivensteuerung. Am Beginn der ,Künstlerkarriere“ steht der Mord an einem jungen Mädchen und der größenwahnsinnige Wunsch, „der größte Parfumeuer aller Zeiten“ zu werden (S. 58). Der Erzähler hebt eigens hervor, wie gewissenlos und letztlich parasitär der Protagonist ist, der „mit abstrakten Begriffen [...], vor allem ethischer und moralischer Natur, [...] die größten Schwierigkeiten“ hat (S. 33): „Daß am Anfang dieser Herrlichkeit ein Mord gestanden hatte, war ihm, wenn überhaupt bewußt, vollkommen gleichgültig. An das Bild des Mädchens aus der Rue des Marais, an ihr Gesicht, an ihren Körper, konnte er sich schon nicht mehr erinnern. Er hatte ja das Beste von ihr aufbewahrt und sich zu eigen gemacht: das Prinzip ihres Duftes.“ (S. 58) Wie eine so beschaffene 
und textintern derart bewertete Figur etwas aussagen soll über Künstlertum, liegt nicht gerade auf der Hand.

Neben Aspekten der Beschaffenheit des Textes, welche diese und andere Applikationen nicht begünstigen, weist er Merkmale auf, die andere Rezeptionsweisen nahelegen. ${ }^{117}$ Der Roman ist in vier Teile mit zusammen 51 Kapiteln untergliedert, bei einer Gesamtlänge von etwas über dreihundert nicht gerade dicht bedruckten Seiten macht das sechs bis sieben Seiten pro Kapitel. Der Satzbau ist einfach. Es wird verschiedentlich mit rhetorischen Figuren gearbeitet, insbesondere solchen der Wiederholung und Variation. Die Schilderungen sind anschaulich und detailreich. Der Erzähler vermittelt, wie die beiden längeren Zitate oben zeigen, wichtige Informationen, die der Einordnung und Bewertung dienen, häufig explizit und en bloc. Es leuchtet sehr ein, wenn die Literaturkritik den Stil als ,traditionelles‘ Erzählen nach Art des 19. Jahrhunderts klassifiziert hat. Der Erzähler ist weder Teil der Geschichte noch der erzählten Welt, er ist ,allwissend' und ,auktorial', verwendet ab und $\mathrm{zu}$ sogar die Erste Person Plural, um auf sich zu verweisen, und scheint souverän über die Geschichte $\mathrm{zu}$ verfügen. Er wertet stark und in der Regel negativ, mitunter lässt sich Ironie in der Darstellung ausmachen. Wiederholt und fast schon penetrant lässt er poetische Gerechtigkeit walten. Die Witwe Madame Galliard, der Gerber Grimal und der Parfümeur Baldini, die alle auf unterschiedlich gravierende Weise den Protagonisten (und andere Menschen) schlecht behandeln, sterben ausnahmslos eines grausamen Todes, die beiden letztgenannten sogar unmittelbar nachdem Grenouille sie verlassen hat (vgl. S. 38-40; dazu S. 26, 112-114 und 141-145).

Vieles von dem, was geschildert wird, gehört der Sache nach zum Bereich menschlicher Extremerfahrungen: soziales Elend, Folter und Hinrichtung, Mord und Selbstmord, Kannibalismus. Die Darstellung tendiert in einigen Szenen zur Drastik. Manche Elemente der Handlung, gerade einige Nebenfiguren, sind geeignet, eine komische Wirkung hervorzurufen. Der Roman zeichnet sich mithin durch eine hohe Lesbarkeit aus, er kann relativ schnell durchgelesen werden und vermittelt eine potenziell spannende Geschichte. Elemente des Kriminalromans, des phantastischen Romans und des historischen Romans werden

117 Vgl. für eine ausführliche Untersuchung des Romans Degler: Aisthetische Reduktionen, S. 173-262; ferner Dieter Stolz: „Niemand weiß, wie gut es gemacht ist“. Über Patrick Süskinds Parfum In: Sprache im technischen Zeitalter 38 (2000), S. 312-324; Gottfried Willems: Die postmoderne Rekonstruktion des Erzählens und der Kriminalroman. Über den Darstellungsstil von Patrick Süskinds Das Parfum. In: Wolfgang Düsing (Hg.): Experimente mit dem Kriminalroman. Ein Erzählmodell in der deutschsprachigen Literatur des 20. Jahrhunderts. Frankfurt a. M. 1993, S. 223-244. 
mit solchen des Schelmen- und Entwicklungsromans verbunden. ${ }^{118}$ Zudem erweist er sich nicht als voraussetzungsreich. In seinen Wissensvoraussetzungen ist er eher niedrigschwellig und zugänglich. Wenn man etwa die Anspielung auf Kleists Michael Kohlhaas nicht erkennt, mit welcher der Roman beginnt, tut das weder dem Leseverstehen noch dem Lesevergnügen in irgendeiner Weise einen Abbruch, zumal man noch nicht einmal bemerken dürfte, dass ein über den Text hinausweisender Bezug vorliegt. ${ }^{119}$ Nicht zuletzt aufgrund dieser Eigenschaften kann man den Text vielleicht am ehesten als postmodernen Unterhaltungsroman ansehen.

118 In der Forschung scheinen viele anzunehmen, dass der Text am ehesten als postmoderner Roman klassifiziert werden kann, der Elemente anderer Gattungen, etwa des Kriminal-, Geschichts- oder Künstlerromans aufnimmt, oder eine postmoderne Spielart solcher Gattungen darstellt. Vgl. z. B. Frizen: Das gute Buch für jedermann oder Verus Prometheus; Florian Grimm: Reise in die Vergangenheit, Reise in die Fantasie? Tendenzen des postmodernen Geschichtsromans. Frankfurt a. M. 2008, S. 95-128; Manfred R. Jacobson: Patrick Süskind's Das Parfum: A Postmodern Künstlerroman. In: The German Quarterly 65 (1992), S. 201-211; Carsten Rhode: Der Roman der Postmoderne. In: Andrea Hübener/Jörg Paulus/Renate Stauf (Hg.): Umstrittene Postmoderne. Lektüren. Heidelberg 2010, S. 185-203, hier S. 194-198; Judith Ryan: Pastiche und Postmoderne. Patrick Süskinds Roman Das Parfum. In: Paul Michael Lützeler (Hg.): Spätmoderne und Postmoderne. Beiträge zur deutschsprachigen Gegenwartsliteratur. Frankfurt a. M. 1991, S. 91-103; Swenta Steinig: Postmoderne Phantasien über Macht und Ohnmacht der Kunst. Vergleichende Betrachtung von Süskinds Parfum und Ransmayrs Letzte Welt. In: Literatur für Leser 20 (1997), S. 37-51. Vgl. zu Elementen des Trivialen Katharina Arnold: Von Erdäpfeläckerchen und goldenen Flakons. Triviale Elemente in postmoderner Literatur am Beispiel von Robert Schneiders Schlafes Bruder und Patrick Süskinds Das Parfum. Marburg 2008, S.67-86. Merkmale des Neo-Phantastischen werden identifiziert in Marcía Cecilia Barbetta: Poetik des Neo-Phantastischen. Patrick Süskinds Roman Das Parfum. Würzburg 2002. Als Aufnahme und Subvertierung des Schelmenromans wurde der Text gesehen in Edith Borchardt, Caricature, Parody, Satire: Narrative Masks as Subversion of the Picaro in Patrick Süskind's Perfume. In: Nicholas Ruddick (Hg.): State of the Fantastic. Studies in the Theory and Practice of Fantastic Literature and Film. Westport, CT/London 1992, S. 97-113.

119 Vgl. zu den intertextuellen Bezügen des Romans v. a. Buß: Intertextualität als Herausforderung für den Literaturunterricht, S. 117-169; außerdem Cinzia Carmina Drăghici: Postmoderne und intertextuelle Bezüge im Roman Das Parfum von Patrick Süskind. In: Temeswarer Beiträge zur Germanistik 9 (2012), S. 81-86; Stefanie Kreuzer: Vom genieästhetischen ,Duften` und postmodernen ,Verduften' der Texte, Figuren und Autoren: Intertextuelle Referenzen in Das Parfum. In: Andreas Blödorn/Christine Hummel (Hg.): Psychogramme der Postmoderne. Neue Untersuchungen zum Werk Patrick Süskinds. Trier 2008, S. 23-38; Raleigh G. Whitinger/M. Herzog: Hoffmann's Das Fräulein von Scuderi and Süskind's Das Parfum: Elements of Homage in a Postmodernist Parody of a Romantic Artist Story. In: The German Quarterly 67 (1994), S. 222-234. 
Patrick Süskinds Das Parfum ist ein Roman, der aufgrund seiner Beschaffenheit ein nur geringes Applikationspotenzial besitzt und sich stattdessen eher für andere Rezeptionsweisen eignet. Umso aussagekräftiger mit Blick auf die Existenz und Relevanz des Phänomens der Applikation ist hingegen, dass der Roman durchaus verschiedentlich $\mathrm{zu}$ applizieren versucht wird, und das bei professionellen und nicht-professionellen Rezipienten gleichermaßen. Applikation als Lektüremodus kann offensichtlich so stark ausgeprägt sein, dass er bei literarischen Texten zum Einsatz kommt, die sich eigentlich eher für andere Rezeptionsweisen eignen. Das Parfum ist ein postmoderner Unterhaltungsroman, der zugänglich und spannend erzählt ist, bei der Lektüre verschiedene ästhetische Erfahrungen hervorrufen kann und dem Zeitvertreib dient - will man ihn applizieren, gelingt dies nur bedingt und dann so, dass die Applikationen bloß in einem eher lockeren Zusammenhang stehen mit der Beschaffenheit des Textes.

\subsection{Bernhard Schlink: Der Vorleser (1995)}

Bernhard Schlinks Der Vorleser erschien 1995. Der Publikumserfolg war vergleichbar mit dem von Das Parfum. ${ }^{120}$ Die deutsche Auflage dürfte die Millionengrenze längst überschritten haben. Im Jahr 2000 betrug die Gesamtauflage in den USA 1,8 Millionen. Der Roman wurde in mehr als vierzig Sprachen übersetzt. Bemerkenswert ist, dass Schlink am 30. März 1999 als erster deutscher Schriftsteller in Oprah Winfrey's Fernsehsendung Oprah's Book Club eingeladen wurde, die ein Millionenpublikum erreichte. Noch im selben Jahr wurden die Filmrechte an eine Produktionsfirma in Hollywood verkauft. Der Film kam 2008/2009 in die Kinos (Regie: Stephen Daldry). Die publizistische Rezeption des Romans ist verschiedentlich beschrieben worden. ${ }^{121}$ Die nicht-professionelle

120 Vgl. zum Folgenden Bodemer: Bestsellermarketing, S. 227 f., S. 285-289 und S. 290-292; Manfred Heigenmoser: Bernhard Schlink. Der Vorleser. Stuttgart 2005, S. 111 f. Der internationale Erfolg dürfte dazu beigetragen haben, dass der Roman gerade auch von der Literaturwissenschaft außerhalb des deutschen Sprachraums beachtet wurde, vgl. z. B. William Collins Donahue/Eva B. Revesz (Hg.): Themenheft: Bernhard Schlinks Der Vorleser. In: Colloquia Germanica 48 (2015), S. 1-150.

121 Vgl. dazu v. a. Bodemer: Bestsellermarketing, S. 237-258, ferner Lothar Bluhm: „Die Würde des Menschen ist unantastbar“. Anmerkungen zu Bernhard Schlinks Roman Der Vorleser. In: Volker Wehdeking/Anne-Marie Corbin (Hg.): Deutschsprachige Erzählprosa seit 1990 im europäischen Kontext. Interpretation, Intertextualität, Rezeption. Trier 2003, S. 149-161, hier S. 150-153; Hannes Fricke: Bernhard Schlink: Der Vorleser. In: Romane des 20. Jahrhunderts. Bd. 3. Stuttgart 2003, S. 274-294, hier S. 287-291; Michael Peter Hehl: Bernhard Schlink: Der 
Rezeption wurde nur im Ausnahmefall beachtet. ${ }^{122}$ Applikationen wurden bei der literaturwissenschaftlichen Untersuchung des Romans und seiner Rezeption nicht festgestellt.

Im Folgenden werden, analog zum Vorgehen im vorangehenden Unterkapitel, Ergebnisse einer Auswertung der Rezensionen bei LovelyBooks vorgestellt (Kap. 5.3.1). Sodann werden die professionelle außerwissenschaftliche Rezeption sowie Selbstaussagen des Autors betrachtet (Kap. 5.3.2). Schließlich wird die Beschaffenheit des Textes untersucht und gefragt, wie sie sich zu den festgestellten Applikationen verhält (Kap. 5.3.3.).

\subsubsection{Applikationen bei LovelyBooks}

Schlinks Der Vorleser wurde bisher 290 Mal bei LovelyBooks rezensiert. ${ }^{123}$ In 81 Besprechungen, also in deutlich mehr als jeder vierten, lassen sich zum Teil deutliche Hinweise finden auf verschiedene Applikationen oder auf dem Text zugeschriebene Potenziale dieser Art. In einer Rezension können durchaus mehrere Applikationen vorkommen. Der Roman wurde rund 5.600 Mal bewertet, der Schnitt liegt bei 3,9 von 5 Sternen. Die neusten Texte stammen von 2020, die ältesten reichen zurück bis in die Jahre 2006 und 2007. Die Verwendung des Romans als Schullektüre und die Verfilmung dürften dazu beigetragen haben, dass und wann der Roman über zehn oder zwanzig Jahre nach seinem Erscheinen auf der Plattform rezensiert wurde. ${ }^{124}$

Vorleser. Roman (Zürich: Diogenes). In: Heribert Tommek/Matteo Galli/Achim Geisenhanslüke (Hg.): Wendejahr 1995. Berlin/Boston 2015, S. 470-475, hier S. 473 f.; Eva Matthes: Bernhard Schlink Der Vorleser. In: Hans Vilmar Geppert/Hubert Zapf (Hg.): Große Werke der Literatur. Bd. 10. Tübingen 2007, S. 241-255, hier S. 251-254.

122 Vgl. dazu Katharina Hall: The Author, the Novel, the Reader and the Perils of ,neue Lesbarkeit': A Comparative Analysis of Bernhard Schlink's Selbs Justiz and Der Vorleser. In: German Life and Letters 59 (2006), S. 446-467. In dieser Untersuchung werden Kundenrezensionen bei Amazon einbezogen. Vgl. für eine Interpretation des Romans aus Sicht einer klassischen Rezeptionsästhetik Carina Hilt: Von wegen banal. Ein rezeptionsästhetisch perspektivierter Blick auf Bernhard Schlinks Verbrecherfigur Hanna Schmitz. In: Zeitschrift für Literaturwissenschaft und Linguistik 181 (2016), S. 69-82.

123 Vgl. https://www.lovelybooks.de/autor/Bernhard-Schlink/Der-Vorleser-40923750-w/ (01.07.2020).

124 Der Roman wurde rasch als Schullektüre kanonisiert. Vgl. als Beispiele für - zum Teil kritische - didaktische Beiträge Juliane Köster: Bernhard Schlink: Der Vorleser (1995) - Eine Interpretation für die Schule. In: Der Deutschunterricht 51 (1999), S. 70-81; Barbara Seeliger: „Was du nicht alles wissen willst, Jungchen!“ Bernhard Schlink: Der Vorleser. In: Valentin 
Wie bei Süskinds Das Parfum findet sich in Rezensionen zu Schlinks Roman immer wieder der Hinweis, dass er ,zum Nachdenken anrege‘, und dies sogar deutlich häufiger. Dazu ausgewählte Beispiele. Das Buch, so eine Nutzerin, „regt zum Nachdenken an über Themen, die auch heute noch aktuell sind“. ${ }^{125}$ In einigen Fällen wurden Angaben dazu gemacht, ob die Reflexion während der Lektüre stattfindet oder danach. Es wurde zum Beispiel gesagt, dass der Roman „beim Lesen immer wieder zum Nachdenken anregt“, ${ }^{126}$ oder mitgeteilt, es sei ein Buch, „über das ich sicher noch länger nachdenken werde“. ${ }^{127}$ Aufschlussreich ist ferner die Meinung, dass der Roman „viele Anhaltspunkte zum Nachdenken und darüber reden“ liefere. ${ }^{128}$ Der Nutzer oder die Nutzerin hob die Eignung des Textes zum Austausch hervor, der wohl die Ergebnisse des Nachdenkens einschließt. Aussagen dieser Art über das Reflexionspotenzial des Romans mögen etwas stereotyp und pauschal wirken. Sie verweisen aber auf etwas, das viele Nutzer/-innen, die sich entsprechend äußerten, als positiven Wertungsmaßstab ansahen, nämlich, allgemein gesprochen, die Eignung des Textes zur Entfaltung von Eigenaktivität im Rezeptionsprozess, bei der das Gelesene mit Blick auf die eigene Person und die Lebenswelt reflektiert wird - und damit potenziell Anlass zu Applikationen ist.

Solche Äußerungen sind mitunter verbunden mit Hinweisen auf die Wichtigkeit des Themas, die Nähe des Geschilderten zur Realität und das emotionale

Merkelbach (Hg.): Romane im Unterricht. Lektürevorschläge für die Sekundarstufe II. Baltmannsweiler 2000, S. 143-153; Klaus Schenk: Bernhard Schlink: Der Vorleser. Schullektüre als „Holo-Kitsch“?. In: Informationen zur Deutschdidaktik. Zeitschrift für den Deutschunterricht in Wissenschaft und Schule 27 (2003), S. 38-44; Andreas Bär: Bernhard Schlinks Der Vorleser. Entwicklungspsychologische und bildungstheoretische Gehalte im punktuell profilorientierten Pädagogikunterricht. In: Literatur im Unterricht 6 (2005), S. 229-239; Tilman von Brand: Kritische Kompetenz als Voraussetzung für historisches Lernen im Literaturunterricht. Bernhard Schlink: Der Vorleser - John Boyne: Der Junge im gestreiften Pyjama - Astrid Rosenfeld: Adams Erbe - Laurent Binet: HHhH. In: Christian Dawidowski/Dieter Wrobel (Hg.): Kritik und Kompetenz. Die Praxis des Literaturunterrichts im gesellschaftlichen Kontext. Baltmannsweiler 2013, S. 148-160.

125 Tyra: Zwischen Schuld und Leidenschaft. 2015. https://www.lovelybooks.de/autor/ Bernhard-Schlink/Der-Vorleser-40923750-w/rezension/1151232886/ (01.07.2020).

126 Nurija: Wie schuldig kann man sein? 2014. https://www.lovelybooks.de/autor/BernhardSchlink/Der-Vorleser-40923750-w/rezension/1081751300/ (01.07.2020).

127 Ein LovelyBooks-Nutzer: [Rezension von Schlink: Der Vorleser]. 2009. https://www. lovelybooks.de/autor/Bernhard-Schlink/Der-Vorleser-40923750-w/rezension/984658476/ (01.07.2020).

128 Ein LovelyBooks-Nutzer: [Rezension von Schlink: Der Vorleser]. 2010. https://www. lovelybooks.de/autor/Bernhard-Schlink/Der-Vorleser-40923750-w/rezension/969754063/ (01.07.2020). 
Wirkungspotenzial. Es wurde des Weiteren gelobt, dass „die moralischen Fragen“, welche der Roman behandele, „großartig ausgearbeitet“ worden seien. ${ }^{129}$ Der Roman, so eine andere Rezension, „liefert immer neue Denkanstöße“. ${ }^{130}$ Im Zusammenhang mit solchen Beobachtungen wurde im Einzelfall die Art und Weise reflektiert, wie der Roman Derartiges bewirken könne: Er sei „nicht überladen von moralischen Fingerzeigen oder Ähnlichem und bewirkt vielleicht gerade dadurch, dass man sich Gedanken macht zu den vom Autor angesprochenen Themen““. ${ }^{131}$ Die Bereitschaft, sich mit den ethischen Fragen auseinanderzusetzen, welche der Roman aufwerfe, werde also dadurch gesteigert, dass explizite Leserlenkung nicht vorkommt. Im Einzelfall wurde positiv angemerkt, dass der Roman, im Unterschied zum Geschichtsunterricht, der Nutzerin „die Grausamkeit noch einmal gründlich vor Augen geführt“ habe. ${ }^{132}$ Damit wird, zumindest andeutungsweise, in diesem Fall dem literarischen Medium eine spezifische Leistung zugeschrieben, die anderweitig nicht erbracht werden konnte.

In allen diesen Fällen gilt, was bereits im vorangehenden Unterkapitel festgestellt werden konnte: Aussagen dieser Art sind Indizien für Applikationen, sie deuten darauf hin, dass bei der Rezeption Applikationen vorkommen - nicht mehr, aber eben auch nicht weniger. Die Äußerungen benennen Voraussetzungen für Applikationen, etwa die Beschaffenheit und Eignung des Textes, und sie beschreiben Tätigkeiten bei der Rezeption, die mit einer gewissen Wahrscheinlichkeit mit Applikationen in Verbindung stehen oder sie begünstigen, nämlich die selbständige Reflexion des Gelesenen. Man kann vermuten, dass zumindest in einigen dieser Fälle das Nachdenken zu Ergebnissen führt, die sich als Applikationen beschreiben lassen.

Manche Nutzer/-innen veranlasste die Lektüre dazu, das Gelesene auf die Gegenwart und auf die eigene Person zu beziehen. Ein Nutzer spricht von der „Erkenntnis, dass heute die Menschen in der unmittelbaren Umgebung genau wie damals zum Mitläufer und Mittäter werden würden“. Und er fügt hinzu:

129 Ein LovelyBooks-Nutzer: [Rezension von Schlink: Der Vorleser]. 2017. https://www. lovelybooks.de/autor/Bernhard-Schlink/Der-Vorleser-40923750-w/rezension/1414208206/ (01.07.2020).

130 SagMal: [Rezension von Schlink: Der Vorleser]. 2009. https://www.lovelybooks.de/autor/ Bernhard-Schlink/Der-Vorleser-40923750-w/rezension/984705181/ (01.07.2020).

131 HannaFunk: [Rezension von Schlink: Der Vorleser]. 2009. https://www.lovelybooks.de/ autor/Bernhard-Schlink/Der-Vorleser-40923750-w/rezension/984540507/ (01.07.2020).

132 LisasBuecherchaos: [Rezension von Schlink: Der Vorleser]. 2013. https://www. lovelybooks.de/autor/Bernhard-Schlink/Der-Vorleser-40923750-w/rezension/1023049658/

(01.07.2020). 
„Man ist während der gesamten Handlung hin- und hergerissen, sich zu fragen, wie Menschen wie du und ich zum Täter werden können, und wie diese Menschen, ja wie unsere Gesellschaft nach dieser Katastrophe die Aufarbeitung der Ereignisse verdrängt hat." 133 Solche Aussagen sind sehr deutliche Beispiele für Applikationen, die an der eigenen Person orientiert sind, oder zumindest für die Zuschreibung entsprechender Potenziale.

Individuelle Applikationen sind allerdings eher die Ausnahme. In der Regel sind die Applikationen auf allgemeinere Sachverhalte bezogen. So steht zum Beispiel in einer Rezension: „Man kommt nicht umhin, sich während des Lesens mit ganz unterschiedlichen Fragen zu beschäftigen, wie zum Beispiel: Wer hat Schuld? Wie müssen wir, als ,Kinder' des Krieges, mit dieser Schuld umgehen? Wie kann aus einer KZ-Aufseherin so ein Mensch wie Hanna werden und umgekehrt?“134 Es zeigt sich eine für die Rezeption dieses Romans bei LovelyBooks charakteristische Tendenz, an dem Roman verschiedene, in der Sache bisweilen eng zusammenhängende thematische Gehalte hervorzuheben, die dann Gegenstand von Applikationen werden können, im konkreten Fall die Frage danach, wie die Täter einzuschätzen und zu beurteilen sind, und wie die Nachgeborenen als Kollektiv, nämlich als Angehörige einer der Nachkriegsgenerationen, mit deren Schuld umgehen sollen. Um die verschiedenen Gesichtspunkte im Folgenden sachangemessen und übersichtlich darzustellen, können Gruppen gebildet werden, denen Gehalte (Teilthemen) des Textes entsprechen: Aussagen über (1) die erinnerungskulturelle Auseinandersetzung mit den Verbrechen zur Zeit der NS-Diktatur allgemein, (2) die Sicht auf die Täter und die Frage nach der Schuld und Beurteilung der Täter sowie das Verhältnis zu ihnen, (3) den Konflikt der ,zweiten Generation“ mit ihren Eltern, (4) das Dilemma, einen geliebten Menschen aufgrund seiner Taten moralisch verurteilen $\mathrm{zu}$ wollen, dies aber

133 Stephan_Schwendele: Eine unglaublich beeindruckende Geschichte. 2020. https://www. lovelybooks.de/autor/Bernhard-Schlink/Der-Vorleser-40923750-w/ (01.07.2020). Vgl. dazu Katchen: [Rezension von Schlink: Der Vorleser]. 2009. https://www.lovelybooks.de/autor/ Bernhard-Schlink/Der-Vorleser-40923750-w/rezension/984438439/ (01.07.2020); Lesefreudebook: [Rezension von Schlink: Der Vorleser]. 2012. https://www.lovelybooks.de/autor/ Bernhard-Schlink/Der-Vorleser-40923750-w/rezension/953983403/ (01.07.2020); Ein LovelyBooks-Nutzer. Ein anspruchsvoller Roman mit vielen Facetten. 2013. https://www.lovelybooks. de/autor/Bernhard-Schlink/Der-Vorleser-40923750-w/rezension/1052536737/ (01.07.2020);

ElkeK: [Rezension von Schlink: Der Vorleser]. 2015. https://www.lovelybooks.de/autor/ Bernhard-Schlink/Der-Vorleser-40923750-w/rezension/1161070889/ (01.07.2020).

134 AnnaTeresa: Angenehmer Schreibstil - schwierige Themen. 2016. https://www. lovelybooks.de/autor/Bernhard-Schlink/Der-Vorleser-40923750-w/rezension/1253219402/ (01.07.2020). 
nicht zu können, (5) die Schuldproblematik. Daneben gibt es zwei weitere Gruppen. Sie sind weitgehend unabhängig von der NS-Thematik und zum einen auf (6) die Beziehung zwischen ungleichen Partnern bezogen, zum anderen auf (7) das Problem des Analphabetismus.

Verschiedentlich gebrauchten die Nutzer/-innen Ausdrücke, die im Zusammenhang stehen mit der politischen und juristischen sowie erinnerungskulturellen Auseinandersetzung mit der NS-Diktatur: ,Aufarbeitung‘, ,Vergangenheitsbewältigung‘, ,Schuldfrage‘ und ,Kollektivschuld‘. Der Roman thematisiere „die Aufarbeitung des Nationalsozialismus in der Nachkriegsgeneration“, „Einzelschuld und Kollektivschuld“. ${ }^{135}$ Man könne in dem Roman „die Aufarbeitung der Nachkriegszeit deutlich erkennen““. ${ }^{136}$ Er sei „Vergangenheitsbewältigung und Verarbeitung, die das Unbegreifliche in keiner Weise begreiflich macht und dennoch aufwühlend und erschütternd erzählt und beleuchtet“". ${ }^{137}$ In einigen Fällen wurde die Thematik historisch eingeordnet, etwa wenn davon die Rede ist, dass der Roman zu einer Zeit spiele, ,in der die kollektive Schuld der Deutschen unter den Teppich des aufkeimenden Wohlstandes gekehrt“ worden sei; eine Zeit, in der „die Alten verdrängen und die Jungen noch schweigen“. ${ }^{138}$ Andere betonten die Bedeutsamkeit des Themas. Es sei „so wichtig, sich mit diesem Thema $z u$ beschäftigen, was mit den Leuten eigentlich geschah, die aktiv während des NS tätig waren“. ${ }^{139}$

Ein gutes und repräsentatives Beispiel dafür, wie eine diesbezügliche Applikation aussehen kann, liefert eine Rezension, in welcher die allgemeine erinnerungskulturelle Perspektive zugleich verschiedentlich konkretisiert wurde:

Dieses Buch bietet einige Gedankenanstöße [!] zu den Themen Vergangenheitsbewältigung und Recht. So fragt man sich selbst im Verlauf der Geschichte: „Was ist eigentlich Recht?“ „Was ist Unrecht?“ „Wodurch äußert sich Schuld?“ Auch der Konflikt zwischen zwei Generationen wird angeschnitten, aber nicht sonderlich großartig ausgeführt, was ich ein wenig schade fand. Dennoch schafft es Bernhard Schlink, bei diesem Thema neut-

135 Anita27a: [Rezension von Schlink: Der Vorleser]. 2009. https://www.lovelybooks.de/ autor/Bernhard-Schlink/Der-Vorleser-40923750-w/rezension/984616878/ (01.07.2020).

136 Basant_B: Der Vorleser. 2015. https://www.lovelybooks.de/autor/Bernhard-Schlink/DerVorleser-40923750-w/rezension/1150564056/ (01.07.2020).

137 Itwt69: [Rezension von Schlink: Der Vorleser]. 2011. https://www.lovelybooks.de/autor/ Bernhard-Schlink/Der-Vorleser-40923750-w/rezension/964501377/ (01.07.2020).

138 Ein LovelyBooks-Nutzer: Eine Schuld, die alles bewegt. 2014. https://www.lovelybooks. de/autor/Bernhard-Schlink/Der-Vorleser-40923750-w/rezension/1109341925/ (01.07.2020).

139 JuliaSchu: Ein empfehlenswerter Klassiker zu einem wichtigen Thema. 2017. https://www. lovelybooks.de/autor/Bernhard-Schlink/Der-Vorleser-40923750-w/rezension/1475076561/ (01.07.2020). 
ral zu bleiben, obwohl hier viele Emotionen wie Scham, Schande, Unverständnis und Wut aufkommen. Schlink verurteilt weder die „Nazi-Generation“ noch die Nachkriegsgeneration, sodass man als Leser sich ein eigenes Bild machen kann und vielleicht sogar versucht, den einen oder anderen zu verstehen und anhand dessen eben die angesprochenen Punkte zum Thema Recht überdenkt. ${ }^{140}$

Hervorgehoben wurde, dass der Roman zu Denkanstößen Anlass gebe und Fragen aufwerfe, trotz der emotional besetzten Sachverhalte keine expliziten Beurteilungen beinhalte und damit zu dem Versuch anrege, selbst Antworten auf die Fragen zu finden und ein eigenes Urteil zu fällen. Es wurde der - an der Beschaffenheit des Textes festgemachte - Ausgangspunkt für einen Prozess der Applikation identifiziert und Andeutungen zur Tätigkeit des Applizierens gemacht. Ergebnisse wurden nicht präsentiert, es liegt jedoch nahe, anzunehmen, dass der Roman in der Wahrnehmung der Person, die diesen Text verfasst hat, mit Blick auf moralische Einstellungen im Zusammenhang mit der ,Vergangenheitsbewältigung' ein Applikationspotenzial besitzt und so rezipiert werden kann und soll. Die Gegenposition wurde in einer anderen Rezension formuliert, die auf eine Negativ-Applikation hinweist. „Das Thema Aufarbeitung“, so wurde dort moniert, „kommt für meinen Geschmack etwas zu kurz“: Der Protagonist „geht [...] selten darauf ein, verurteilt niemanden und stellt kaum Fragen dazu, wie Menschen anderen so furchtbare Dinge antun konnten“. Lediglich bei Hanna Schmitz mache er sich Gedanken, die in diese Richtung gingen; sie seien aber speziell auf deren Fall bezogen und ließen sich nicht verallgemeinern. ${ }^{141}$ Der Nutzer oder die Nutzerin vermisste gerade die Möglichkeit, zu neuen Überzeugungen zu gelangen und sich ein Urteil zu bilden, also das Gelesene zu applizieren.

In den Fokus rückten immer wieder die Akteur/-innen, ihre Taten und das Bestreben, sich dazu wertend ins Verhältnis zu setzen. Man könne, so eine Rezension, den Roman „auch kritisch“ sehen, er stelle jedoch einen „Versuch“ dar, sich „über das Grauen, welches auch ,normale‘ Menschen verübt haben, im Klaren zu werden und es zu verstehen“. ${ }^{142}$ Man könne eine neue Sicht auf „Mittäter“ wie Hanna gewinnen, obgleich feststehe, „dass sie dennoch schuldig

140 Ein LovelyBooks-Nutzer: [Rezension von Schlink: Der Vorleser]. 2011. https://www. lovelybooks.de/autor/Bernhard-Schlink/Der-Vorleser-40923750-w/rezension/964394721/ (01.07.2020).

141 LaLecture: Schwierig. 2014. https://www.lovelybooks.de/autor/Bernhard-Schlink/DerVorleser-40923750-w/rezension/1081462212/ (01.07.2020).

142 Rallus: [Rezension von Schlink: Der Vorleser]. 2010. https://www.lovelybooks.de/autor/ Bernhard-Schlink/Der-Vorleser-40923750-w/rezension/969953188/ (01.07.2020). 
sind““ ${ }^{143}$ Die Einsichten und neuen Perspektiven, von denen hier die Rede ist, setzen einen Akt der Applikation voraus oder beziehen sich auf dessen Konsequenzen. Besonders deutlich wird das dem Roman zugeschriebene Applikationspotenzial in einer Aussage wie der folgenden: „Neben der Beziehungsgeschichte behandelt Schlink die Aufarbeitung der Nazi-Zeit im 2. Weltkrieg. Was haben die Menschen bewusst gemacht, welche Beweggründe hatten sie, andere Menschen in den Tod zu schicken? Diese Fragen bewegen auch den Leser, man beginnt, sich eigene Gedanken zu machen, und schweift gedanklich ab." ${ }^{144}$ Es wird also explizit beschrieben, wie das Gelesene zur Auseinandersetzung mit den besagten Fragen Anlass gibt. Man kann vermuten, dass dabei auch versucht wird, Antworten zu geben, und das Gelesene in diesem Zuge appliziert wird.

In einer Rezension wurde kritisiert, dass der Roman unterschwellig eine unzulässige Frage aufwerfe, nämlich: „Kann jemand, der aufgrund einer Beeinträchtigung so handelt, wirklich als vollschuldiger Täter gesehen werden oder handelt es sich nicht vielmehr um ein Opfer?“"145 Andere verwahrten sich gegen den Vorwurf, der Roman sei, wie es in einer Rezension formuliert wird, „geschichtsverklärend oder auch revisionistisch“.146 Es gab Bestrebungen, eine potenziell mildere Beurteilung mancher Akteur/-innen mit einer Absage an jeglichen Revisionismus $\mathrm{zu}$ vermitteln. ${ }^{147}$ Dezidiert revisionistische Aussagen lassen sich kaum ausmachen. Es gibt Ausnahmefälle, die in eine solche Richtung zu gehen scheinen, etwa eine Rezension, in welcher vom Autor gesagt wurde, er habe zeigen wollen, „dass auch die Nachkriegsgeneration die (ver-

143 Vgl. FriediM: [Rezension von Schlink: Der Vorleser]. 2012. https://www.lovelybooks.de/ autor/Bernhard-Schlink/Der-Vorleser-40923750-w/rezension/972785384/ (01.07.2020).

144 Sommerlese: Ergreifende Darstellung von Schuld im Dritten Reich. 2015. https://www. lovelybooks.de/autor/Bernhard-Schlink/Der-Vorleser-40923750-w/rezension/1149637114/ (01.07.2020).

145 Labellokiss: [Rezension von Schlink: Der Vorleser]. 2011. https://www.lovelybooks.de/ autor/Bernhard-Schlink/Der-Vorleser-40923750-w/rezension/966500625/ (01.07.2020).

146 HomersEvil: [Rezension von Schlink: Der Vorleser]. 2009. https://www.lovelybooks.de/ autor/Bernhard-Schlink/Der-Vorleser-40923750-w/rezension/984676679/ (01.07.2020). Vgl. dazu Rumi: [Rezension von Schlink: Der Vorleser]. 2010. https://www.lovelybooks.de/autor/ Bernhard-Schlink/Der-Vorleser-40923750-w/rezension/967361256/ (01.07.2020).

147 So etwa in einer Aussage wie dieser: „Herr Schlink vermittelt uns den Eindruck, dass nicht jeder, der an diesen faschistischen Handlungen beteiligt war, auch wirklich verurteilt werden sollte. Passiv flüstert er uns aber auch ein, dass Massenmorde während den Zeiten des Dritten Reichs niemals vergänglich sein werden und dieses Thema immer wichtig sein wird." Daniel_Allertseder: Ein Klassiker! 2017. https://www.lovelybooks.de/autor/Bernhard-Schlink/ Der-Vorleser-40923750-w/rezension/1468368601/ (01.07.2020). 
dammte) Pflicht hat, genauer hinzuschauen, bevor man die Väter-Generation wegen ihrer Nazi-Vergangenheit in Bausch und Bogen verurteilt“. Verstärkt wird ein solcher Eindruck dadurch, dass Andeutungen gemacht wurden über eine „versteckte politische Aussage“, die von zentraler Bedeutung sei, um den Roman angemessen zu verstehen. ${ }^{148}$ Gerade diese kontroversen Einschätzungen sind geeignet, deutlich zu machen, wie der Roman manche Nutzer/-innen dazu herausforderte, in sachlicher und moralischer Hinsicht Stellung zu nehmen; ein Vorgang, welcher voraussetzt, dass man das im Roman Geschilderte in Beziehung setzt $z u$ eigenen Überzeugungen und Einstellungen, die modifiziert werden können, und dessen Konsequenz eine positive oder negative Applikation ist.

Eher selten wurde der Generationenkonflikt herausgestellt und wenn, dann in der Regel zusammen mit anderen Gesichtspunkten. ${ }^{149}$ Zumindest die Andeutung einer Applikation lässt sich ausmachen, wenn davon die Rede ist, dass der Roman diesbezüglich „neuartige und interessante Sichtweisen“ ermögliche. Zu einem früheren Zeitpunkt hätte das Buch, so die Rezension, eine starke Wirkung haben können: „Wenn das Buch noch in den 70er Jahren geschrieben worden wäre, wäre die Aufarbeitung genial gewesen. “150 Worin genau diese Wirkung oder die neue Sichtweise bestehen kann, wurde nicht gesagt; die Möglichkeit einer Applikation bleibt Andeutung.

Deutlicher ist der Befund bei einem damit in Verbindung stehenden Gesichtspunkt, nämlich dem Dilemma, einen Menschen zu lieben, der während der NS-Diktatur an Verbrechen beteiligt war, aufgrund deren man die Person verurteilen muss, und den daraus resultierenden Schuldgefühlen. In einer Rezension wurden derartige Fragen aufgeworfen: „Kann eine Liebe zu einer Person, die Schlimmes begangen hat, falsch sein? Macht sich der Liebende, egal ob

148 Ein LovelyBooks-Nutzer: [Rezension von Schlink: Der Vorleser]. 2008. https://www. lovelybooks.de/autor/Bernhard-Schlink/Der-Vorleser-40923750-w/rezension/985719986/ (01.07.2020).

149 Vgl. eine Aussage wie: „Es geht vor allem um den Generationenkonflikt, der in den 60ern vorherrschend war und die Frage, wie mit den Tätern des Dritten Reiches umgegangen werden soll.“ - Ein LovelyBooks-Nutzer: [Rezension von Schlink: Der Vorleser]. 2011. https://www. lovelybooks.de/autor/Bernhard-Schlink/Der-Vorleser-40923750-w/rezension/964532856/ (01.07.2020). Ein weiteres Beispiel: „In außergewöhnlicher Weise thematisiert das Buch die Verbrechen des Dritten Reichs und den Generationenkonflikt der 1960er Jahre, ohne dabei mit dem erhobenen Zeigefinger zu operieren.“ - Ulf Borkowski: [Rezension von Schlink: Der Vorleser]. 2011. https://www.lovelybooks.de/autor/Bernhard-Schlink/Der-Vorleser-40923750-w/ rezension/966816071/ (01.07.2020).

150 Awogfli: [Rezension von Schlink: Der Vorleser]. 2012. https://www.lovelybooks.de/autor/ Bernhard-Schlink/Der-Vorleser-40923750-w/rezension/950319454/ (01.07.2020). 
er davon weiß oder nicht, mitschuldig?“. ${ }^{151}$ Ganz ähnlich eine andere: „Wie sollen die Kinder mit ihren Eltern umgehen? Ist es richtig, Menschen zu lieben, sie nicht zu verurteilen, wenn sie doch verurteilt gehören? Ist es richtig, sie zu verurteilen, wenn man selber nicht weiß, wie es gewesen ist?“152 Es wurde in diesem Zusammenhang erkannt, dass der Fokus auf dem Erzähler liegt, genauer, auf der Frage, „wie Michael damit umgeht, dass er Hanna, die viele Juden in den Tod geschickt hat, geliebt hat“. Der Autor habe den Roman so gestaltet, „dass sich jede folgende Generation wieder damit identifizieren und auseinandersetzen kann“. Es sei zu beachten, dass das Erzählte eine fiktive Geschichte ist, welche „den Leser direkt anspricht und viele Fragen aufwirft“. ${ }^{153}$ Der Roman wurde als Darstellung eines moralischen und emotionalen Dilemmas begriffen, dessen Reflexion in Verbindung mit lebensweltlichen Überzeugungen zu Applikationen Anlass geben kann: Ist die Haltung, die der Protagonist einnimmt, nachvollziehbar und verständlich, ratsam und richtig? Gibt es Alternativen? Vorausgesetzt ist eine Annahme, die selbst mit einer Applikation verbunden ist: Der Roman macht ein Dilemma einsichtig, das für manche Angehörigen der zweiten Generation tatsächlich existiert.

Einige Nutzer/-innen betrachteten die Frage nach der Schuld an den Verbrechen der NS-Diktatur als besonders prominent. Es hieß dann zum Beispiel: „Das Hauptthema ,Schuld‘ wird von vielen Seiten beleuchtet und bringt den Leser zum Nachdenken.“154 Der Roman werfe „sehr philosophische und moralische Fragen“ auf, „die kaum richtig zu beantworten sind“, etwa die „Frage, was die Schuld ist, ob und wie sehr man für solche Taten schuldig sein kann“. Der Roman sei so beschaffen, dass man sich „mit diesen Fragen auseinandersetzen

151 November: [Rezension von Schlink: Der Vorleser]. 2009. https://www.lovelybooks.de/ autor/Bernhard-Schlink/Der-Vorleser-40923750-w/rezension/984663493/ (01.07.2020).

152 Franzis2110: Ein aufrüttelndes Werk. 2016. https://www.lovelybooks.de/autor/BernhardSchlink/Der-Vorleser-40923750-w/rezension/1223615630/ (01.07.2020).

153 Jens65: [Rezension von Schlink: Der Vorleser]. 2009. https://www.lovelybooks.de/autor/ Bernhard-Schlink/Der-Vorleser-40923750-w/rezension/984713833/ (01.07.2020). Dort auch die beiden vorangehenden Zitate. Ähnlich auch eine andere Rezension: „Wie soll er [Michael] umgehen mit der Schuld, eine Schuldige geliebt zu haben? Wie kann man überhaupt umgehen mit der kollektiven Schuld einer ganzen Generation? Schlink verbindet Michaels individuelles Fühlen mit dem prinzipiellen Konflikt von Schuld und Verantwortung." - Ulrikerabe: Schuld und Scham. 2019. https://www.lovelybooks.de/autor/Bernhard-Schlink/Der-Vorleser40923750-w/ (01.07.2020).

154 Yvette: Schuld! 2015. https://www.lovelybooks.de/autor/Bernhard-Schlink/Der-Vorleser40923750-w/rezension/1132415651/ (01.07.2020). 
muss“. ${ }^{155}$ Die „Art des Erzählens“ führe dazu, dass der Text „ein immenses Potenzial an weiterführenden Fragen [besitze], die man ausführlich diskutieren kann“. ${ }^{156}$ Er wurde als Aufforderung zur moralischen Reflexion begriffen, bei der man das Geschilderte mit eigenen ethischen Überzeugungen in Beziehung setzen und zu einer Entscheidung kommen muss, die darauf hinauslaufen kann, neue Überzeugungen $\mathrm{zu}$ bilden oder bestehende $\mathrm{zu}$ verändern. Es zeigt sich einmal mehr die Tendenz, die Aktivität zu betonen, die man als Rezipient entfalten kann: „Der Leser wird zum Nachdenken angeregt und muss sich eine eigene Meinung bilden.“157 Das Publikum werde „dazu aufgerufen, sich selbst Gedanken zu machen, auch wenn das wehtut und verstört“". ${ }^{158}$ Der Roman hält demnach keine Antwort parat, sondern fungiert als Anregung, selbst eine Antwort $\mathrm{zu}$ formulieren anhand dessen, was der Text an Informationen und Perspektiven anbietet. Dabei wurde auf die Möglichkeit einer Relativierung hingewiesen: „Es ist ein Buch, das mit Gefühlen spielt und den Leser zweifeln lässt an der Liebe und an der Schuld des Einzelnen im Nationalsozialismus. "159 Solche potenziellen Konsequenzen scheinen aber eher selten vorzukommen. ${ }^{160}$

Mitunter betrachteten Nutzer/-innen die Liebe zwischen zwei ungleichen Partnern, von denen der eine jugendlich und charakterlich noch ungefestigt ist, nicht allein als Voraussetzung für die vorangehend dargestellten Gesichtspunkte, sondern als das eigentlich zentrale Thema. Der Roman konnte dann zum Beispiel so gelesen werden, dass er Einsichten ermöglicht in die Dynamik einer Partnerschaft: „Dieses Buch zeigt auf, wie viele Geheimnisse eine zwischenmenschliche Beziehung und vor allem der Mensch selbst verträgt. Es zeigt die Facetten der Liebe und es stellt die Frage, ob man Vergangenes ruhen lassen kann.“161 Der Roman veranschauliche, „dass man von einem Menschen nicht

155 Cherrylouu: Eine Lehre für das Leben. 2014. https://www.lovelybooks.de/autor/BernhardSchlink/Der-Vorleser-40923750-w/rezension/1093420844/ (01.07.2020).

156 120_miles: Der Vorleser. 2020. https://www.lovelybooks.de/autor/Bernhard-Schlink/DerVorleser-40923750-w/ (01.07.2020).

157 K-lu: Außergewöhnlich, aber gut. 2016. https://www.lovelybooks.de/autor/BernhardSchlink/Der-Vorleser-40923750-w/rezension/1252307851/ (01.07.2020).

158 Elenchen_h: Ein moderner Klassiker. 2020. https://www.lovelybooks.de/autor/BernhardSchlink/Der-Vorleser-40923750-w/ (01.07.2020).

159 Sommerlese: Ergreifende Darstellung von Schuld im Dritten Reich.

160 Ein Beispiel könnte eine Aussage wie diese sein: „Man sollte sich der Pflicht bewusst sein, sich mit dem Thema auseinanderzusetzten, doch sollte man trennen, wer wirklich schuldig war und wer nicht.“ - Strigoia: Eine zeitlose Erzählung. 2015. https://www.lovelybooks.de/ autor/Bernhard-Schlink/Der-Vorleser-40923750-w/rezension/1136688438/ (01.07.2020).

161 Wrathchild: [Rezension von Schlink: Der Vorleser]. 2008. https://www.lovelybooks.de/ autor/Bernhard-Schlink/Der-Vorleser-40923750-w/rezension/985537590/ (01.07.2020). 
jede Seite kennt. Insbesondere die eine Seite nicht, die er gekonnt verbirgt zumal derjenige selbst auch mit der Vergangenheit nichts mehr zu tun haben will, bis sie ihn einholt, ob gewollt oder nicht“. ${ }^{162}$ Außerdem konnte diese Beziehung Gegenstand ethischer Applikationen werden, etwa hinsichtlich der „moralischen Berechtigung dieser Liebe“. ${ }^{163}$ Vereinzelt wurde auf die gesellschaftlichen Verhältnisse hingewiesen. Dargestellt werde eine „Beziehung, die gesellschaftlich in den 60er Jahren nicht akzeptiert wurde und auch heute nicht auf mehr Verständnis stoßen würde“. ${ }^{164}$ Ferner konnte das Gelesene auf die eigene Person bezogen werden. In Anbetracht des Dilemmas, in welchem sich der Protagonist befinde, „fühlt der Leser mit ihm und stellt sich unweigerlich auch selbst die Frage, wie er entscheiden würde“. ${ }^{165}$ In einem Fall hieß es dazu: „Zu verfolgen, wie einen Jungen die erste Leidenschaft in Form einer 20 Jahre älteren Frau verfolgt und sein Leben beeinflusst, lässt einen auch das eigene Leben nochmal mit ganz anderen Augen betrachten." 166 Solche die NS-Thematik ausblendenden Aussagen können zu Applikationen hinsichtlich von Liebe und Partnerschaft führen, auch bezogen auf die eigene Person.

In ähnlicher Weise konnte der Analphabetismus (weitgehend) losgelöst von dem konkreten historischen Hintergrund betrachtet werden. Das konnte bedeuten, dass dessen lebensweltliche Bedeutsamkeit herausgestellt wurde. Es sei „ein ernstes Thema und die damit verbundenen Gefühle des Betroffenen [...] nicht immer leicht“, ${ }^{167}$ Analphabetismus sei ,auch noch heute ein riesiges Problem". ${ }^{168}$ Anhand dieser Problematik ermöglichte der Roman moralische Einsichten. Es wurde zum Beispiel beobachtet: „Durch dieses Buch wird deutlich, dass Menschen ihre eigene Würde oft $\mathrm{zu}$ hoch anstellen. Es zeigt, dass man eher eine

162 Herbstapfel: Hannas Geheimnis. 2016. https://www.lovelybooks.de/autor/BernhardSchlink/Der-Vorleser-40923750-w/rezension/1234081485/ (01.07.2020).

163 Sommerlese: Ergreifende Darstellung von Schuld im Dritten Reich.

164 Becciboo: Ein Wiedersehen zweier Liebenden, das die Vergangenheit verändert. 2016. https://www.lovelybooks.de/autor/Bernhard-Schlink/Der-Vorleser-40923750-w/rezension/ 1227686470/ (01.07.2020). Ähnlich auch Ein LovelyBooks-Nutzer: Eine Schuld, die alles bewegt.

165 Becciboo: Ein Wiedersehen zweier Liebenden, das die Vergangenheit verändert.

166 Perlchen: [Rezension von Schlink: Der Vorleser]. 2011. https://www.lovelybooks.de/autor/ Bernhard-Schlink/Der-Vorleser-40923750-w/rezension/966045988/ (01.07.2020).

167 Rieke93: Der Vorleser als Schulbuch! 2014. https://www.lovelybooks.de/autor/BernhardSchlink/Der-Vorleser-40923750-w/rezension/1083284663/ (01.07.2020).

168 Reading_ani: Ein Klassiker, der gelesen werden muss! 2015. https://www.lovelybooks.de/ autor/Bernhard-Schlink/Der-Vorleser-40923750-w/rezension/1130172384/ (01.07.2020). 
Strafe auf sich nimmt, als sich selber bloßzustellen.“169 Ähnlich eine andere Rezension: „Ist es das wirklich wert, nur um sich nicht Tag für Tag für eine für Außenstehende harmlose Schwäche zu rechtfertigen, sich in solche Verschleierungen zu verhüllen, sein Leben in Freiheit zu riskieren, nur um nicht entblößt $\mathrm{zu}$ werden und so nur noch viel schlimmer dazustehen?“170 Wenn der Roman zu der Überzeugung Anlass war, dass und warum Analphabetismus allgemein oder heute ein besonderes Problem darstellt, oder wenn er Anlass gab zu Einsichten in das moralisch nicht ratsame Handeln mancher Menschen, die aus solchen oder ähnlichen Gründen sich in einer bestimmten Weise verhalten, dann liegen Applikationen vor. Die „Verschränkung von Analphabetismus und Schuld“ kann jedoch aufgrund vermuteter problematischer Implikationen zugleich kritisiert werden. ${ }^{171}$ Das ist mithin ein Fall negativer Applikation.

Schlinks Der Vorleser, so legt die Auswertung der Quellen nahe, bietet Anlass zur unterschiedlichen Applikation des Gelesenen. Darauf deuten jedenfalls zahlreiche Aussagen hin, die sich als Applikationen klassifizieren lassen, auf Potenziale des Textes hinweisen oder Applikation zur Voraussetzung oder Konsequenz haben. Dass der Roman ein vergleichsweise großes Applikationspotenzial zu haben scheint, kann eigentlich in Anbetracht des behandelten Themas (genauer: der verschiedenen Teilthemen) und der Art der Darstellung nicht überraschen, wie im weiteren Verlauf noch auszuführen sein wird. Aufschlussreich sind insbesondere Beobachtungen, die mit dem Applikationspotenzial in Zusammenhang stehen. Verschiedene Nutzer/-innen hoben immer wieder hervor, dass der Roman Eigenaktivität im Rezeptionsprozess erforderlich mache. Er konnte Anlass sein zu selbstständigen Überlegungen; eine Eignung, die von manchen auf die Beschaffenheit des Textes oder Absichten des Autors zurückgeführt und überwiegend positiv beurteilt wird. Der Text wurde so wahrgenommen, dass er in manchen maßgeblichen Hinsichten, etwa der Perspektivensteuerung, ,offen“ ist und somit als ,Aufforderung“ oder ,Einladung“ verstanden werden kann. Es mag verschiedene Faktoren geben, die dazu beitragen können, den Befund zu erklären, angefangen bei einer in Teilen von der Rezeptionsästhetik der 1960er Jahre oder vergleichbaren Ansätzen beeinflussten Literaturdidaktik, welche die Eigenständigkeit des Lesers betonten, bis hin zur Natur der

169 Occasiuncula: [Rezension von Schlink: Der Vorleser]. 2010. https://www.lovelybooks.de/ autor/Bernhard-Schlink/Der-Vorleser-40923750-w/rezension/968804932/ (01.07.2020).

170 Franzis2110: Ein aufrüttelndes Werk.

171 Ein LovelyBooks-Nutzer: [Rezension von Schlink: Der Vorleser]. 2011. https://www. lovelybooks.de/autor/Bernhard-Schlink/Der-Vorleser-40923750-w/rezension/966907927/ (01.07.2020). 
NS-Verbrechen, welche zur Positionierung und Beurteilung herausfordert und mit der Tendenz einhergeht, auf der Unabhängigkeit des eigenen Urteils zu bestehen. Das zeigt bereits die Alltagserfahrung. Solche Überlegungen können und müssen an dieser Stelle aber Spekulation bleiben.

\subsubsection{Professionelle Rezeption, Autor und Gegebenheiten}

Was die professionelle Rezeption des Romans in den Medien angeht, lassen sich zwei Gruppen unterscheiden. Es gibt zum einen die unmittelbar nach Veröffentlichung des Romans publizierten Besprechungen. Zum anderen fallen Artikel auf, die zu einer Kontroverse im Jahr 2002 gehören.

Die ersten Rezensionen bezogen sich mitunter auf die Gehalte des Romans, die bei den LovelyBooks-Rezensionen beachtet werden. Der Roman gebe Aufschluss über sogenannte ,Vergangenheitsbewältigung“ und zeige, dass „Vergangenheit [...] nicht beherrscht, sondern nur erkannt werden“ könne. In derselben Rezension wurde mit Blick auf den Generationenkonflikt festgestellt, dass der Text „das Verhältnis von der Schuld der Zeitgenossen Hitlers und der Scham der Nachgeborenen in der Studentenbewegung aufklärt“. ${ }^{172}$ Ein Rezensent kritisierte dagegen das, was er als „parabelnde Zeitlosigkeit“ und „Vermeidungsstrategie“ ansah. ${ }^{173}$ Zur Konzeption der Figur der Hanna wurden mehrfach Beobachtungen angestellt. An einer Täterin zeige der Roman, wie sich „das Monströse und das Banale untrennbar mischen“, ${ }^{174}$ der Autor „führt die Banalität des Bösen in seinem Alltagsgesicht von Eitelkeit und Schwäche vor“. ${ }^{175}$ Die Frage danach, wer die Täter waren, und nach ihrer Beurteilung, wurde also durchaus identifiziert; sie sei aber, so ein Rezensent, aus generischen Gründen nachrangig:

172 Peter Mosler: Ein Generationen-Vorfall. Ein Buch über den heißen Sommer von '68 - aus der Feder des Kriminalautors und Rechtsprofessors Bernhard Schlink. In: Frankfurter Rundschau. Nr. 5, 6. Januar 1996, S. 7.

173 Peter Michalzik: Das Monster als Mensch. Zu zeitlos, um konkret zu sein: Bernhard Schlinks parabelnde Annäherung an eine analphabetische Ex-KZ-Wärterin. In: die tageszeitung. Nr. 4795, 9./10. Dezember 1995, S. 14.

174 Claus-Ulrich Bielefeld: Die Analphabetin. Bernhard Schlinks Roman Der Vorleser. In: Süddeutsche Zeitung. Nr. 254, 4./5. November 1995, SZ am Wochenende, S. IV.

175 Marion Löhndorf: Die Banalität des Bösen. Bernhard Schlinks Roman Der Vorleser. In: Neue Zürcher Zeitung. Internationale Ausgabe. Nr. 251, 28./29. Oktober 1995, S. 35. 
Schlinks mutiges Buch mündet nicht in die Lösung ,alles verstehen heißt alles verzeihen`. Wenn es denn eine Lehre vermittelt, so heißt sie eher: ,Man wird nie alles verstehen, darum sollte man sich gerechterweise mit dem Verurteilen zurückhalten.' Da wir es aber mit Literatur zu tun haben, steht die Lehre gar nicht im Vordergrund. In erster Linie ist es eine aufregende Fallgeschichte, so gezügelt wie Genuß gewährend erzählt. Das sollte man sich nicht entgehen lassen, weil es in der deutschen Literatur unserer Tage hohen Seltenheitswert besitzt. ${ }^{176}$

Entscheidend sei demnach der ästhetische ,Genuss', welchen die Lektüre gewähre, nicht die angedeutete Möglichkeit zur Applikation, bei welcher die Einsicht, dass manche Handlungen historischer Akteur/-innen nicht hinreichend verstanden werden können, zu einer Mäßigung des moralischen Urteils führen soll. In einer Rezension war von „unlösbaren Fragen“ die Rede, welche „in der Schwebe gehalten“ werden: ob Hannas Lebensgeschichte ein „deutsches Schicksal“ sei, ob Michael Bergs Leben als „generationstypisch“ aufzufassen sei und ob Hannas Selbstmord „ein Akzeptieren der Schuld durch den eigenen Tod" ausdrücke. ${ }^{177}$ Neben Besprechungen, die eher etwas anderes hervorhoben als eine denkbare Applikation oder die eine Negativ-Applikation zur Folge hätten, gab es also durchaus vereinzelte Aussagen, die dahingehend verstanden werden können: Sich die Einsicht zu eigen machen, dass Vergangenheit nicht ,bewältigt' werden kann, einen Eindruck von der Scham der zweiten Generation zu erhalten, die ,Banalität des Bösen' zu erkennen, mit Beurteilungen vorsichtig zu sein oder manche Fragen als ,unlösbar‘ zu betrachten - mit Blick auf den konkreten Umgang mit dem Roman bedeutet das, den Text mit der Lebenswelt in Beziehung zu setzen und Überzeugungen zu bilden oder zu modifizieren, das im Text Dargestellte folglich zu applizieren.

In der Regel wurde in den ausgewerteten Rezensionen, die 1995 und 1996 erschienen, die elementare Konzeption der Figur einer analphabetischen KZAufseherin nicht als problematisch wahrgenommen. In einer Rezension wurde auf die „Provokation des Buches“ hingewiesen, die „in dem positiven Blickwinkel“ zu sehen sei, unter dem Hanna aufgrund ihres „Analphabetismus“ und der „Liebesgeschichte“ dargestellt werde. ${ }^{178}$ Daran schloss sich jedoch keine Kritik

176 Tilman Krause: Keine Elternaustreibung. Ein Höhepunkt im deutschen Bücherherbst: Bernhard Schlinks Roman über 68er und die deutsche Schuld. In: Der Tagesspiegel. Nr. 15377, 3. September 1995, S. W5.

177 Michael Stolleis: Die Schaffnerin. In: Frankfurter Allgemeine Zeitung. Nr. 210, 9. September 1995, S. B5.

178 Michalzik: Das Monster als Mensch. Dass im Roman die Figur der Hanna positiv dargestellt werde, kann man mit Gründen bezweifeln. Es scheint vielmehr das Gegenteil der Fall zu sein. 
an. Anders verhielt es sich mit Artikeln, die 2002 in der Süddeutschen Zeitung erschienen und im Zusammenhang $\mathrm{zu}$ sehen sind mit Leserbriefen, die aus Anlass der Veröffentlichung der englischen Übersetzung von Schlinks Liebesfluchten im Times Literary Supplement abgedruckt wurden. Der Vorleser wurde, allgemein gesprochen, als formal misslungen, sentimental und trivial bewertet, vor allem aber als moralisch fragwürdig, weil er eine apologetische und revisionistische Sicht nahelege. ${ }^{179}$ Was die hier interessierenden Gesichtspunkte betrifft, lassen sich Aussagen finden, die so verstanden werden können, dass der Roman Anlass sein kann zu problematischen Applikationen.

In einem Artikel wurde der Vorwurf erhoben, wonach der Text ein revisionistisches Bedürfnis großer Teile des Publikums bediene: „Das ist das eigentliche Thema des Romans: Es hätte doch alles auch ganz anders sein können. Er handelt von der Sehnsucht eines Millionenpublikums am Ausgang des zwanzigsten Jahrhunderts nach einer ungeschehenen Zeitgeschichte. “180 Wenn der Roman zu revisionistischen Überzeugungen Anlass gibt, dann wird er appliziert. In einem anderen Artikel wurde kritisiert, dass der Roman zum einen zahlreiche Fehler bei der Darstellung historischer Sachverhalte aufweise und zum anderen zu einer von Mitleid geprägten Sicht auf Hanna anleite. Mit Blick auf das, was man über Hannas Zeit im Gefängnis erfährt, schrieb Jeremy Adler, man werde „eingeladen“, an die „Läuterung“ einer „Massenmörderin“ zu glauben, die „als virtuelle Heilige präsentiert“ werde. ${ }^{181}$ Gerade der Analphabetismus spiele eine Rolle: Der Roman „manipuliert uns Leser an einen Punkt, wo wir Mitleid für ein Ungeheuer empfinden, und fordert uns dann heraus: Wagt ihr es, euch moralisch überlegen zu fühlen?" ${ }^{182}$ Aufgrund der Romanlektüre eine durch Mitleid und Verständnis geprägte Sicht auf jemanden einzunehmen, der in dieser Weise an NS-Verbrechen beteiligt war, und von einer Verurteilung abzu-

179 Vgl. dazu den Bericht über die Debatte in Großbritannien in Willi Winkler: Vorlesen, Duschen, Durcharbeiten. Schlechter Stil, unaufrichtige Bilder: England begreift nicht mehr, was es an Bernhard Schlinks Bestseller Der Vorleser fand. In: Süddeutsche Zeitung. Nr. 75, 30./31. März 2002, S. 16; dazu Volker Hage: Unter Generalverdacht. In: Der Spiegel. Nr.15, 8. April 2002, S. 178-181; Felicitas von Lovenberg: Literatur und Holocaust. In: Frankfurter Allgemeine Zeitung. Nr. 82, 9. April 2002, S. 47.

180 Lawrence Norfolk: Die Sehnsucht nach der ungeschehenen Geschichte. Warum Bernhard Schlinks Roman Der Vorleser ein so schlechtes Buch ist und allein sein Erfolg einen tieferen Sinn hat. In: Süddeutsche Zeitung. Nr. 98, 27./28. April 2002, S. 16.

181 Jeremy Adler: Die Kunst, Mitleid mit den Mördern zu erzwingen. Einspruch gegen ein Erfolgsbuch: Bernhard Schlinks Der Vorleser betreibt sentimentale Geschichtsfälschung. In: Süddeutsche Zeitung. Nr. 92, 20./21. April 2002, S. 18.

182 Norfolk: Die Sehnsucht nach der ungeschehenen Geschichte. 
sehen, lässt sich als Resultat einer emotionalen und ethischen Applikation auffassen: Realen Menschen, die so sind wie die fiktive Figur, soll auf eine solche Weise begegnet werden. Es sei angemerkt, dass zumindest die ausgewerteten Rezensionen bei LovelyBooks, wie gesehen, in der ganz überwiegenden Mehrzahl keinerlei Applikationen dieser Art erkennen lassen.

Schlink hat sich zu seinem Roman verschiedentlich in Interviews geäußert und zu Kritik Stellung genommen, die daran geübt wurde. Als aufschlussreich erweist sich außerdem der Text einer Poetikvorlesung. Verschiedentlich hat er die Konzeption der Figur der Hanna verteidigt. In einem Interview sagte er zum Beispiel: „Dass in Hanna Schmitz die Täterin zur Heldin werde und ein inakzeptables menschliches Antlitz gewinne - mit diesem Vorwurf lebe ich, seit das Buch erschienen ist. Aber wenn die Täter immer Monster wären, wäre die Welt einfach. Sie sind es nicht. “183 Hier wird eine Begründungsstrategie erkennbar: Er habe einen Sachverhalt lediglich so dargestellt, wie er tatsächlich sei. Es sei eben zutreffend, dass viele Täter ,gewöhnliche“ Menschen gewesen seien; um solche Taten zu begehen, hätten sie keine „Monster“ sein müssen. ${ }^{184}$ Im Zentrum seines Buches stehe gar nicht der Genozid an den europäischen Juden, vielmehr habe er die Absicht gehabt, über die ,zweite Generation“ zu schreiben, über den Konflikt mit der Elterngeneration und das Dilemma, in dem sie sich befunden habe: „Ich wollte über meine Generation schreiben. Ich habe kein Holocaust-Buch geschrieben - dass ich es getan hätte, ist noch eine krasse Fehldeutung. Ich habe ein Buch über meine Generation im Verhältnis zur Elterngeneration und $\mathrm{zu}$ dem, was die Elterngeneration gemacht hat, geschrieben. “ ${ }^{185}$ Als eine „Erfahrung meiner Generation“ hat er die Entdeckung bezeich-

183 Andreas Kilb: Herr Schlink, ist „Der Vorleser“ schon Geschichte? In: Frankfurter Allgemeine Zeitung. Nr. 44, 21. Februar 2009, S. Z6.

184 Vgl. dazu die Aussagen in Volker Hage/Martin Doerry: „Ich lebe in Geschichten“. In: Der Spiegel. Nr. 4, 21. Januar 2000, S. 180-184, hier S. 183; Bernhard Schlink: Gedanken über das Schreiben. Zürich 2011, S. 19 und 34.

185 Kilb: Herr Schlink, ist „Der Vorleser“ schon Geschichte? Ähnlich die Aussage in einem anderen Interview, wonach es um das „Schicksal der Zweiten Generation“ gehe - Jörn Jacob Rohwer: „Ich kann auch sehr fröhlich sein“. Interview mit Bernhard Schlink. In: Frankfurter Rundschau. Nr. 232, 6. Oktober 2001, Magazin, S. 4 f., hier S. 5. Präzisierend heißt es an anderer Stelle, er habe „das Problem der Verstrickung in die Schuld der Täter nicht nur als Generationenproblem und schon gar nicht als Konflikt innerhalb der Familie darstellen“ wollen; ihm sei es vielmehr um „ein allgemeines Problem“ gegangen, weswegen er sich für eine Liebesbeziehung ungleicher Partner entschieden habe - Peter von Becker: „Mein Erfolg bleibt ein Traum“. Bernhard Schlink über sein Doppelleben als Jurist und Bestseller-Autor, über die Spannung vor dem Erscheinen seines Buches Liebesfluchten. In: Der Tagesspiegel. Nr. 16924, 5. Januar 2000, S. 5. In diesem Interview weist er darauf hin, dass „die großen Gerichtsprozesse ab Beginn der 
net, dass geschätzte Personen an NS-Verbrechen beteiligt waren oder die NSIdeologie vertraten: „Da gab es den glänzenden Lehrer, der später als an irgendwelchen Furchtbarkeiten beteiligter ehemaliger SS-Mann enttarnt wurde, oder den Professor, dem ich viel zu verdanken habe und der sich einst massiv antisemitisch geäußert hatte." ${ }^{186}$

Äußerungen, die explizit auf intendierte Applikationen hinweisen, lassen sich nicht ausmachen. Eine Rezeption des Romans im Sinne der Darstellungsabsicht des Autors kann allerdings Applikationen zur Konsequenz haben. Das ist zum Beispiel dann der Fall, wenn man die Sicht auf die NS-Täter als zutreffend akzeptiert, welche der Text anbietet, oder wenn man Einblicke erhält in das Dilemma der zweiten Generation. Aussagekräftig sind die Äußerungen des Autors in zwei anderen Hinsichten. Zum einen schilderte er in einem Interview, wie die Diskussion über seinen Roman mit Leser/-innen in der Fernsehsendung Oprah's Book Club verlief:

Also unterhielten wir uns darüber, ob hier sexueller oder emotionaler Mißbrauch vorliege. Dann kamen wir zu der Frage, ob die Liebesbeziehung zwischen Michael und Hanna nicht doch echt sei. Ob es Kriterien für ,normale und gesunde' Liebesbeziehungen gebe. Weiter kamen wir auf das Problem des Widerstands im Dritten Reich und in totalitären Regimen überhaupt. Was hätte man selbst getan? Woraus resultiert Anpassung, wovon lebt Widerstand? Hanna, die sich im Laufe des Romans als KZ-Wärterin entpuppt und die trotzdem nicht einfach ein Monster ist, führte zu der Frage des Dilemmas von Verstehen und Verurteilen. Am Ende der Diskussion sagte Oprah: ,They are us', sie sind wie wir - und gerade weil wir die Täter des Dritten Reiches nicht als Monster weit von uns wegschieben können, sind sie so beunruhigend, bedrohlich. ${ }^{187}$

60er Jahre: Eichmann in Jerusalem, die Frankfurter Auschwitzprozesse“ für das Verhältnis seiner Generation zur Elterngeneration von großer Wichtigkeit gewesen seien. Die Generation der Studentenbewegung beschreibt er als „eine selbstgerechte Generation“ und bezieht sich selbst durchaus ein - Hage/Doerry: „Ich lebe in Geschichten“, S. 183, ähnlich Rohwer: „Ich kann auch sehr fröhlich sein“, S. 5.

186 Hage/Doerry: „Ich lebe in Geschichten“, S. 183. Dazu in der Poetikvorlesung: Seine Generation habe „wieder und wieder erlebt[], dass jemand, den wir respektiert und gemocht hatten, an den Furchtbarkeiten des Dritten Reichs beteiligt war" - Schlink: Gedanken über das Schreiben, S. 20.

187 Tilman Krause: Gegen die Verlorenheit an sich selbst. Gute Literatur lebt von der Auseinandersetzung mit der Umwelt - ein Gespräch mit Bernhard Schlink, dem Autor des Vorleser. In: Die Welt. 3. April 1999, Die literarische Welt, S. 3. Vgl. zur Rezeption des Romans in den USA und in der besagten Fernsehsendung u. a. Volker Hage: Gewicht der Wahrheit. In: Der Spiegel. Nr. 13, 29. März 1999, S. 242 f.; Jordan Mejias: Schlink ist okay! Frankfurter Allgemeine Zeitung. Nr. 78, 3. April 1999, S. 44; bei letzterem handelt sich um einen deutlich negativ wertenden Bericht. 
Hier ergeben sich aufschlussreiche Schnittmengen mit den Applikationen in LovelyBooks-Rezensionen. Das betrifft die Frage, wie man selbst gehandelt hätte, und die Aufschlüsse über unterschiedliche Sachverhalte wie die Täterschaft in der NS-Diktatur oder die Natur von Liebesbeziehungen, welche die Lektüre ermöglichen soll.

Zum anderen hat Schlink Angaben zu seiner Auffassung von Literatur, ihren Funktionen und Wirkungen gemacht. Seine Aussagen beziehen sich auf Qualitäten der Texte, welche Applikationen begünstigen, und korrespondieren mit manchen Beobachtungen der Nutzer-/innen bei LovelyBooks. Schlink wünschte sich eine Gegenwartsliteratur, die „Unterhaltung auf hohem Niveau“ biete, indem sie „spannende Geschichten“ erzählt, „die den Leser zugleich mit wichtigen, interessanten Problemen konfrontieren“. ${ }^{188}$ Neben der Relevanz des Dargestellten betonte er den Wirklichkeitsbezug der Literatur: „Wir wollen, dass Literatur uns unsere Wirklichkeit erklärt und dass sie uns einlädt, uns in andere Wirklichkeiten hineinzuversetzen, die nicht die unseren sind."189 Außerdem sprach er sich gegen eine zu starke Leserlenkung aus und gegen eine auktoriale Strategie, Deutungen zum Geschilderten gleich mitzuliefern: Er hege eine „Abneigung gegen Bücher [...], in denen ich selbst zu sehr bei der Hand genommen werde oder präsentiert bekomme, wie ich die Dinge zu sehen oder zu verstehen habe“, und „fände es meinen Lesern gegenüber respektlos, ihnen alle möglichen Deutungen mit auf den Weg zu geben“". ${ }^{190}$ Vor diesem Hintergrund ist wohl seine Verteidigung der Art und Weise zu sehen, wie er über die NS-Diktatur und ihre Verbrechen geschrieben hat. Man müsse nicht, wie manche forderten, „stets die volle Wahrheit, das ganze Bild sichtbar werden lassen“; eine solche Forderung ,zeugt von zu wenig Vertrauen in die Fähigkeit der Leser und Zuschauer, selbst das ganze Bild herzustellen“. ${ }^{191}$ Schlink nahm also an, dass die Rezipienten das im Text Dargestellte korrekt zu den historischen Tatsachen in Beziehung setzen können und erkennen, dass der Roman in einem nicht trivialen Sinne nur einen Ausschnitt der Wirklichkeit zum Gegenstand habe. Entscheidender sei daher der Anspruch, mit dem man schreibe: Was Literatur darstelle, müsse „nicht die volle Wahrheit sein; ein winziges Element der Wahrheit reicht, solange es nicht vorgibt, mehr zu sein, als es ist“. ${ }^{192}$ Hier lässt sich ebenfalls das Bestreben erkennen, darstellerische Entscheidungen mit Hinweis auf

188 Krause: Gegen die Verlorenheit an sich selbst.

189 Schlink: Gedanken über das Schreiben, S. 26.

190 Rohwer: „Ich kann auch sehr fröhlich sein“.

191 Schlink: Gedanken über das Schreiben, S. 13.

192 Schlink: Gedanken über das Schreiben, S. 26. 
die Wirklichkeit zu rechtfertigen. Sie sei „eher vielfältig als einförmig“, weswegen man nicht nur das „Typische[]“ der NS-Diktatur thematisieren müsse. Man setze sich im Gegenteil eher der Gefahr aus, zur Bildung von „Stereotypen“ beizutragen und den tatsächlichen Verhältnissen nur unzureichend gerecht zu werden. ${ }^{193}$

Um zu verstehen, was in der Welt des Textes der Fall ist, und um es korrekt einzuordnen, bedarf es eines Wissens über die historischen Gegebenheiten, sowohl die Zeit der NS-Diktatur und den Völkermord an den europäischen Juden betreffend als auch die Auseinandersetzung damit in der Zeit nach $1945 .{ }^{194}$ $\mathrm{Zu}$ denken ist an die systematischen Verschleppungen und das Lagersystem, Erschießungen durch ,Einsatzkommandos‘ hinter der Front, Zwangsarbeit und ,Vernichtung durch Arbeit‘, den industriellen Massenmord und die ,Todesmärsche“ ebenso wie an die nur in Teilen durchgeführte ,Entnazifizierung in den Besatzungszonen der Westalliierten, die Karriere vieler Belasteter in der jungen BRD, insbesondere im Öffentlichen Dienst, die Strafprozesse wegen Verbrechen gegen die Menschlichkeit (Eichmann-Prozess in Jerusalem, Frankfurter Auschwitzprozesse u. a.), die Auseinandersetzung mit dem NS im Umfeld der Studentenbewegung. Die Forschung hat manche Aspekte besonders herausgearbeitet. So wurde etwa der Majdanek-Prozess (1975-1981) gegen ehemalige KZAufseherinnen als Vorbild für die Darstellung des Prozesses im Roman identifiziert. ${ }^{195}$ Eine der Angeklagten, Hermine Braunsteiner-Ryan, die sogenannte ,Stute von Majdanek', wurde als Vorbild für Hanna ausgemacht, der historische Hintergrund (Frauen als Mitglieder der SS und KZ-Aufseherinnen) beleuchtet und - besonders wichtig - geltend gemacht, dass man in einer solchen Stellung kaum Analphabetin gewesen sein konnte. ${ }^{196}$ Ferner liegen Arbeiten vor zur Auseinandersetzung mit der Vergangenheit im Roman, zum Problem des angemessenen Erinnerns und zum Stellenwert des Romans im Rahmen der Erinnerungs-

193 Schlink: Gedanken über das Schreiben, S. 18.

194 Vgl. allein den Kommentar und die Erläuterungen in Heigenmoser: Bernhard Schlink, S. 5-97.

195 Vgl. z. B. Fricke: Bernhard Schlink, S. 279-281.

196 Vgl. Lynn Wolff: „The Mare of Majdanek“. Intersections of History and Fiction in Bernhard Schlink's Der Vorleser. In: Internationales Archiv für Sozialgeschichte der Literatur 29 (2004), S. 84-117. Vgl. auch die zahlreichen Hinweise auf Ergebnisse der historiographischen Forschung zu den NS-Tätern und zu KZ-Aufseherinnen in Jürgen Zarusky: Betäubung einer Vergangenheit. Bernhard Schlinks Roman Der Vorleser (1995). In: Johannes Hürter/Jürgen Zarusky (Hg.): Epos Zeitgeschichte. Romane des 20. Jahrhunderts in zeithistorischer Sicht. München 2010, S. 133-152. 
kultur. ${ }^{197}$ In einem Lexikon der „Vergangenheitsbewältigung“ gibt es sogar einen eigenen Eintrag zu dem Roman. ${ }^{198}$

In den allermeisten Rezensionen bei LovelyBooks scheint ein historiographisches Wissen vorausgesetzt zu werden, thematisiert wurde es jedoch in der Regel nicht. Aussagen zur Auseinandersetzung mit dem NS nach 1945 (,Aufarbeitung‘, ,Bewältigung' usw.) bleiben vage oder partiell. ${ }^{199}$ Es scheint ein allgemeines Wissen darüber zu geben und einen gewissen Konsens, der darauf hinausläuft, dass die Verbrechen zu verurteilen sind, die Täter mitunter einer differenzierten Beurteilung bedürfen. Selten wird von der weitverbreiteten Annahme abgewichen, dass die Erinnerung an die NS-Verbrechen wichtig bleibt. Man kann in diesem Zusammenhang von einer Mentalität sprechen, die auf ein Geschichtsbewusstsein verweist, welches durch Medien, Institutionen wie die Schule und nicht zuletzt wohl die Literatur vermittelt wird. Es ist jedenfalls zu vermuten, dass sich eine solche Haltung aus dem Schulunterricht (Deutsch, Geschichte) ergibt und aus der Rezeption von Medien wie Spiegel-Serien zur

197 Vgl. Wolfgang Struck: Reisen ins Herz der Finsternis. Fünf deutsche Bücher. In: Heinrich Detering/Herbert Krämer (Hg.): Kulturelle Identitäten in der deutschen Literatur des 20. Jahrhunderts. Frankfurt a. M. 1998, S. 123-142, hier S. 123-128; Carlotta von Maltzan: „Die Angst davor, daß es rauskommt“. Über das Schweigen von Opfern und Tätern bei Katja Behrens und Bernhard Schlink. In: Pól O’Dochartaigh (Hg.): Jews in German Literature Since 1945: German-Jewish Literature. Amsterdam/Atlanta 2000, S. 463-476, hier S. 469-473; Claas Morgenroth: Erinnerungspolitik und Gegenwartsliteratur. Das unbesetzte Gebiet, The Church of John F. Kennedy, really ground zero, Der Vorleser. Berlin 2014, S. 238-277; Achim Geisenhanslüke: In der Erinnerung. Gedächtnispolitik 1995. In: Heribert Tommek/Matteo Galli/A. G. (Hg.): Wendejahr 1995. Berlin/Boston 2015, S. 31-49. Christian Rink: Die Erinnerungskultur der 1990er-Jahre. Ein Vergleich der Romane Der Vorleser, Faserland und Morbus Kitahara. In: Triangulum 21 (2015), S. 438-447.

198 Vgl. Hans-Joachim Hahn: Bernhard Schlink, Der Vorleser (1995). In: Torben Fischer/Matthias N. Lorenz (Hg.): Lexikon der „Vergangenheitsbewältigung“ in Deutschland. Debatten- und Diskursgeschichte des Nationalsozialismus nach 1945. Bielefeld ${ }^{32015}$, S. 371373.

199 Vgl. aus der großen Fülle historiographischer Darstellungen exemplarisch Norbert Frei: Vergangenheitspolitik. Die Anfänge der Bundesrepublik und die NS-Vergangenheit. München 2012; Peter Reichel: Vergangenheitsbewältigung in Deutschland. Die Auseinandersetzung mit der NS-Diktatur von 1945 bis heute. München 2001; Fischer/Lorenz: Lexikon der „Vergangenheitsbewältigung“ in Deutschland. An Arbeiten zu den ,gewöhnlichen“ Deutschen als Tätern vgl. Christopher Browning: Ganz normale Männer. Das Reserve-Polizeibataillon 101 und die „Endlösung“ in Polen. Reinbek b. H. 1993; Daniel Jonah Goldhagen: Hitlers willige Vollstrecker. Ganz gewöhnliche Deutsche und der Holocaust. Berlin 1996. Instruktiv mit Blick auf die Frage, was die deutsche Bevölkerung vom Genozid an den europäischen Juden wissen konnte und welche Einstellung sie dazu hatte, ist Peter Longerich: „Davon haben wir nichts gewußt!“ Die Deutschen und die Judenverfolgung 1933-1945. München 2006. 
Geschichte des NS, Dokumentationen im ZDF und Hollywoodfilmen wie Schindlers Liste. Derlei muss hier allerdings Spekulation bleiben, nicht zuletzt, weil sich keine Angaben zu den Nutzer/-innen bei LovelyBooks machen lassen.

Ein Bezug auf tagespolitische Ereignisse oder erinnerungskulturelle Praktiken fehlt in der Regel. Betrachtet man grob die Zeit von 1995 bis heute, dann ließen sich zahlreiche Beispiele für Debatten und Ereignisse sowie Medien der Erinnerung finden, von denen einzelne Nutzer/-innen bei LovelyBooks in der einen oder anderen Form Kenntnis gehabt haben könnten: die Wehrmachtsausstellung ab März 1995, der Holocaust-Gedenktag, der in Deutschland seit dem 27. Januar 1996 begangen wird, die Debatte um Entschädigungszahlungen an ehemalige NS-Zwangsarbeiter 1998 bis 2000, das 2001 eröffnete Jüdische Museum in Berlin, das 2005 nach fünfzehnjähriger Planung eröffnete HolocaustMahnmal, Täterprozesse, z. B. 2009 bis 2011 vor dem Münchner Landgericht gegen den Ukrainer Iwan Demjanjuk, 2015 vor dem Landgericht Lüneburg gegen Oskar Gröning. Im Feuilleton und, mit einigen Ausnahmen, in der Forschung werden eher pauschale und immer wieder dieselben Bezüge hergestellt (,Banalität des Bösen‘, ,Unfähigkeit, zu trauern‘, Generationenkonflikt der 1968er). ${ }^{200}$

Diese Überlegungen können aus verschiedenen Gründen knapp ausfallen. Zum einen bedarf es zur Untersuchung der Applikationen keiner Erklärungen dafür, wie die Akteur/-innen zu ihren Dispositionen gelangt sind und welche historischen Gegebenheiten dafür einschlägig sind. Dass ein Wissen über den NS, seine Verbrechen und den Umgang damit vorhanden ist, lässt sich jedenfalls annehmen. Es ist dieses allgemeine Wissen und die damit verbundene moralische Einstellung, die mit Blick auf die Applikationen relevant ist. Zum anderen ist die Beschaffenheit des Textes $\mathrm{zu}$ beachten, auf die im folgenden Unterkapitel einzugehen sein wird.

Die Zahl der Aussagen in Feuilleton-Rezensionen, die mit Applikationen in Verbindung gebracht werden können, ist relativ gering, sodass ein Vergleich mit den Rezensionen bei LovelyBooks nur von begrenzter Aussagekraft sein kann. Feststellen lässt sich jedenfalls, dass mit Blick auf Applikationen kein prinzipieller Unterschied besteht, dafür aber bisweilen ein quantitativer oder qualitativer. So lassen sich etwa Applikationen mit Blick auf die Liebesbeziehung und den Analphabetismus, die verschiedentlich in Rezensionen bei LovelyBooks vorkommen, erwartungsgemäß in den Feuilleton-Rezensionen nicht

200 Eine Ausnahme ist, wie gesagt, Adler: Die Kunst, Mitleid mit den Mördern zu erzwingen. Dort wird dargelegt, dass Schlink verschiedene Fehler in der Darstellung historischer Tatsachen unterlaufen seien. 
ausmachen. Hier sind zum Beispiel die auf Täterschaft und deren Beurteilung bezogenen Applikationen etwas komplexer, weil Deutungsmuster wie die ,Banalität des Bösen' aus Hannah Arendts Bericht über den Prozess gegen Eichmann in Jerusalem den Nutzer/-innen bei LovelyBooks vermutlich nicht mit der gleichen Selbstverständlichkeit zur Verfügung stehen.

Die in den Artikeln von 2002 geäußerten Befürchtungen werden mit Aussagen über den Text begründet, etwa, dass der Text geeignet sei, Mitleid für Hanna $\mathrm{zu}$ evozieren und eine apologetische Sicht $\mathrm{zu}$ befördern. Vergleicht man diese Kritik mit den Rezensionen bei LovelyBooks, dann fällt auf, dass solche Äußerungen zwar vorkommen, aber nur sehr sporadisch. Außerdem sind, wie gezeigt, Auffassungen in der Minderheit, die man als relativierend oder revisionistisch auffassen kann. Rezeptionsweisen, die sich als Sehnsucht nach einer ungeschehenen Geschichte begreifen lassen, können kaum nachgewiesen werden. Es gibt allerdings im Einzelfall Rezensionen, in denen das Buch aus einer allgemein ablehnenden Haltung heraus negativ bewertet wird, weil es sich mit der NS-Diktatur beschäftigt. ${ }^{201}$ Dass manche Nutzer/-innen Aspekte wie die Liebesbeziehung oder den Analphabetismus fokussierten, die man gegenüber denjenigen als nachgeordnet betrachten kann, die auf die Verbrechen des NS bezogen sind, ist wohl nicht als Beleg für eine prinzipielle Indifferenz gegenüber letzteren zu werten. Es scheint im Gegenteil einen recht weitreichenden, eher allgemeinen Konsens zu geben, dass die Auseinandersetzung mit der NSDiktatur und dem Genozid an den europäischen Juden wichtig ist.

Vergleicht man die Aussagen des Autors mit den beiden Gruppen von Rezeptionsdokumenten, dann fallen zum einen gewisse Schnittmengen mit den Rezensionen bei LovelyBooks auf, etwa bezüglich der Sicht auf die Täter, der Generationenproblematik und des Dilemmas der zweiten Generation. Die Rezeption ist aufs Ganze gesehen etwas breiter als intendiert. Zum anderen erweist es sich als aufschlussreich, dass den Aussagen des Autors über die Wahl eines relevanten Themas, über die Zurückhaltung bei der Leserlenkung und die Ei-

201 Die ablehnende Haltung resultiert aus einer als übermäßig empfundenen Thematisierung der NS-Verbrechen in der Schule, verbunden mit einem diffusen Gefühl, persönlich dafür verantwortlich gemacht zu werden. Eine Nutzerin schreibt, ,dass ich die NS-Zeit und die Sache mit den Konzentrationslagern zwar schrecklich finde, aber langsam nicht mehr hören kann. Überall hört man nur noch KZ-Lager, Judenvernichtung usw.“ - Rieke93: Der Vorleser als Schulbuch! Eine andere meint: „Wir hatten den Nationalsozialismus in Geschichte, Sozialkunde, Englisch, Deutsch und immer wieder wurde mit dem Finger auf uns gezeigt.“ - Yoyomaus: Eine Pflichtlektüre aus meiner Schulzeit, die ich aber abgrundtief gehasst habe. 2016. https://www.lovelybooks.de/autor/Bernhard-Schlink/Der-Vorleser-40923750-w/rezension/ 1236278681/ (01.07.2020). 
genleistung bei der Rezeption, wie gesehen, zahlreiche Aussagen in Rezensionen bei LovelyBooks entsprechen.

\subsubsection{Beschaffenheit und Potenzial des Textes}

Betrachtet man vor dem Hintergrund der vorangehend dargestellten Befunde den Text des Romans, dann fällt es in der Regel nicht schwer, die identifizierten Applikationen an der Beschaffenheit des Textes festzumachen. Es zeigt sich, dass der Text in einem gewissen Maße geeignet ist, derartige Applikationen zu veranlassen. Zugleich wird ersichtlich, wo ihre Grenzen liegen, zumindest die der meisten Applikationen.

Als Beobachter eines Prozesses gegen ehemalige KZ-Aufseherinnen, darunter Hanna, mit dem Völkermord an den europäischen Juden konfrontiert, problematisiert der Erzähler in der Rückschau die Möglichkeit einer angemessenen Auseinandersetzung mit diesen Verbrechen gegen die Menschlichkeit aus der Sicht seiner Generation. Er schreibt: „Zugleich frage ich mich und habe mich schon damals zu fragen begonnen: Was sollte und soll meine Generation der Nachlebenden eigentlich mit den Informationen über die Furchtbarkeit der Vernichtung der Juden anfangen?“202 Der Frage lässt er eine längere Reflexion folgen (vgl. S. 99 f.). An anderer Stelle sagt er, dass es damals in den 1960er Jahren, anders als in der Erzählgegenwart, nur wenig Bildmaterial oder andere Möglichkeiten gegeben habe, sich einen konkreten Eindruck von den Verbrechen zu verschaffen. Die wenigen Bilder seien „zu Klischees erstarrt[]“ (S. 143). Er beschreibt relativ ausführlich seinen Versuch, sich durch Besichtigung des nächstgelegenen Konzentrationslagers Natzweiler Struthof ein Bild zu machen (vgl. S. 144-152). Der Versuch bleibt erfolglos: „Meine Eindrücke vom Struthof gesellten sich den wenigen Bildern von Auschwitz und Birkenau und BergenBelsen zu, die ich schon hatte, und erstarrten mit ihnen.“ (S. 152) Er empfindet lediglich „eine große Leere“ (S. 150) und „Betäubung“ (S. 155). Von „Betäubung“ spricht er immer wieder und meint, dergleichen außerdem bei den am Gerichtsprozess beteiligten Personen und den Opfern ausmachen zu können (vgl. S. 96-99, 114 f. und 160).

Die Frage nach der Sicht auf die Täter ist zum einen in der Konzeption der Figur einer analphabetischen KZ-Wärterin angelegt, zum anderen wird Hanna Schmitz stets als ,einfacher` Mensch geschildert, der ein ,alltägliches` Leben

202 Bernhard Schlink: Der Vorleser. Zürich 1995, S. 99. Nachweise im Folgenden stets unmittelbar im Anschluss an das Zitat. 
führt. Ferner sind Aussagen anderer Figuren zu nennen. So sagt der aus der Emigration zurückgekehrte Professor, welcher das Seminar anbietet, in dessen Rahmen Michael Berg den Prozess beobachtet, zu den Studierenden: „Sehen Sie sich die Angeklagten an - Sie werden keinen finden, der wirklich meint, er habe damals morden dürfen.“ (S. 87) Damit wird eine Perspektive angeboten, wonach es keine besonderen Umstände gab, auf welche sich die Täter hätten berufen können, und ihre Verbrechen daher schlicht als Mord beurteilt werden müssen. In brutaler und zynischer Weise spricht eine nur als „Mercedes-Fahrer“ bezeichnete Figur, die den Protagonisten auf dem Weg zur KZ-Gedenkstätte ein Stück mitnimmt, von den Tätern: „Der Henker befolgt keine Befehle. Er tut seine Arbeit, haßt die nicht, die er hinrichtet [...]. Sie sind ihm völlig gleichgültig.“ (S. 146) Er beschreibt eine Photographie, die Massenerschießungen von Juden durch ,Einsatzgruppen' hinter der Front im besetzten Osteuropa zeigt und seine Aussage belegen soll (vgl. S. 146 f.). Neben der durch das Wort ,Henker` nahegelegten Rechtmäßigkeit der Exekutionen, durch welche die Figur sich ungewollt als unzuverlässig erweist, ist entscheidend, dass eine Sicht auf die Täter angeboten wird, wonach der Massenmord von Menschen begangen wurde, die nicht ideologisch indoktriniert waren, weder aus weltanschaulichen Motiven noch aus persönlicher Animosität handelten, sondern ihre Taten als bloße „Arbeit“ begriffen.

Der Generationenkonflikt wird explizit thematisiert. Michael und seine Kommilitonen, die den Prozess gegen KZ-Wärterinnen begleiten, sehen sich als „Avantgarde der Aufarbeitung“ (S. 87), einer Aufarbeitung, die sich auf die Generation als ganze beziehen soll: „Die Generation, die sich der Wächter und Schergen bedient oder sie nicht gehindert oder sie nicht wenigstens ausgestoßen hatte, als sie sie nach 1945 hätte ausstoßen können, stand vor Gericht, und wir verurteilten sie in einem Verfahren der Aufklärung und Aufarbeitung zur Scham.“ (ebd., vgl. dazu S. 88) Der Erzähler registriert das Befremden, auf das er und seine Mitstreiter mit dieser Haltung stießen, und urteilt rückblickend, dass ihr Verhalten „abstoßend“ war (ebd.). Im „Sommer der Studentenbewegung“ geht er auf „Distanz“ zu ihren Akteuren (S. 160) und meint, „daß die Auseinandersetzung mit der nationalsozialistischen Vergangenheit nicht der Grund, sondern nur der Ausdruck des Generationenkonflikts war“ (S. 161). Er sagt in diesem Zusammenhang, dass Schuld und Scham eine generationelle Erfahrung gewesen seien: „Was immer es mit Kollektivschuld moralisch und juristisch auf sich haben oder nicht auf sich haben mag - für meine Studentengeneration war sie eine erlebte Realität.“ (ebd.) Sie ist nicht auf die Verbrechen während der NS-Diktatur beschränkt, sondern bezieht die antisemitischen Straftaten mit ein, die es danach in der BRD gegeben hat, sowie den Umstand, dass 
„alte Nazis“ in der Nachkriegszeit im öffentlichen Dienst Karriere machen konnten, die Nichtanerkennung des Staates Israel durch die BRD und den Mangel an Anerkennung und Erinnerung an „Emigration und Widerstand“ (ebd.). Mit dem Hinweis auf ,Kollektivschuld“ ist die Schuldproblematik angesprochen, die verschiedentlich zum Tragen kommt. In einer hervorstechenden Szene fragt Hanna den Richter: „Was hätten Sie denn gemacht?“ Die Frage bezieht sich auf ihre Rolle bei ,Selektionen“. Der Richter antwortet, vom Erzähler ausführlich kommentiert: „Es gibt Sachen, auf die man sich einfach nicht einlassen darf und von denen man sich, wenn es einen nicht Leib und Leben kostet, absetzen muß.“ (S. 107, vgl. dazu S. 107 f.)

Es ist daran $\mathrm{zu}$ erinnern, dass beschreibende Aussagen wie die vorangehenden zur Beschaffenheit des Textes in diesem Zusammenhang erforderlich sind, weil sie zeigen, inwiefern Applikationen auf Gehalte des Textes bezogen sind. Bei allen wird man sagen können, dass man den Text sicherlich nicht missversteht oder in einer unangemessenen Weise appliziert, wenn man so mit ihm umgeht, wie in den Rezeptionsdokumenten der Fall. Durch die Konstruktion der Handlung, durch die Konzeption der Figuren, durch Schauplatz und Zeit, vor allem durch die Kommentare und Reflexionen des Erzählers werden sie möglich. Es fällt aber auf, dass sie sich textintern nicht zu einer vollständigen Erörterung der Schuldfrage, der Darstellung und Beurteilung der ,gewöhnlichen Deutschen“ unter den Tätern, des Generationenkonfliktes, der richtigen und angemessenen Auseinandersetzung mit der NS-Vergangenheit verbinden. ${ }^{203}$ Häufig genug dürfte der Eindruck entstehen, dass der Erzähler eher Fragen aufwirft und Probleme benennt, anstatt Antworten und Lösungen anzubieten. Daneben sind Aussagen einer Erzählerfigur eben genau das: Aussagen einer

\footnotetext{
203 Ähnliches gilt für eine im Prinzip denkbare Applikation hinsichtlich rechtsphilosophischer Fragen, die im Roman vereinzelt zur Sprache kommen (vgl. S. 86 f.). In Rezensionen bei LovelyBooks lassen sich nur vereinzelte Indizien ausmachen, vgl. ZwergPinguin: [Rezension von Schlink: Der Vorleser]. 2009. https://www.lovelybooks.de/autor/Bernhard-Schlink/DerVorleser-40923750-w/rezension/984295638/ (01.07.2020); Ein LovelyBooks-Nutzer: [Rezension von Schlink: Der Vorleser]. 2011. https://www.lovelybooks.de/autor/Bernhard-Schlink/DerVorleser-40923750-w/rezension/964394721/ (01.07.2020). Der Autor hat sich mit rechtsphilosophischen Fragen eingehender beschäftigt, vgl. z. B. Bernhard Schlink: Vergangenheitsschuld und gegenwärtiges Recht. Frankfurt a. M. 2002; Bernhard Schlink: Vergangenheitsschuld. Beiträge zu einem deutschen Thema. Zürich 2007. Forschung, die den Roman in dieser Hinsicht betrachtet, liegt ebenfalls vor, vgl. Bluhm: „Die Würde des Menschen ist unantastbar“; Beate M. Dreike: Was wäre denn Gerechtigkeit? Zur Rechtskepsis in Bernhard Schlinks Der Vorleser. In: German Life and Letters 55 (2002), S. 117-129; Karin Tebben: Bernhard Schlinks Der Vorleser. Zur ästhetischen Dimension rechtsphilosophischer Fragestellungen. In: Euphorion 104 (2010), S. 455-474.
} 
fiktiven Instanz, die man nicht ohne Weiteres als zutreffend und richtig anerkennen kann. Gerade dies scheint von vielen Nutzer/-innen bei LovelyBooks als positiv wahrgenommen zu werden und dürfte in der Konsequenz dazu führen, dass man feststellt, dass das Gesagte nur partiell appliziert werden kann, dass es bestehende Überzeugungen verstärkt oder nur partiell ergänzt oder zu negativen Applikationen Anlass gibt, wenn die Einschätzung überwiegt, dass der Erzähler in seinen Ansichten nicht richtigliegt. Zugleich könnte in diesem Umstand eine Erklärung dafür zu suchen sein, dass manche Nutzer-/innen eher allgemein bleiben in ihren auf Applikationen bezogenen Aussagen. Es erscheint denkbar, dass Textstellen wie die genannten Anlass sein können für Applikationen anhand des Textes, bei welchen das Gelesene den Ausgangspunkt bildet für relativ eigenständige und dann nur noch mittelbar oder gar nicht auf den Text bezogene Applikationen.

Was die in LovelyBooks-Rezensionen identifizierbaren Applikationen mit Blick auf die Einsichten angeht, die sich in Liebesbeziehungen ergeben sollen, so steht der Text ihnen weitgehend entgegen. Es scheint sich um eine einseitige Liebe zu handeln. Der Erzähler erklärt: „[Ü]ber ihre Liebe zu mir weiß ich nichts“ (S. 67). Aufgrund unterschiedlicher Lebenserfahrung und anderer Milieus sind die beiden Partner wesentlich ungleich. Die Natur der Beziehung wird einseitig definiert: „Wir hatten keine gemeinsame Lebenswelt, sondern sie gab mir in ihrem Leben den Platz, den sie mir geben wollte.“ (S. 75) Daneben ist im Blick zu behalten, dass der Altersunterschied 21 Jahre beträgt und Michael nicht als charakterlich gefestigte Person gelten kann, wie gerade am Beginn des Romans deutlich wird. Die besagten Applikationen sind weitgehend assoziativ. Details des Textes müssen selektiv und relativ frei von deren Einbindung in den Gesamtzusammenhang der Handlung wahrgenommen oder die erzählte Welt mit Details angereichert werden, die sich der eigenen Kreativität verdanken. Hier besteht gleichfalls die Möglichkeit, dass anhand des Gelesenen relativ freie Applikationen vorgenommen werden.

Bei Applikationen, welche den Analphabetismus zum Gegenstand haben, wird der Text ebenfalls nur in Teilen wahrgenommen. Aufgrund der Beschaffenheit des Textes sind sie zwar prinzipiell, aber nur partiell möglich. Der Erzähler beurteilt die ethischen Implikationen explizit. Er nennt Hannas Verhalten eine „Lebenslüge“ und stellt fest: „Mit der Energie, mit der sie ihre Lebenslüge aufrechterhielt, hätte sie längst lesen und schreiben lernen können.“ (S. 132) Selbst als sie in der Haft dann doch Lesen und Schreiben gelernt hat, ist er „traurig über ihr verspätetes und verfehltes Leben“ (S. 178). Ob der Analphabetismus ein wesentlicher Grund für sie war, um sich für die SS zu melden, bleibt offen. Der Erzähler wirft die Frage an einer Stelle auf: „Aus Angst vor der Bloß- 
stellung als Analphabetin das Verbrechen?“ (S. 127) Beantworten kann er sie nicht. Mit Gewissheit lässt sich wohl nur sagen, dass der Analphabetismus für Hannas häufige Wohnortwechsel verantwortlich ist und ihr Verhalten während des Prozesses negativ beeinflusst. Der Analphabetismus dürfte außerdem mittelbar eine Ursache dafür sein, dass eine Frau von 36 Jahren eine vor allem auf Sexualität basierende Beziehung zu einem Jungen eingeht, den sie für einen Siebzehnjährigen hält. Bezeichnenderweise wird erwähnt, dass sie seine Motive völlig korrekt einschätzt (,Darum bist du doch hier!“, S. 26), der Erzähler allerdings an keiner Stelle darüber nachdenkt, was sie eigentlich dazu veranlasst haben mag. Es liegt nahe, dass ihr Dasein als Alleinstehende in einer Zeit, in welcher die Ehe allgemein als erstrebenswert und als ,Normalfall ' des Erwachsenendaseins angesehen wurde, letztlich mit dem unsteten Leben in der Nachkriegszeit zu tun hat, das wiederum, ähnlich wie der überstürzte Arbeitsplatzwechsel, welcher die Beziehung der beiden beendet, auf ihre Angst davor zurückzuführen ist, dass ihr Analphabetismus entdeckt wird. Damit erweist sich, dass die Analphabetismus-Problematik, ebenso wie die Liebesbeziehung, im Roman funktional eingebunden ist. Sie motiviert das Figurenhandeln. Beide Themen sind zugleich den anderen funktional nachgeordnet.

Alle Befunde zur Thematisierung der NS-Diktatur und ihrer Verbrechen haben eines gemeinsam: Sie sind durch den Erzähler vermittelt, häufig explizit und in Form reflektierender, bilanzierender Textpassagen. Das führt zur Frage nach der Figur des Erzählers und nach der Erzählsituation. Konstitutiv für die narrative Vermittlung ist, dass ein erzählendes Ich über sich selbst als erlebendes Ich spricht. Instanzen oder Perspektivierungen, die unabhängig von dieser Vermittlung wären, sind nicht greifbar. Es liegt in weiten Teilen ein deutlich späterer Zeitpunkt des Erzählens vor. Wesentliche Teile der Gesamthandlung, die Liebesbeziehung und der Gerichtsprozess, liegen zum Zeitpunkt des Erzählens Jahrzehnte zurück. Am Ende gibt der Erzähler Einblick in seine Motive und betont seine Aufrichtigkeit, relativiert aber zugleich den objektiven Geltungsanspruch des Erzählten:

Den Vorsatz, Hannas und meine Geschichte zu schreiben, habe ich bald nach ihrem Tod gefaßt. Seitdem hat sich unsere Geschichte in meinem Kopf viele Male geschrieben, immer wieder ein bißchen anders, immer wieder mit neuen Bildern, Handlungs- und Gedankenfetzen. So gibt es neben der Version, die ich geschrieben habe, viele andere. Die Gewähr dafür, daß die geschriebene die richtige ist, liegt darin, daß ich sie geschrieben und die anderen Versionen nicht geschrieben habe. Die geschriebene Version wollte geschrieben werden, die vielen anderen wollten es nicht. (S. 205 f.)

Wenn es „viele andere“ Versionen der Geschichte gibt, für die Richtigkeit der vorliegenden aber letztlich das subjektive Mitteilungsbedürfnis ausschlagge- 
bend ist, dann mag die Geschichte aufrichtig erzählt sein, aber „Gewähr“, die über die subjektive Befindlichkeit hinausgeht, gibt es ausdrücklich nicht. Der für die Beschaffenheit des Textes zentrale narratologische Befund besteht in der beinahe schon aufdringlich $\mathrm{zu}$ nennenden Unzuverlässigkeit dieses Erzählers. $^{204}$

204 Vgl. zur erzählerischen Unzuverlässigkeit Morgenroth: Erinnerungspolitik und Gegenwartsliteratur, S. 248-252; Oliver Müller: Ich-Erzähler mit beschränkter Haftung. Zum hermeneutischen Hintergrund des Antisemitismusvorwurfs gegen Bernhard Schlinks Roman Der Vorleser. In: Der Deutschunterricht 67 (2015), S. 62-71, hier S.62-66; Bill Niven: Bernhard Schlink's Der Vorleser and the Problem of Shame. In: The Modern Language Review 98 (2003), S. 381-396, hier S. 382. Man kann mit Blick auf die Forschung zu dem Eindruck kommen, dass die für die angemessene Einschätzung des Romans zentrale Frage nach der Zuverlässigkeit des Erzählers nicht immer hinreichend beachtet wird. Zahlreiche Interpretationen kritisieren den Roman oder seinen Verfasser aus ideologiekritischer Warte. Es wird anscheinend nicht selten angenommen, dass Aussagen des Erzählers für bare Münze zu nehmen sind. Der Roman soll u. a. relativistisch und revisionistisch sein, einer Viktimisierung der Deutschen das Wort reden, den Unterschied zwischen Tätern und Opfern verwischen, Schuld nivellieren, Empathielosigkeit zeigen, keine genuine oder angemessene Auseinandersetzung mit dem Genozid an den europäischen Juden bieten. Dem stehen die Beschaffenheit des Textes, die erklärte Absichten des Autors und v. a., hier besonders wichtig, die außerwissenschaftliche Rezeption entgegen, soweit sie anhand von Quellen untersucht werden konnte. - Vgl. Omer Bartov: Germany as Victim. In: New German Critique 80 (2000), S. 29-40; William Collins Donahue: Illusions of Subtlety: Bernhard Schlink's Der Vorleser and the Moral Limits of Holocaust Fiction. In: German Life and Letters 54 (2001), S. 60-81; William Collins Donahue: Revising '68: Bernhard Schlink's Der Vorleser, Peter Schneider's Vati, and the Question of History. In: Seminar. A Journal of Germanic Studies 40 (2004), S. 293-311; Manfred Durzak: Opfer und Täter im Nationalsozialismus. Bernhard Schlinks Der Vorleser und Stephan Hermelins Die Kommandeuse. In: Literatur für Leser 23 (2000), S. 203-213; Hans-Joachim Hahn: Empathielosigkeit als ,deutsches Schicksal' (Schlink). In: H.-J. H.: Repräsentationen des Holocaust. Zur westdeutschen Erinnerungskultur seit 1979. Heidelberg 2005, S. 215-240; Hans-Jörg Knobloch: Eine ungewöhnliche Variante in der Täter-Opfer-Literatur. Bernhard Schlinks Roman Der Vorleser. In: Gerhard Fischer/David Roberts (Hg.): Schreiben nach der Wende. Ein Jahrzehnt deutscher Literatur. 1989-1999. Tübingen 2001, S. 89-98; Klaus Köhler: Eine runde Geschichte - Bernhard Schlink tut der deutschen Seele gut. In: K. K.: Alles in Butter. Wie Walter Kempowski, Bernhard Schlink und Martin Walser den Zivilisationsbruch unter den Teppich kehren. Würzburg 2009, S. 251337; Jonathan J. Long: Bernhard Schlink's Der Vorleser and Binjamin Wilkomorski's Bruchstücke: Best-selling responses to the Holocaust. In: Arthur Williams/Stuart Parkes/Julian Preece (Hg.): German-Language Literature Today: International and Popular? Oxford u. a. 2000, S. 49-66; John E. MacKinnon: Crime, Compassion, and The Reader. In: Philosophy and Literature 27 (2003), S. 1-20; Tim Reiß: Selbstkritik als Immunisierungsstrategie in Bernhard Schlinks Der Vorleser. In: Evi Zemanek/Susanne Krones (Hg.): Literatur der Jahrtausendwende. Themen, Schreibverfahren und Buchmarkt um 2000. Bielefeld 2008, S. 179-189; Ernestine Schlant: Die Sprache des Schweigens. Die deutsche Literatur und der Holocaust. München 
Die Unzuverlässigkeit ist zunächst epistemischer Art. Sporadisch betont der Erzähler, sich nicht oder nur ungenau erinnern zu können (vgl. S. 12-14, 41, 84 und 125). Damit erweist er sich zwar nicht grundsätzlich als unzuverlässig, allerdings sind derartige Aussagen geeignet, das, an was er sich $\mathrm{zu}$ erinnern meint, unter Vorbehalt zu stellen und bewusst zu machen, dass dem Erzählen allgemein ein Akt des Erinnerns zugrunde liegt, mit all den Verzerrungen, die das bedeuten kann. Epistemische Unzuverlässigkeit äußert sich ferner darin, dass er Behauptungen aufstellt, bei denen man sich fragen kann, ob er das eigentlich genau wissen kann. Das ist zum Beispiel immer dann der Fall, wenn er stellvertretend für seine Generation spricht (vgl. z. B. S. 161 f.). Man mag skeptisch sein, ob er gerechtfertigt ist, das in dieser allgemeinen Form zu behaupten. Gleiches gilt, um ein weiteres Beispiel zu nennen, für eine Aussage wie: „Alle Literatur der Überlebenden berichtet von dieser Betäubung, unter der die Funktionen des Lebens reduziert, das Verhalten teilnahms- und rücksichtslos und Vergasung und Verbrennung alltäglich wurden.“ (S. 98) Es sind vielleicht Stellen dieser Art, die ein Rezensent im Sinn hatte, als er die „enervierende[] Selbstgewißheit“ des Erzählers konstatierte, und kritisierte, seine „Reflexionen“ seien „dürftig“ und „von erstaunlicher Selbstgerechtigkeit“. 205

Die Unzuverlässigkeit ist dann aber vor allem axiologischer Art. An einer Stelle bemerkt der Erzähler über sich selbst als Prozessbeobachter, er habe „Hannas Haft als natürlich und richtig empfunden“, und zwar nicht wegen der ihr zur Last gelegten Verbrechen, sondern „,weil sie in der Zelle raus aus meiner Welt, raus aus meinem Leben war“ (S. 93). Gegenüber seinen persönlichen Befindlichkeiten treten die Schwere der Verbrechen und die rechtsstaatlichen Grundsätze (hier die Frage, ob die Untersuchungshaft rechtmäßig ist) zurück, wenn es darum geht, was er für richtig hält. Ein anderes Beispiel ist ein längerer Erzählerkommentar anlässlich der oben bereits zitierten Frage von Hanna an den Vorsitzenden Richter und dessen Antwort:

Vielleicht hätte es genügt, wenn er dasselbe gesagt, dabei aber über Hanna oder auch sich selbst geredet hätte. Davon zu reden, was man muß und was man nicht darf und was einen was kostet, wurde dem Ernst von Hannas Frage nicht gerecht. Sie hatte wissen wollen, was sie in ihrer Situation hätte machen sollen, nicht daß es Sachen gibt, die man

2001, S. 259-268; Jan Süselbeck: Die Kraft der Tränen - Über die Melodramatisierung des ,Täterschicksals‘ in Bernhard Schlinks Roman Der Vorleser und Stephen Daldrys Verfilmung The Reader. In: Carsten Gansel/Markus Joch/Monika Wolting (Hg.): Zwischen Erinnerung und Fremdheit. Entwicklungen in der deutschen und polnischen Literatur nach 1989. Göttingen 2015, S. 195-207.

205 Bielefeld: Die Analphabetin. 
nicht macht. Die Antwort des Richters wirkte hilflos, kläglich. Alle empfanden es. Sie reagierten mit enttäuschtem Aufatmen und schauten verwundert auf Hanna, die den Wortwechsel gewissermaßen gewonnen hatte. (S. 107 f.)

Was dem Erzähler zu entgehen scheint, ist die unmittelbare Anwendbarkeit dessen, was der Richter gesagt hat, auf die Frage von Hanna. Jedenfalls dürfte es ein anerkannter juristischer und moralischer Grundsatz sein, dass man sich auf bestimmte Dinge nicht einlassen darf und gehalten ist, sich daran nicht zu beteiligen, sofern nicht Leib und Leben in Gefahr sind. Das ist die in diesem Zusammenhang entscheidende Frage, nicht Hannas konkrete Frage, wie sie denn bei den ,Selektionen“ anders hätte verfahren können, wenn neue Gefangene kommen und alte ihnen Platz machen müssen, weil das Lager überfüllt ist. Hannas Frage mag für sie selbst durchaus ,ernst' sein, entscheidend ist jedoch der letztlich freiwillige Entschluss, sich an den Verbrechen zu beteiligen. Überdies wird sie als Figur gezeigt, die moralisch nur bedingt zuverlässig ist. ${ }^{206}$ Dass dem Erzähler das entgeht, zeugt nicht gerade von seiner Zuverlässigkeit in diesen Dingen. Aufgrund solcher Textstellen geraten andere Urteile des Erzählten ins Zwielicht, darunter diejenigen, die auf die Auseinandersetzung mit den Verbrechen der NS-Diktatur bezogen sind. Dem Erzähler „moralischen Autismus“ vorzuwerfen, geht wohl zu weit; die Annahme jedoch, „[d]ass Schlink historische Ereignisse durch die Subjektivität eines Erzählers filtert, bis sie jede Verbindung mit dem tatsächlichen Geschehen verloren haben“, ist aufgrund dieser Befunde wohl in Teilen nicht von der Hand zu weisen. ${ }^{207}$

Die Unzuverlässigkeit wird textintern motiviert, zum einen durch das, was man über die psychischen Dispositionen des Protagonisten erfährt, zum anderen dadurch, dass der Erzähler immer wieder und häufig ungewollt zu verstehen gibt, wie tiefgreifend die kurze Beziehung zu Hanna sein weiteres Leben negativ beeinflusst hat. Von früher Kindheit an, so scheint es, ist dem Erzähler eine Disposition zu Schuldgefühlen eigen. Körperliche Schwäche (vgl. S. 5 f.) und Sexualität, sowohl des Jugendlichen als auch des Erwachsenen (vgl. S. 20

206 Vgl. etwa eine Aussage wie die folgende, mit der die alte Hanna kurz vor ihrem Selbstmord im Gespräch mit Michael auf den Prozess zurückblickt: „Und weißt du, wenn dich keiner versteht, dann kann auch keiner Rechenschaft von dir fordern. Aber die Toten können es. Sie verstehen. Dafür müssen sie gar nicht dabei gewesen sein, aber wenn sie es waren, verstehen sie besonders gut. Hier im Gefängnis waren sie viel bei mir. Sie kamen jede Nacht, ob ich sie haben wollte oder nicht. Vor dem Prozess habe ich sie, wenn sie kommen wollten, noch verscheuchen können.“ (S. 187) Man wird hier sicherlich davon sprechen können, dass sie sich ihrer Schuld bewusst ist und darunter leidet. Verstehen jedoch zur Voraussetzung für ein Urteil nach rechtsstaatlichen Grundsätzen zu machen, ist in dieser Form wohl unzulässig.

207 Adler: Die Kunst, Mitleid mit den Mördern zu erzwingen. 
und 28), sind schambesetzt. Man könnte darin ein Indiz für ein besonders waches Gewissen sehen, es scheint sich jedoch eher um eine frühkindliche Prägung zu handeln (vgl. die Kindheitserinnerung S. 28 f.).

Zumindest als Fünfzehnjähriger dürfte das erlebende Ich aus rein ontogenetischen Gründen nur bedingt zuverlässig gewesen sein im Erleben und Beurteilen der Beziehung zu einer erwachsenen Frau. Ein gutes Beispiel dafür ist die Unfähigkeit des erlebenden Ich, sich darüber klar zu werden, warum ihn die ältere Frau sexuell anzieht, als er sie ungewollt durch einen Türspalt beim Umkleiden beobachtet: „Ich war sicher, daß sie mir nicht aufgefallen wäre, wenn ich sie im Schwimmbad gesehen hätte. Sie hatte sich auch nicht nackter gezeigt, als ich Mädchen und Frauen im Schwimmbad schon gesehen hatte. Überdies war sie viel älter als die Mädchen, von denen ich träumte.“ (S. 17) Was ihm offenkundig entgeht, ist, dass die Wirkung wohl mit der Intimität der Szene zusammenhängt. Selbst „Jahre später“ geht ihm das nicht auf, ebenso wenig wie dem erzählenden Ich. Dessen Feststellung jedenfalls, es sei „die Einladung“ gewesen, „im Innern des Körpers die Welt zu vergessen“, die ihn angezogen habe (S.18), verunklart den Sachverhalt eher und erscheint als eine rückwirkende Projektion, die sich am ehesten aus psychischen Dispositionen oder der Lebenssituation des älteren Ich erklärt.

In dem, was der Erzähler sagt, deutet er verschiedentlich an, wie sehr die Beziehung zu einer deutlich älteren und dominant auftretenden Frau sein weiteres Leben beeinträchtigt, zumal in Fragen der Partnerschaft. Dazu ist etwas über die Natur der Beziehung zu sagen. Offensichtlich kann die Beziehung vor Dritten nicht gelebt werden, wie nicht zuletzt eine Episode in der Straßenbahn zeigt. Der sich daran entzündende Konflikt offenbart Michaels emotionale Abhängigkeit, ja Hörigkeit, sowie die damit verbundenen Machtspiele und Hannas Forderung nach Unterordnung (vgl. S. 45-50, v. a. S. 50). Gewalttätigkeit und Sexualität liegen eng beieinander (vgl. S. 54 f.). Die Beziehung ist also in vielerlei Hinsicht problematisch und asymmetrisch und kann nicht von Dauer sein. So kurz die Beziehung ist, so gravierend und langanhaltend sind jedoch ihre Folgen.

Den Verlust Hannas durch ihr plötzliches Verschwinden kann er nur schwer verkraften, in der Folge nimmt er ein Verhalten an, das sich durch vermeintliche Leichtigkeit auszeichnet, allerdings eher eine Panzerung ob der erfahrenen Verletzungen ist; zudem legt er ein „großspuriges, überlegenes Gehabe“ an den Tag (S. 84, vgl. dazu S. 83-85). Die Erfahrung der Beziehung und des Verlassenwerdens prägt sein Verhalten zu Partnerinnen. Er sagt explizit: „Mich nach Hanna nie mehr demütigen lassen und demütigen, nie mehr schuldig machen und schuldig fühlen, niemanden mehr so lieben, daß ihn verlieren weh tut - ich 
habe das damals nicht in Deutlichkeit gedacht, aber mit Entschiedenheit gefühlt." (S. 84) Gezeigt wird das insbesondere an der Beziehung zu zwei Figuren, der altersgerechten Jugendliebe Sophie (vgl. v. a. S. 84 f.) und Gertrud, der Ehefrau im Erwachsenenalter, von der er sich zum Leidwesen der gemeinsamen Tochter scheiden lässt (vgl. S. 164-166, v. a. S. 165 f.). Es kommen verschiedene Details hinzu. So wird gleich zu Beginn erwähnt, dass das Haus, in welchem Hanna wohnt, den Protagonisten sein Leben lang in Träumen begleitet (vgl. S. 9-11).

Kurz vor Ende der Romanhandlung bleibt es der nur als „die Tochter“ bezeichneten Überlebenden vorbehalten, die Beziehung eindeutig zu bewerten. ${ }^{208}$ Michael trifft die mittlerweile in den USA lebende Frau, um ihr die Ersparnisse Hannas zu übergeben, die sie ihr testamentarisch vermacht hatte. Sie nennt den von Hanna ausgehenden Geschlechtsverkehr „brutal“, meint, Michael habe die Erfahrung nicht „verkraftet“ und kann allein aus der Information, dass er später geheiratet hat, eine Prognose ableiten: „Und die Ehe war kurz und unglücklich, und Sie haben nicht wieder geheiratet, und das Kind, wenn's eines gibt, ist im Internat.“ (S. 202) In allen diesen Fällen liegt die Figur, die einzige im Roman, die als epistemisch und axiologisch zweifelsfrei zuverlässig erscheint, völlig richtig, wie der Gang der Handlung zeigt. Bezeichnenderweise leugnet Michael alles ab: „Das trifft auf Tausende zu; dazu braucht es keine Frau Schmitz.“ (ebd.) Bevor er das Thema wechselt, hat aber wiederum die jüdische Frau das Wort. Sie stellt die entscheidende Frage: „Hatten Sie, wenn Sie in den letzten Jahren mit ihr Kontakt hatten, jemals das Gefühl, daß sie wußte, was sie Ihnen angetan hat?“ (ebd.)

Mithin ist der Erzähler eine zu Schuldgefühlen neigende Figur, deren Sicht auf die NS-Verbrechen untrennbar verquickt ist mit einer überfordernden Beziehung zu einer dominanten Frau, die sein Leben nachhaltig und negativ prägt. Die Konsequenz aus alledem ist von erheblicher Tragweite. Das Meiste, was der Erzähler sagt, wenn er sich zu den NS-Verbrechen äußert, steht textintern unter dem massiven Vorbehalt, dass der Urheber der Äußerungen epistemisch und axiologisch unzuverlässig ist. Dafür wird, gegen die Absicht des Erzählers, eine textinterne Motivierung angeboten. Es ist $\mathrm{zu}$ betonen, dass es keines Wissens über den Begriff oder die Sache des unzuverlässigen Erzählens bedarf, um in außerwissenschaftlichen Zusammenhängen zu erkennen, dass man dem Erzähler nicht ohne Weiteres glauben darf. Dafür genügt basales le-

208 Vgl. für eine kritische Sicht auf die Darstellung der Tochter im Roman Jane Alison: The Third Victim in Bernhard Schlink's Der Vorleser. In: The Germanic Review. Literature, Culture, Theory 81 (2006), S. 163-178. 
bensweltliches Wissen über die menschliche Psyche und menschliches Verhalten. ${ }^{209}$ Er kann bis zum Schluss keine angemessene Haltung zu Hanna als der ehemaligen Geliebten finden. Er weiß nicht, welche Rolle Hannas Analphabetismus spielte bei ihrer Entscheidung, zur SS zu gehen. ${ }^{210}$ Er verbindet unweigerlich alles, was die Auseinandersetzung der Nachgeborenen mit den NSVerbrechen betrifft, mit seiner jugendlichen Liebe zu einer Verbrecherin. Von einer solchen Erzählerfigur sind aufgrund der Anlage des Textes keine tiefgreifenden Aufschlüsse in dieser Sache zu erwarten. Jedenfalls muss alles, was er sagt, genau geprüft werden. In allen diesen Fällen liefert der Text häufig kein Modell für eine Applikation, das sich eins zu eins übernehmen ließe; er zeigt dann vielmehr negativ, wie eine Applikation nicht beschaffen sein sollte, und gibt Anlass zur Frage, wie eine bessere Alternative aussehen könnte.

Es gibt aber eine Form der Applikation, die von dieser Relativierung dessen, was der Erzähler sagt und denkt, nicht berührt wird, und zwar das Dilemma, dass ein geliebter Mensch an den NS-Verbrechen beteiligt war. ${ }^{211}$ Hier zeigt sich

$209 \mathrm{Vgl}$. als Beispiele für psychoanalytische und traumatheoretische Interpretationen, die unabhängig sind von dem, worum es hier geht, Claudia Benthien: Täterschaft, Gewalterfahrung und Demaskulinisierung in biografischen Ich-Erzählungen zu Holocaust und Nationalsozialismus (Bernhard Schlink, Thomas Lehr, Uwe Timm). In: Uta Fenske/Gregor Schuhen (Hg.): Geschichte(n) von Macht und Ohnmacht. Narrative von Männlichkeit und Gewalt. Bielefeld 2016, S. 291-311; Dieter Kampmeyer: Trauma-Konfigurationen. Bernhard Schlinks Der Vorleser, W. G. Sebalds Austerlitz, Herta Müllers Atemschaukel. Würzburg 2004, S. 31-82; Alison Lewis, Das Phantasma des Masochisten und die Liebe zu Hanna. Schuldige Liebe und intergenerationelle Schuld in Bernhard Schlinks Der Vorleser. In: Weimarer Beiträge 52 (2006), S. 554-573; Ursula R. Mahlendorf: Trauma Narrated, Read and (Mis)understood: Bernhard Schlink's The Reader: „... irrevocably complicit in their crimes ...“. In: Monatshefte für deutschsprachige Literatur und Kultur 95 (2003), S. 458-481; Heidi M. Schlipphacke: Enlightenment, Reading, and the Female Body: Bernhard Schlink's Der Vorleser. In: Gegenwartsliteratur. Ein germanistisches Jahrbuch 1 (2002), S. 310-328; Helmut Schmitz: Malen nach Zahlen? Bernhard Schlinks Der Vorleser und die Unfähigkeit zu trauern. In: German Life and Letters 55 (2002), S. 296-311; Achim Würker: Mutterimago und Ambivalenz. Bernhard Schlink: Der Vorleser. In: Eva Jaeggi/Hilde Kronberg-Gödde (Hg.): Zwischen den Zeilen. Literarische Werke psychologisch betrachtet. Gießen 2004, S. 251-263.

210 Dass Hanna dem Erzähler letztlich unverständlich bleibe, betont z. B. Erin McGlothlin: Theorizing the Perpetrator in Bernhard Schlink's The Reader and Martin Amis's Time's Arrow. In: R. Clifton Spargo/Robert M. Ehrenreich (Hg.): After Representation? The Holocaust, Literature, and Culture. New Brunswick u. a. 2010, S. 210-230.

211 Vgl. für einen Forschungsbeitrag, in dem angenommen wird, dass dieses Dilemma für den Roman zentral sei und für seine Wirkung mitverantwortlich, Jeremiah P. Conway: Compassion and Moral Condemnation: An Analysis of The Reader. In: Philosophy and Literature 23 (1999), S. 284-301. 
das umfassende, gegenüber allen anderen denkbaren Applikationen dominierende Applikationspotenzial des Gesamttextes. Der Roman vermittelt einen Eindruck davon, wie es ist, wenn man als Angehöriger der zweiten Generation feststellt, dass eine geliebte Person sich solche Verbrechen hat zuschulden kommen lassen. Über die Bewertung der Verbrechen besteht keine Unklarheit. Den Menschen will man aufgrund seiner Taten verurteilen. Die emotionale Beziehung zu ihm macht das jedoch schwer, wenn nicht unmöglich, und zwar nicht aus sachlichen oder ethischen Gründen, sondern allein aufgrund der Gefühle, die man für diesen Menschen hegt und die Anlass sind für Schuldgefühle. Die Applikation, welche der Roman anbietet, besteht nun darin, dass man als Rezipient annimmt, dass es reale Menschen gibt oder gab, die sich in einem solchen Dilemma befinden, und Einsicht in dieses Dilemma erhält. Das ist eine kognitive Applikation. Sie ist vielleicht mit einer emotionalen Applikation verbunden, dann nämlich, wenn man zu der Einschätzung kommt, dass diese Menschen ob des Dilemmas Verständnis und Mitgefühl verdienen - sie, nicht die Täter. Jedenfalls dürfte sie Anlass zu einer ethischen Applikation sein können: Sind solche Schuldgefühle richtig? Der Verquickung von Liebesgeschichte und NS-Verbrechen, die auf den ersten Blick schwer verständlich wirkt, ja den Text als misslungen erscheinen lassen mag, kann eine klare Funktion zugeordnet werden. Es ist eine Technik der Verfremdung. Das Dilemma wird nicht an einem vermeintlichen ,Standardfall' gezeigt (etwa: Student/-in im Umfeld der 68er und durch seine Vergangenheit im NS belasteter Vater), sondern an einem außergewöhnlichen Fall, der eine unverstellte und eindrückliche Sicht darauf bewirken soll.

Im Text kommt das Dilemma an verschiedenen Stellen explizit zur Sprache. In dieser Sache ist der Erzähler nicht als unzuverlässig einzuschätzen. Der Erzähler sagt explizit, er sei „schuldig“, weil er „eine Verbrecherin geliebt hatte“ (S. 129). Seine Liebe zu ihr macht es ihm unmöglich, sie oder andere ihrer Generation zu verurteilen (vgl. S. 162). Er will ihre Verbrechen zugleich verstehen und verurteilen, kann dies allerdings nicht (vgl. S. 151 f.). An seiner Aufrichtigkeit besteht, wie gesehen, durch die am Schluss des Romans transparent gemachte Relativierung kein Zweifel. Das Dilemma ist weder epistemisch noch axiologisch, sondern letztlich emotional. Es geht um Gefühle, die nicht empirisch korrekt oder moralisch richtig sein müssen, um ihre Wirkung zu entfalten. Man mag mit Befremden registrieren, dass der Erzähler, dessen Vater selbst im NS seine Stelle als Professor verlor (weil er eine Vorlesung über Spinoza angekündigt hatte), solche Schuldgefühle hat, bei denen ja ausdrücklich nicht die Zugehörigkeit zur deutschen Nation den Ausschlag gibt, sondern eine problematische Liebesbeziehung. Aber genau das ist die Pointe: Entscheidend ist 
nicht die Berechtigung der Schuldgefühle und überhaupt die moralische Beurteilung, sondern deren bloße Existenz. Das zentrale Applikationspotenzial des gesamten Romans besteht mithin darin, dieses emotionale Dilemma einsichtig $\mathrm{zu}$ machen. Wie gesehen, kommen manchen Rezensionen bei LovelyBooks dieser Applikationsmöglichkeit zumindest nahe. Auch manche Aussagen des Autors können in diese Richtung verstanden werden.

Bernhard Schlinks Der Vorleser ist ein Roman, der sich aufgrund seiner Beschaffenheit besonders gut für Applikationen zu eignen scheint. Betrachtet man die elementare stoffliche Konstellation - ungleiches Liebespaar, ein Partner ist an den NS-Verbrechen gegen die Menschlichkeit beteiligt, der andere befindet sich deswegen in einem Dilemma -, dann ist das erwartbar. Es kommen jedoch, neben den zeitgeschichtlichen Gegebenheiten seit der Wiedervereinigung, Faktoren hinzu, die sich aus der Beschaffenheit des Textes ergeben. Der Erzähler ist reflexionsfreudig, aber unzuverlässig. Aufgrund der Erzählsituation kann gar nicht erst der Anschein entstehen, es spreche jemand mit Autorität und Expertise. Das führt zu einer gewissen Offenheit des Textes, die, vom Autor programmatisch so gewollt, zu Missverständnissen Anlass geben kann, vor allem aber, so legen es die Rezensionen bei LovelyBooks nahe, positiv gewertet wird und zu einer reflexiven, auf selbständiger gedanklicher Durchdringung beruhenden Rezeption des Romans führt. In diesen Rezensionen finden sich jedenfalls zahlreiche Indizien für Applikationen und für die Zuschreibung entsprechender Potenziale, außerdem lassen sich Hinweise finden auf damit verbundene Tätigkeiten und Prozesse sowie Aussagen zu den Voraussetzungen und Konsequenzen einer Applikation.

\subsection{Daniel Kehlmann: Die Vermessung der Welt (2005)}

Daniel Kehlmanns Die Vermessung der Welt erschien 2005. Der Roman wurde rasch zum Publikumserfolg, Angaben zu den Verkaufszahlen schwanken zwischen 850.000 und 1,4 Millionen. ${ }^{212}$ Er wurde in über 40 Sprachen übersetzt. ${ }^{213}$ Eine Verfilmung kam 2012 in die Kinos (Regie: Detlev Buck). Die Forschung hat die Rezeption verschiedentlich beschrieben und Erklärungen für den Erfolg zu geben versucht. ${ }^{214}$ Applikationen kamen nicht in den Blick. Allerdings gibt es

212 Vgl. Bodemer: Bestsellermarketing, S. 313.

213 Vgl. Bodemer: Bestsellermarketing, S. 371.

214 Vgl. v. a. Bodemer: Bestsellermarketing, S. 311-387, und Wilhelm Haefs: „Deutschlands literarischer Superstar“? Daniel Kehlmann und sein Erfolgsroman Die Vermessung der Welt im literarischen Feld. In: Markus Joch u. a. (Hg.): Mediale Erregungen? Autonomie und Aufmerk- 
vereinzelt Forschungsbeiträge, die sich so auffassen lassen, dass in ihnen der Sache nach Applikationen vorgenommen werden. In einem Forschungsbeitrag wird beobachtet, dass Kehlmann vermittels bestimmter Darstellungstechniken einen Bezug zur Gegenwart herstelle. Er habe „durch Selektion und Stilisierung des gegebenen Materials die historische Signifikanz und damit zugleich die Aktualität von Humboldt und Gauß [verschärft]“. ${ }^{215}$ Außerdem wird dem Roman das Potenzial zugeschrieben, Erfahrungen zu ermöglichen, die Einsichten in die conditio humana eröffnen und handlungspraktische Konsequenzen haben können: „Auch für den Leser wird erfahrbar: Der Mensch ist so wunderbar, daß er sogar darüber lachen kann, ein armer Kerl zu sein. Und so könnte ihn die Erfahrung seiner Begrenztheit zu einem maßvollen Gebrauch seiner Freiheit führen. Das ist eine Chance, kein Fahrplan. “216 Ebenfalls ein Beispiel für eine Applikation dürfte ein Forschungsbeitrag sein, der in dem Roman die Grenzen der Möglichkeit dargestellt sieht, die Welt wissenschaftlich $\mathrm{zu}$ erfassen, wie Humboldt und Gauß dies versuchen. ${ }^{217}$

Bei diesem Roman sollen ebenfalls in einem ersten Schritt die Ergebnisse einer Auswertung der Rezensionen bei LovelyBooks vorgestellt (Kap. 5.4.1), in einem zweiten Schritt dann die professionelle außerwissenschaftliche Rezeption sowie Selbstaussagen des Autors betrachtet werden (Kap. 5.4.2). In einem dritten Schritt wird die Beschaffenheit des Textes untersucht und gefragt, wie sie sich zu den festgestellten Applikationen verhält (Kap. 5.4.3.).

samkeit im Literatur- und Kulturbetrieb der Gegenwart. Tübingen 2009, S. 233-251; daneben Heinz-Peter Preußer: Zur Typologie der Zivilisationskritik. Was aus Daniel Kehlmanns Roman Die Vermessung der Welt einen Bestseller werden ließ. Text + Kritik. Heft 177: Daniel Kehlmann (2008), S. 73-85, hier S. 73 f.; Julia Stein: „Germans and humor in the same book“. Die internationale Rezeption der Vermessung der Welt. In: Gunther Nickel (Hg.): Daniel Kehlmanns Die Vermessung der Welt. Materialien, Dokumente, Interpretationen. Reinbek b. H. 2008, S. 136150; Wieblitz: Geniale Bestseller, S. 89-129; Klaus Zeyringer: Vermessen. Zur deutschsprachigen Rezeption der Vermessung der Welt. In: Nickel: Daniel Kehlmanns Die Vermessung der Welt, S. 78-94.

215 Gerhard Kaiser: Erzählen im Zeitalter der Naturwissenschaften. Zu Daniel Kehlmanns Roman Die Vermessung der Welt. In: Sinn und Form 62 (2010), S. 122-134, hier S. 123.

216 Kaiser: Erzählen im Zeitalter der Naturwissenschaften, S. 133.

217 Vgl. Leonhard Herrmann: Literarische Vernunftkritik. Formen, Funktionen und Paradoxien eines Konzepts literarischer Eigenwertigkeit. In: Andrea Bartl/Marta Famula (Hg.): Vom Eigenwert der Literatur. Reflexionen zu Funktion und Relevanz literarischer Texte. Würzburg 2017, S. 147-165. 


\subsubsection{Applikationen bei LovelyBooks}

$\mathrm{Zu}$ Die Vermessung der Welt gibt es bei LovelyBooks bisher 214 Rezensionen und rund 3.400 Bewertungen. Der Durchschnitt liegt bei 3,8 von 5 Sternen. ${ }^{218}$ In 21 Besprechungen, und damit in jeder zehnten, lassen sich Indizien für Applikationen ausmachen. Die neusten Texte stammen von 2020, die ältesten von 2006 und 2007. Wie bei Süskind und Schlink wird der Roman also kontinuierlich besprochen und bewertet. Erneut dürften die Verwendung als Schullektüre und die Verfilmung in Rechnung zu stellen sein.

Vereinzelt lassen sich, wie bei Süskind und Schlink, in den Rezensionen Aussagen ausmachen, die als allgemeine Indizien für Applikationen angesehen werden können. So wurde etwa festgestellt: „Kehlmanns Worte regen zum Nachdenken an“. ${ }^{219}$ Eine andere Nutzerin lobte „die vielen Lebensweisheiten, die dem Leser auf seinem Weg durch das Buch begegnen“. ${ }^{220}$ In einer dritten Rezension wurden lehrreiche anthropologische Einsichten gegenüber vermeintlichem Faktenwissen über historische Persönlichkeiten hervorgehoben: „Ich weiß nicht, wie viel ich über die historischen Personen gelernt habe - aber mir wurde einiges über Menschen (Genies und andere) bewusst und ich habe viel gelernt. “221 Einen Schwerpunkt scheinen solche Applikationen zu bilden, die auf Wissenschaft und Erkenntnisgewinn oder auf die Person des Wissenschaftlers abheben. Jedenfalls enthält die Gruppe von Aussagen, die auf Applikationen hindeuten, mehrere zu diesen Themen. Die restlichen Applikationen weisen thematisch eine breitere Streuung auf.

Der Roman sei, so eine Rezension, eine „Hommage an zwei große Wissenschaftler“, und zeige an ihnen, dass man auf sehr unterschiedliche Weise zu wissenschaftlichen Erkenntnissen gelangen könne. ${ }^{222}$ Er vermittle „eine Vorstel-

218 Vgl. https://www.lovelybooks.de/autor/Daniel-Kehlmann/Die-Vermessung-der-Welt41788273-w/ (01.07.2020).

219 PrinzessinMurks: [Rezension von Kehlmann: Die Vermessung der Welt]. 2013. https:// www.lovelybooks.de/autor/Daniel-Kehlmann/Die-Vermessung-der-Welt-41788273-w/ rezension/1018840014/ (01.07.2020).

220 LaLecture: [Rezension von Kehlmann: Die Vermessung der Welt]. 2013. https://www. lovelybooks.de/autor/Daniel-Kehlmann/Die-Vermessung-der-Welt-41788273-w/rezension/ 1016699534/ (01.07.2020).

221 Luther: [Rezension von Kehlmann: Die Vermessung der Welt]. 2007. https://www. lovelybooks.de/autor/Daniel-Kehlmann/Die-Vermessung-der-Welt-41788273-w/rezension/ 986325956/ (01.07.2020).

222 Leselust: Wissenschaft in schöner Sprache. 2016. https://www.lovelybooks.de/autor/ Daniel-Kehlmann/Die-Vermessung-der-Welt-41788273-w/rezension/1238310656/ (01.07.2020). 
lung [...], wie man damals Wissenschaft betrieben hat““.223 Nach der Lektüre sehe man „so ein Bergwerk mit ganz anderen Augen. So kann Wissenschaft für alle gut vermittelt werden!“224 In allen drei Beispielen wurde das Buch mithin so verstanden, dass es zeigt, wie Wissenschaft tatsächlich ist oder war, und solche Tatsachen in angemessener Weise darstellt. Derartigen Annahmen liegt ein Akt der Applikation zugrunde. Details, die in einem fiktionalen Roman geschildert werden, müssen als lebensweltlich zutreffend angesehen werden. Im Einzelfall gab es Applikationen bezüglich der eigenen Person. Eine sich selbst als „wissenschaftlich interessierter Mensch“ bezeichnende Nutzerin meinte, sich in der Darstellung des wissenschaftlichen Arbeitens „,wiederfinden“ zu können. ${ }^{225}$ Eine andere empfahl das Buch all denjenigen, die Umgang mit Wissenschaftlern haben, denn „viele Wissenschaftler sind wirklich so, wie in diesem Buch beschrieben“. 226 Sie hat das im Buch Geschilderte also mit ihrer Erfahrung verglichen und ist zu dem Ergebnis gekommen, dass manche Menschen tatsächlich so sind wie die Figuren in diesem Roman. Mitunter wurde der Roman so gelesen, dass er die Problematik einer Wissenschaftlerexistenz verdeutliche. Humboldt und Gauß ,wirken wegen ihres Willens zur unbedingten Forschung und ihrer jeweiligen Einsamkeit tragisch““.227 Etwas direkter formuliert: „Der Versuch zweier Männer, Ruhm und Wissenschaft zu vereinen und dabei noch irgendwie ihr Leben auf die Reihe zu bekommen.“228

Die Applikationen weisen eine gewisse thematische Breite auf. Noch am ehesten mit den auf Wissenschaft bezogenen Applikationen sind solche ver-

223 Kleinstadtkatze: [Rezension von Kehlmann: Die Vermessung der Welt]. 2012. https:// www.lovelybooks.de/autor/Daniel-Kehlmann/Die-Vermessung-der-Welt-41788273-w/ rezension/969540407/ (01.07.2020).

224 HeikeG: [Rezension von Kehlmann: Die Vermessung der Welt]. 2007. https://www. lovelybooks.de/autor/Daniel-Kehlmann/Die-Vermessung-der-Welt-41788273-w/rezension/ 986367926/ (01.07.2020).

225 Leselea: Von zwei, die auszogen, die Welt zu vermessen. 2015. https://www. lovelybooks.de/autor/Daniel-Kehlmann/Die-Vermessung-der-Welt-41788273-w/rezension/ 1165967842/ (01.07.2020).

226 Sabisteb: [Rezension von Kehlmann: Die Vermessung der Welt]. 2011. https://www. lovelybooks.de/autor/Daniel-Kehlmann/Die-Vermessung-der-Welt-41788273-w/rezension/ 966369406/ (01.07.2020).

227 GreenTea: [Rezension von Kehlmann: Die Vermessung der Welt]. 2012. https://www. lovelybooks.de/autor/Daniel-Kehlmann/Die-Vermessung-der-Welt-41788273-w/rezension/ 1000499331/ (01.07.2020).

228 Ein LovelyBooks-Nutzer: [Rezension von Kehlmann: Die Vermessung der Welt]. 2013. https://www.lovelybooks.de/autor/Daniel-Kehlmann/Die-Vermessung-der-Welt-41788273-w/ rezension/1015007714/ (01.07.2020). 
bunden, die in den beiden Protagonisten Figuren eines bestimmten Typs sehen, nämlich des herausragend begabten Menschen mit Fehlern. Es werde gezeigt, dass „[s]elbst die genialsten, am meisten bewunderten Männer [...] ihre persönlichen Krisen und charakterlichen Schwächen“ hätten. ${ }^{229}$ Im Einzelfall wurde dem Roman die Eignung zugeschrieben, Faktenwissen über Geschichte zu vermitteln und einen guten Einblick in die historischen Verhältnisse, zumal das Leben der Akteure, zu geben; ein Potenzial, zu dessen Realisierung es der Applikation bedarf. Der Roman sei „sehr interessant wegen der vielen Fakten, die ich persönlich nicht kannte“, schrieb eine Nutzerin. ${ }^{230}$ Das Buch, so eine andere Rezension, „zeigt die Personen so, wie sie sind“. Damit werde „Geschichte [...] real, nachvollziehbar und vor allem menschlich“. ${ }^{231}$ In ähnlicher Weise wurde gelobt, dass der Roman „einem die Zeit der großen Dichter und Denker näherbringt und den eigentlich leeren Namen deutscher Genies aus dem Geschichtsunterricht wie Humboldt, Gauß, Kant, Goethe ... Leben einhaucht und sie sehr sehr menschlich macht“. ${ }^{232}$ Im Einzelfall wurde dem Roman eine kritische Botschaft zugewiesen. Er biete „Wissenschaftskritik“, „Entzauberung deutscher Intelligenz und Gesellschaftskritik“.233 Außerdem konnte der Roman als Satire auf Rationalität und das Deutschsein verstanden werden. ${ }^{234}$

229 LaLecture: [Rezension von Kehlmann: Die Vermessung der Welt]. Vgl. dazu Kleinstadtkatze: [Rezension von Kehlmann: Die Vermessung der Welt]; Estel90: [Rezension von Kehlmann: Die Vermessung der Welt]. 2012. https://www.lovelybooks.de/autor/Daniel-Kehlmann/DieVermessung-der-Welt-41788273-w/rezension/950606080/ (01.07.2020); Cvcoconut: Genies unter sich. 2013. https://www.lovelybooks.de/autor/Daniel-Kehlmann/Die-Vermessung-derWelt-41788273-w/rezension/1036447807/ (01.07.2020).

230 LeonoraVonToffiefee: Eine ungewöhnliche Weltreise. 2014. https://www.lovelybooks.de/ autor/Daniel-Kehlmann/Die-Vermessung-der-Welt-41788273-w/rezension/1106485384/ (01.07.2020).

231 Ein LovelyBooks-Nutzer: [Rezension von Kehlmann: Die Vermessung der Welt]. 2010. https://www.lovelybooks.de/autor/Daniel-Kehlmann/Die-Vermessung-der-Welt-41788273-w/ rezension/969836097/ (01.07.2020).

232 Awogfli: [Rezension von Kehlmann: Die Vermessung der Welt]. 2012. https://www. lovelybooks.de/autor/Daniel-Kehlmann/Die-Vermessung-der-Welt-41788273-w/rezension/ 950325042/ (01.07.2020).

233 Golondrina: [Rezension von Kehlmann: Die Vermessung der Welt]. 2011. https://www. lovelybooks.de/autor/Daniel-Kehlmann/Die-Vermessung-der-Welt-41788273-w/rezension/ 964379169/ (01.07.2020). Vgl. dazu Ein LovelyBooks-Nutzer: [Rezension von Kehlmann: Die Vermessung der Welt]. 2010. https://www.lovelybooks.de/autor/Daniel-Kehlmann/DieVermessung-der-Welt-41788273-w/rezension/967401638/ (01.07.2020).

234 Das ist zumindest in einer Rezension der Fall, in welcher bemerkt wird: „Auch das ,Deutschtum“ wird an vielen Stellen aufs Korn genommen, ebenso die Abstraktheit des Verstandes.“ - DriftinHeart: [Rezension von Kehlmann: Die Vermessung der Welt]. 2011. https:// 
Dass die Zahl der Applikationen sich auf einem ähnlichen Niveau bewegt wie bei Süskind, führt erneut zu der Frage, was denn außerdem den Umgang mit dem Roman bestimmt, soweit er sich aus den Angaben in Rezensionen rekonstruieren lässt. Dazu sollen zumindest exemplarische Angaben gemacht werden. Bereits eine oberflächliche Sichtung zeigt, dass Unterhaltung und Spannung häufig genannt werden, ferner eine komische Wirkung oder Immersion. Sympathie oder Antipathie für die Figuren erweisen sich als bedeutsam. Der Stil wird gleichfalls erwähnt. Es geht also um ästhetische Erfahrung in einem weiten Sinne und um bestimmte Wirkungen. Die Urteile gehen bisweilen auseinander. Eine Nutzerin vermisste die Möglichkeit zur Immersion und kritisierte einen Mangel an Unterhaltung: „Ich war insgesamt etwas enttäuscht, wie oberflächlich für meine Vorstellung die Charaktere und die Geschichte an sich beschrieben sind. Ich hatte nie den Eindruck, voll in die Geschichte abtauchen zu können. Alles in allem konnte mich die Geschichte nicht wirklich mitreißen, weder die Charaktere noch die Handlung an sich.“"235 In einer anderen Rezension dagegen wurde der Roman als „unheimlich spannend“ wahrgenommen, Komik und Rührungspotenzial ausgemacht: „Das Buch ist sowohl zum Lachen als auch zum Weinen. Oder halt Weinen vor Lachen.“'236 Von Einzelfällen abgesehen, scheint es keine Unsicherheit zu geben mit Blick auf die Fiktivität des im Roman Geschilderten. Dass ein fiktionaler Text vorliegt, der nicht oder jedenfalls nicht in erster Linie Tatsachen berichtet, scheint den meisten Nutzer/innen klar zu sein. Aufschlussreich ist in diesem Zusammenhang eine Rezension, in welcher die Nutzerin in der fehlenden Faktentreue ein ästhetisches Defizit sah und erklärte, sich auf den Roman in der vorliegenden Form keinen Reim machen zu können:

Und da komme ich zu der Frage, was mir Kehlmann mit diesem Buch denn nun sagen will, denn um die rein biographischen Komponenten scheint es ihm nicht zu gehen - und dafür kann man wirklich die Biographien beider zu Rate ziehen. Ich kann es nicht wirklich sagen. Und ja, mir ist klar, dass Kehlmann eine Fiktion, einen Roman geschrieben hat kein wissenschaftliches Werk, das nach Exaktheit ruft. Dennoch wünschte ich mir diese

www.lovelybooks.de/autor/Daniel-Kehlmann/Die-Vermessung-der-Welt-41788273-w/ rezension/965874091/ (01.07.2020).

235 Primrose24: Geschichte zweier Genies. 2018. https://www.lovelybooks.de/autor/DanielKehlmann/Die-Vermessung-der-Welt-41788273-w/ (01.07.2020).

236 Booksaredifferentworlds: Sehr schönes Buch. 2018. https://www.lovelybooks.de/autor/ Daniel-Kehlmann/Die-Vermessung-der-Welt-41788273-w/ (01.07.2020). 
Genauigkeit, denn dadurch hätte das Buch etwas Großes werden können. So ist es nur ein Schatten seiner selbst und eine Karikatur auf die Wissenschaft des 19. Jahrhunderts. ${ }^{237}$

Der Roman ist von den dreien, die in diesem Kapitel behandelt werden, der komplexeste. Das hat, wie sich zeigen wird, Konsequenzen für sein Applikationspotenzial.

\subsubsection{Professionelle Rezeption, Autor und Gegebenheiten}

Der Roman wurde, wenig überraschend, von der Literaturkritik vielfach wahrgenommen. ${ }^{238}$ Es wurden verschiedene Aspekte erwähnt. Das gilt gleichermaßen für Selbstaussagen des Autors in Interviews und poetologischen Texten.

Manche Rezensenten sahen in dem Roman eine Kritik geistesgeschichtlich beschreibbarer Positionen oder eine Darstellung mentalitätsgeschichtlicher Entwicklungen. Der Roman übe „Kulturkritik“, „Kritik an einem klassischen Idealismus/Humanismus“ und „Humanismuskritik“. ${ }^{239}$ Es ist von der ,Dialektik der Aufklärung` die Rede und davon, dass der Text dazu Fragen aufwerfe oder eine bestimmte Sicht darauf vermittle. ${ }^{240}$ Aufgrund mancher Textstellen, die als Anspielung auf den NS und seine Ideologie zu verstehen sind, wurde beobachtet, dass der Autor „ein subtiles mentalitätsgeschichtliches Mosaik in seinen

237 Orisha: Gauß und Humboldt im wissenschaftlichen Wettbewerb. 2017. https://www. lovelybooks.de/autor/Daniel-Kehlmann/Die-Vermessung-der-Welt-41788273-w/ (01.07.2020).

238 Vgl. als Beispiele für Artikel, die den Erfolg des Romans thematisieren und zu erklären versuchen, Tilmann Krause: Kein Rätsel Kehlmann. In: Die Welt. Nr. 9, 4. März 2006, Die literarische Welt, S. 2; Felicitas von Lovenberg: Vermessung eines Erfolgs. In: Frankfurter Allgemeine Zeitung. Nr. 22, 26. Januar 2006, S. 39.

239 Helmut Gollner: Auf Besuch beim deutschen Geist. Zu Daniel Kehlmanns neuem Roman Die Vermessung der Welt. In: Literatur und Kritik. Jg. 40, H. 397/398 (2005), S. 79-81, hier S. 79 und 80 .

240 So heißt es, der Roman zeige, dass Aufklärung ihren „Preis“ habe - Martin Lüdke: Doppelleben, einmal anders. Der neue Roman von Daniel Kehlmann über Carl Friedrich Gauß und Alexander von Humboldt vermisst die Welt und ist ein Geniestreich. In: Süddeutsche Zeitung. Nr. 226, 28. September 2005, S. 15. Der Roman werfe unter anderem die Frage auf: „Wo eigentlich liegt der Punkt, an dem das hehre Projekt der Aufklärung in die Entzauberung der Welt umkippte und ihre Bewohner ins Joch von Fortschritt und instrumenteller Vernunft gezwungen wurden?“ - Hubert Spiegel: Der Schrecken der Welt läßt sich messen, aber nicht bannen. In: Frankfurter Allgemeine Zeitung. Nr. 246, 22. Oktober 2005, S. 52. In einer weiteren Rezension wird festgestellt: „Die Dialektik der Aufklärung - und der Autor illustriert mit seinem Buch eines ihrer interessantesten Kapitel - wird entpathetisiert.“ - Marius Meller: Die Krawatte im Geiste. In: Merkur. Jg. 61, H. 7 (2007), S. 248-252, hier S. 250. 
Text [gelegt hat], das auf die Ingredienzien des späteren faschistischen Höllencocktails verweist, ohne in eine zweifelhafte Zwangsläufigkeit der geschichtlichen Entwicklung einzurasten und die gängige anachronistische Vergangenheitsbewältigung zu betreiben“. ${ }^{241}$ In beiden Fällen kann man davon sprechen, dass damit Applikationspotenziale identifiziert werden, obwohl dies wohl nicht die Absicht der Rezensenten war. Wenn der Text geeignet ist, eine kritische Sicht auf Positionen der deutschen Geistesgeschichte $\mathrm{zu}$ vermitteln oder auf mentalitätsgeschichtliche Kontinuitäten aufmerksam zu machen, dann kann er zu einer ethischen oder kognitiven Applikation Anlass sein: Man kann aufgrund der Lektüre des Romans zu dem Ergebnis kommen, dass manche Ideen problematische Konsequenzen haben, und dass der NS, fernab jeglicher Zwangsläufigkeit, mentalitätsgeschichtliche Wurzeln hat, die weit in die deutsche Geschichte zurückreichen. Im Einzelfall wurde ein Gegenwartsbezug des Romans identifiziert: „Es bleibt ein aktuelles Buch, das mit historischen Personen agiert.“242

Als charakteristisch für die Rezeption des Romans in der professionellen Literaturkritik erweist sich ferner die Tendenz, den Roman so zu verstehen, dass er verschiedene Themen behandelt, die mit Wissen und Erkenntnis, Wissenschaft und der Person des (genialen) Wissenschaftlers zusammenhängen. Es ist etwa die Rede von dem „subtile[n] Motivgefüge, das vom Freiheitsthema und der Entzauberung der Welt über den Konstruktivismus der Naturgesetze bis zu Wissenschaft und Ideologie reicht““. ${ }^{243}$ In einer Rezension wurde festgestellt:

Kehlmann beschäftigt sich mit zahlreichen Fragen, die im Buch nie ausgesprochen werden: Welche Opfer verlangt die Wissenschaft? Warum ist so vielen Genies jedes menschliche Mitgefühl fremd? Was treibt den Forscher wirklich an? Warum sind so viele Söhne genialer Männer die Opfer ihrer Väter? Wo eigentlich liegt der Punkt, an dem das hehre

241 Meller: Die Krawatte im Geiste, S. 249, vgl. dazu S. 250, und bereits Marius Meller: Die Weisheit der Wissenslücke. Dem Genie auf der Spur: Daniel Kehlmann und sein neuer Roman Die Vermessung der Welt. In: Der Tagesspiegel. Nr.18965, 24. September 2005, S. 23. Kritik daran, wie im Roman mit historischen Tatsachen umgegangen werde, übt Wolfgang Griep: Der Kehlmann-Kanal. In: Zeit online. 2007. https://www.zeit.de/online/2007/16/L-Kehlmann (01.07.2020); vgl. dazu Wolfgang Griep/Lieselotte de Vareschi/ Peter Brosche: Auch ein Beitrag zum Humboldt-Jahr. Drei Stimmen zu Daniel Kehlmanns Roman Die Vermessung der Welt. In: Lichtenberg-Jahrbuch 2009, S. 253-265.

242 Lüdke: Doppelleben, einmal anders. Einen „Gegenwartsbezug“ vermisst dagegen Hubert Winkels: Als die Geister müde wurden. Daniel Kehlmann lässt gekonnt zwei Melancholiker des Wissens aufeinander los. In: Die Zeit. Nr. 42, 13. Oktober 2005, Zeit Literatur, S. 14 f., hier S. 15.

243 Meller: Die Krawatte im Geiste, S. 250. 
Projekt der Aufklärung in die Entzauberung der Welt umkippte und ihre Bewohner ins Joch von Fortschritt und instrumenteller Vernunft gezwungen wurden?244

Es sei ein Roman „über die deutsche Klassik auf Reisen, über den unbedingten Glauben an die Vernunft, über Obsessionen und Visionen, über die ,Vermessung der Welt‘, im Geist und in der Wirklichkeit“. ${ }^{245}$ Mitunter wurden einzelne Aspekte besonders akzentuiert, etwa die Frage, was ein Genie sei, ${ }^{246}$ die Diskrepanz von genialem Geist und gebrechlichem Körper, ${ }^{247}$ die Einsicht in die Begrenztheit menschlichen Erkenntnisvermögens und Wissens. ${ }^{248}$ In allen diesen Fällen kann man davon sprechen, dass der Roman ein Applikationspotenzial besitzt. Es wird zwar in den Feuilleton-Rezensionen nicht erkennbar realisiert, dafür aber, wie gesehen, in manchen Rezensionen bei LovelyBooks - allerdings nicht in der komplexeren Form, wie es die professionelle Literaturkritik nahelegt.

Es fällt auf, dass der Roman generisch verschiedentlich klassifiziert wurde: Er gehöre zu Gattung des historischen Romans, sei ein komischer Roman oder eine Doppelbiographie. ${ }^{249}$ Eine Untersuchung der professionellen Rezeption kommt zu dem Ergebnis, dass der Roman als Biographie, Doppelbiographie/Doppelporträt, pseudo-historisches Porträt, historischer Roman, Geschichtsroman, Satire, Abenteuerroman und Forscherroman aufgefasst wurde. ${ }^{250}$ Erwähnenswert ist in diesem Zusammenhang eine Rezension, in welcher dem Roman als literarischem Text eine besondere Darstellungs- und Erkenntnisleistung zugeschrieben wurde. ${ }^{251}$ In dem Umstand, dass der Roman generisch

244 Spiegel: Der Schrecken der Welt läßt sich messen, aber nicht bannen.

245 Volker Weidermann: Der Weltvermesser. In: Frankfurter Allgemeine Sonntagszeitung. Nr. 37, 18. September 2005, S. 28.

246 Manfred Schneider: Vermessene Messlust. In: Literaturen. H. 10 (2005), S. 53-55, hier S. 54 .

247 Ijoma Mangold: Da lacht der Preuße, und der Franzose staunt. Unglaublich, was der junge Mann so alles kann: Daniel Kehlmanns heiterer Roman von der „Vermessung der Welt“. In: Süddeutsche Zeitung. Nr. 221, 24./25. September 2005, S. 16.

248 Meller: Die Weisheit der Wissenslücke. Mehr Einsicht in das „Drama der Erkenntnis“ wird dagegen in einer anderen Rezension gewünscht - Winkels: Als die Geister müde wurden, S. 15. 249 Vgl. Lüdke: Doppelleben, einmal anders; Mangold: Da lacht der Preuße, und der Franzose staunt; Winkels: Als die Geister müde wurden.

250 Vgl. Bodemer: Bestsellermarketing, S. 358.

251 „Die Vereinigung der empirischen und der rationalen Vermessung der Welt kann erst der Schriftsteller leisten, indem er in seiner Einbildungskraft eine eigene, poetisch begründete Welt schafft, die die Erklärungsversuche anderer mit in sich einbezieht. Kehlmanns humorvoller und geistreicher, spannender wie lehrreicher Roman, der gewagt und spielerisch mit den historischen Fakten umgeht, ist daher die eigentliche Vermessung der Welt.“ - Sebastian 
unterschiedlich eingeordnet und verschiedene Themen identifiziert werden, kann ein Grund dafür gesehen werden, dass sich unterschiedliche Applikationen und Applikationsmöglichkeiten identifizieren lassen.

Betrachtet man die Selbstaussagen des Autors, wie sie sich in Interviews finden sowie in einer Poetik-Vorlesung und in einem Band mit Essays, dann fällt auf, dass er verschiedentlich Fragen der Faktizität und Wahrheit ansprach. Wer den Roman in der Erwartung lese, zu erfahren, „wie es eigentlich gewesen ist bei Humboldt und Gauß“, dem müsse er „abrate[n]“: „Bei mir erfährt man nicht, wie es eigentlich gewesen ist, sondern höchstens, wie es gewesen sein könnte. Das Buch ist durch und durch ein Roman.“252 Er machte mithin einen Unterschied geltend zwischen dem historiographischen Anspruch auf Faktizität (und verwendete dabei das bekannte Diktum Leopold von Rankes) und dem literarischen Anspruch, Möglichkeiten darzustellen (im Sinne der Aristotelischen Unterscheidung von Historiographie und Literatur). Außerdem verwies er auf den „Unterschied zwischen dem bloß faktisch Richtigen und dem Wahren, den jeder historische Roman berührt“. ${ }^{253}$ Hier ist vom ,historischen Roman“ die Rede; an anderer Stelle wurde der Text als „Vergangenheitsroman, der in der Gegenwart spielt“, bezeichnet. ${ }^{254}$ Damit wird der Gegenwartsbezug besonders hervorgehoben. Mit Blick auf die konkrete Rezeption lässt sich sagen, dass es der Applikation bedarf um das ,Wahre‘ zu erkennen, welches der Roman im Unterschied zum faktisch Richtigen zeige.

Ein weiterer Aspekt, den der Autor häufig erwähnte, betrifft die komische, satirische Auseinandersetzung mit Deutschsein, deutscher Kultur und Ge-

Domsch: Der Raum im Geist. Hier die Herren Alexander von Humboldt, Carl Friedrich Gauß und ein sich objektiv gebendes Weltbild historischer und wissenschaftlicher Fakten, dort die subjektive Perspektive des Romanciers: Daniel Kehlmanns humorvoller, geistreicher und spannender neuer Roman Die Vermessung der Welt. In: die tageszeitung. Nr.7777, 24./25. September 2005, S. 19.

252 Hamlet trifft Pythagoras. [Gespräch mit Daniel Kehlmann]. In: Der Tagespiegel. Nr. 19133, 15. März 2006, S. 27.

253 Daniel Kehlmann: Wo ist Carlos Montúfar? In: D. K.: Wo ist Carlos Montúfar? Über Bücher. Reinbek b. H. 2005, S. 9-27, hier S. 18. Vgl. dazu die ähnlich lautende Aussage in einem Interview aus demselben Jahr: Matthias Matussek/Mathias Schreiber/Olaf Stampf: Mein Thema ist das Chaos. Ein Gespräch mit Daniel Kehlmann. In: Der Spiegel. Nr. 49, 5. Dezember 2005, S. 174-178, hier S. 175. Vgl. zur Notwendigkeit, zu erfinden, zum Wahrheitsanspruch der Fiktion sowie zum Umgang mit historischen Fakten und fiktiven Elementen in dem Roman Kehlmann: Wo ist Carlos Montúfar?, S. 12 und 14 f.; Daniel Kehlmann: Diese sehr ernsten Scherze. Poetikvorlesungen. Göttingen 2007, S. 25-43.

254 Sebastian Kleinschmidt: Gespräch mit Daniel Kehlmann. In: Sinn und Form. Jg. 58, H. 6 (2006), S. 786-799, hier S. 792. 
schichte; ein Gesichtspunkt, der von der professionellen Literaturkritik in Deutschland nicht hinreichend wahrgenommen worden sei, dafür aber von der internationalen. In einem Interview beobachtete er: „Das Buch wird auch als ein Buch über Deutschland gelesen - anders als hierzulande, wo man es vorwiegend als Geschichte zweier Käuze auffaßt. “255 Insbesondere hat er sich gegen die Vorstellung verwahrt, dass sein Roman ein „patriotisches Buch“ sei oder zeige, „dass das Große in der deutschen Geschichte es uns erlauben soll, die NS-Zeit zu relativieren“. ${ }^{256}$ Der Roman stelle unter anderem „Größe und Komik deutscher Kultur“ dar, ${ }^{257}$ er sei „[e]ine satirische, spielerische Auseinandersetzung mit dem, was es heißt, deutsch zu sein“ beziehungsweise „eine recht aggressive Satire über das Deutschsein“. ${ }^{258}$ Man kann hierin, bezogen auf die Rezeption, eine Möglichkeit der Applikation erkennen: Der Roman bietet eine Perspektive auf das Deutschsein an, die man akzeptieren oder verwerfen kann.

Andere Gesichtspunkte, die am Rande erwähnt werden, betreffen zum Beispiel „das Thema Genialität, Hochbegabung“. ${ }^{259}$ Als Erklärung für das Publikumsinteresse gab Kehlmann in einem Interview das „Interesse an dem wissenschaftlichen Weltzugang“ an und die „Frage, welche Rolle Vernunft überhaupt noch spielen soll“. ${ }^{260}$ Er führte den Erfolg damit, zumindest in Teilen, auf die Thematisierung von Wissenschaft, Erkenntnis und dergleichen zurück.

Den Roman und seine Rezeption auf die historischen und literaturgeschichtlichen Gegebenheiten zu beziehen, fällt nicht ganz leicht. Am aussichtsreichsten dürfte es sein, ihn aufgrund des Umstandes, dass und wie er deutsche Geschichte und Identität behandelt, mit Tendenzen der deutschsprachigen Literatur nach der Wiedervereinigung im Zusammenhang $\mathrm{zu}$ sehen und den

255 Matussek/Schreiber/Stampf: Mein Thema ist das Chaos, S. 178.

256 Matussek/Schreiber/Stampf: Mein Thema ist das Chaos, S. 178; Frederik Jötten: „darwin ist lustig“. Der Schriftsteller Daniel Kehlmann über den missverstandenen Schöpfer der Evolutionstheorie, den Gegensatz von Poesie und Aufklärung und die Debatte um Günter Grass. In: Frankfurter Rundschau. Nr. 192, 19. August 2006, Magazin, S. 4 f., hier S. 5.

257 Kehlmann: Wo ist Carlos Montúfar?, S. 14.

258 Felicitas von Lovenberg: Ich wollte schreiben wie ein verrückt gewordener Historiker. Ein Gespräch mit Daniel Kehlmann über unseren Nationalcharakter, das Altern, den Erfolg und das zunehmende Chaos in der modernen Welt. In: Frankfurter Allgemeine Zeitung. Nr. 34, 9. Februar 2006, S. 41. Dort auch der Hinweis, dass dies in seiner Wahrnehmung ,eines der Hauptthemen des Romans“ sei, das „[i]n der breiten Rezeption [...] merkwürdigerweise vernachlässigt worden" sei.

259 Kleinschmidt: Gespräch mit Daniel Kehlmann, S. 786.

260 „Die Fremdheit ist ungeheuer.“ Daniel Kehlmann und Michael Lentz im Gespräch über historische Stoffe in der Gegenwartsliteratur. In: Neue Rundschau. Bd. 118, H. 1 (2007), S. 3347, hier S. 44. 
mentalitätsgeschichtlichen Entwicklungen, auf welche sie Bezug nehmen. Das ist in einem Forschungsbeitrag in Grundzügen demonstriert worden, der an drei Romanen - Georg Kleins Libidissi (1998), Uwe Tellkamps Der Turm (2008) und eben Kehlmanns Die Vermessung der Welt - exemplarisch „zu veranschaulichen versucht, dass die Beschäftigung mit dem Deutschsein im Roman der Nachwendezeit eine Renaissance und allmähliche Entproblematisierung erlebt“. ${ }^{261}$ Der Roman markiere „durch seine eigentümliche Synthese aus Verspottung und Würdigung des deutschen Wesens eine wichtige Zwischenetappe“ zwischen „erbarmungsloser Entlarvung“ bei Klein und der „Bezugnahme auf deutsche Kulturtradition in der Hoffnung auf Identitätsstabilisierung “ bei Tellkamp.

Wo die Rezensionen bei LovelyBooks Indizien für Applikationen liefern, äußern sich die Feuilleton-Rezensionen und andere literaturkritische Texte vor allem über Aspekte des Textes, aufgrund deren man aus literaturwissenschaftlicher Sicht ein Applikationspotenzial annehmen kann. In der Sache lassen sich durchaus Schnittmengen ausmachen, wobei festzustellen ist, dass die Aussagen der professionellen Literaturkritiker/-innen komplexer sind, etwa mit Blick auf Fragen von Wissenschaft und Erkenntnis oder hinsichtlich einer kritischen Perspektive, aber keinen kategorialen Unterschied markieren. Unterschiede ergeben sich etwa darin, dass die - vom Autor selbst erwähnte - Bezugnahme auf den NS in LovelyBooks-Rezensionen nicht vorkommt und stattdessen der Überzeugung Ausdruck verliehen wird, etwas über historische Tatsachen und die historischen Personen zu erfahren. Ein Vergleich der Selbstaussagen des Autors mit den Rezeptionszeugnissen zeigt unter anderem, dass die satirische Sicht auf das Deutschsein eine eher untergeordnete Rolle spielt. Allgemein fällt die relative Breite der Applikationen oder Applikationsmöglichkeiten auf, die im Zusammenhang zu sehen ist mit der Beschaffenheit des Textes.

\subsubsection{Beschaffenheit und Potenzial des Textes}

Betrachtet man, was im Roman erzählt und wie es erzählt wird, dann fällt es leicht, mehr oder weniger alle Aussagen zu Applikationen und diejenigen, die

261 Tom Kindt: Die Vermessung der Deutschen. Zur Reflexion deutscher Identität in Romanen Georg Kleins, Daniel Kehlmanns und Uwe Tellkamps. In: Zeitschrift für Germanistik 22 (2012), S. 362-373, hier S. 373. Die anschließenden Zitate an derselben Stelle. Vgl. dazu Stuart Taberner: Literature and Unification. Günter Grass's Im Krebsgang, Feridun Zaimoğlu's German Amok, and Daniel Kehlmann's Die Vermessung der Welt. In: Literatur für Leser 33 (2010), S. 6777; Stuart Taberner: Daniel Kehlmann's Die Vermessung der Welt (Measuring the World). In: S.T. (Hg.): The Novel in German since 1990. Cambridge 2011, S. 255-269. 
darauf hindeuten, am Text festzumachen - in dem schwächeren Sinne, dass sich Textmerkmale identifizieren lassen, die eine entsprechende Rezeption bewirkt haben mögen. Zugleich fällt auf, dass sie eine begrenzte Reichweite haben. Das spricht nicht gegen sie, lässt aber die Frage aufkommen, ob der Roman auf textthematischer Ebene ein übergreifendes Applikationspotenzial besitzt, in dem die verschiedenen partiellen Applikationen ihren Platz finden und das die Beschaffenheit des Textes umfassend berücksichtigt. Im Folgenden soll $\mathrm{zu}$ zeigen versucht werden, dass der Gesamttext ein solches Applikationspotenzial aufweist. Es besteht darin, dass er eine bestimmte Sicht auf Geschichte nahelegt, fokussiert auf die deutsche Geschichte. Maßgeblich für diese Sicht ist ironische Distanz. Sie ermöglicht eine ausgewogene Haltung zur deutschen Geschichte, bei welcher die positiven Aspekte prinzipiell angemessen gewürdigt werden können, ohne der Gefahr zu erliegen, die Vergangenheit zu verklären oder revisionistisch gegen die NS-Verbrechen auszuspielen.

Der NS ist der entscheidende Grund für die Notwendigkeit einer solchen Perspektive. Es kann, so legt der Roman nahe, danach keine ungebrochene Sicht auf die deutsche Geschichte davor geben, obwohl sie nicht allein Vorgeschichte des NS ist. Der historische Abstand des Autors und seines Publikums von der Zeit des NS wiederum mag eine Voraussetzung dafür sein, dass es mittlerweile möglich ist, auf diese Weise auf die deutsche Geschichte zu blicken. Der Text enthält Passagen, die als mehr denn eindeutige Leseanweisung verstanden werden können, dass der Blick auf die deutsche Geschichte um $1800 \mathrm{im}$ Roman einer ist, der nicht unabhängig von dem ist, was in den Jahren 1933 bis 1945 geschah. Auf seiner Südamerikaexpedition mit der Information konfrontiert, dass bei der Einweihung eines Tempels zwanzigtausend Menschen geopfert worden seien, gibt Alexander von Humboldt sich ungläubig: „Zwanzigtausend an einem Ort und Tag, das sei undenkbar. Die Opfer würden es nicht dulden. Die Zuschauer würden es nicht dulden. Ja mehr noch: Die Ordnung der Welt vertrüge derlei nicht. Wenn so etwas wirklich geschähe, würde das Universum enden. " ${ }^{262}$ Zum Kontrast, in dem derlei zu den architektonischen und astronomischen Leistungen der Ureinwohner steht, bemerkt er etwas später: „So viel Zivilisation und so viel Grausamkeit [...]. Was für eine Paarung! Gleichsam der Gegensatz zu allem wofür Deutschland stehe.“ (S. 208) Solche Aussagen kann man wohl nicht anders lesen denn als über das Bewusstsein der Figuren hinausgehende Anspielung auf den NS. Dabei ergibt sich eine ironische, ja zynisch zu nennende Diskrepanz zwischen dem aufklärerischen Glauben an eine

262 Daniel Kehlmann: Die Vermessung der Welt. Roman. Reinbek b. H. 2005, S. 202. Alle Nachweise im Folgenden im Anschluss an das Zitat. 
prinzipiell gute Weltordnung und dem überheblichen Bewusstsein dezidiert deutscher Zivilisiertheit auf der einen Seite und den historischen Tatsachen auf der anderen Seite.

Es lassen sich Selbstaussagen des Autors anführen, auf die man sich in diesem Zusammenhang berufen kann. Man kann darauf verweisen, dass Kehlmann meinte, der Roman als Gattung könne, „bestehende Meinungen untergraben - und eine der wirksamsten Arten, das zu tun, besteht darin, sich die Vergangenheit neu zu erzählen und von der offiziellen Version ins Reich erfundener Wahrheit abzuweichen“. ${ }^{263}$ Was die Zeit angeht, zu welcher Die Vermessung der Welt spielt, betonte er die historische Alterität zur Gegenwart, die „ungeheuer“ sei: „Die Unterschiede zwischen den Zeitaltern sind gewaltig - im Verhalten, im Denken, in den emotionalen Prozessen.“..264 Dass man die Zeit um 1800 vom heutigen Standpunkt nicht betrachten könne ohne ein Wissen über den NS, hat er explizit festgestellt: „Es gelingt uns einfach nicht, die große Humanität der Weimarer Klassik zu betrachten, ohne mitzudenken, wie traurig und entsetzlich es ist, daß diese Tradition nicht verhindern konnte, was dann in der NS-Zeit geschah.“"265 Eigens betont hat er die Ironie, welche die Perspektive auf das im Roman Geschilderte bestimme: „Das Buch gibt sich als ernstes Geschichtswerk und ist das Gegenteil davon. Das ist nicht bloß eine Ironie des Tones, sondern eine der Haltung. “266 $\mathrm{Zu}$ erwarten ist also ein Roman, der eine alternative und ironisch-distanzierte, von Wissen über den NS informierte Perspektive entwirft auf die Zeit um 1800, die dem heutigen Publikum in vielerlei Weise fremd ist - trotz oder vielleicht gerade wegen ihrer wissenschaftlichen und kulturellen Glanzleistungen.

Wie gezeigt werden soll, muss man sich allerdings nicht auf den Autor berufen, um das in Rede stehende Applikationspotenzial annehmen zu können. Es lässt sich anhand von Textbeobachtungen hinreichend plausibilisieren. Im Folgenden soll nun, anders als im vorangehenden Unterkapitel, nicht zunächst detailliert der Nachweis geführt werden, dass und wie die festgestellten Applikationen mit dem Text zusammenhängen. Stattdessen sollen Beobachtungen angeführt werden, welche die These zum Applikationspotenzial stützen. In diesem Zuge wird ersichtlich werden, worauf die anderen Applikationen bezogen sind und welche Reichweite sie haben.

263 Kehlmann: Wo ist Carlos Montúfar?, S. 12.

264 „Die Fremdheit ist ungeheuer.“, S. 37.

265 Matussek/Schreiber/Stampf: Mein Thema ist das Chaos, S. 178.

266 Kehlmann: Diese sehr ernsten Scherze, S. 27. 
Es ist festzustellen, dass historischer Abstand und historische Bedingtheit im Roman verschiedentlich verdeutlicht werden. Gleich $\mathrm{zu}$ Beginn wird in komischer Perspektivierung explizit darauf hingewiesen, dass der jeweilige Standpunkt eines Menschen maßgeblich ein historischer ist: „Seltsam sei es und ungerecht, sagte Gauß, so recht ein Beispiel für die erbärmliche Zufälligkeit der Existenz, daß man in einer bestimmten Zeit geboren und ihr verhaftet sei, ob man wolle oder nicht. Es verschaffe einem einen unziemlichen Vorteil vor der Vergangenheit und mache einen zum Clown der Zukunft.“ (S. 9) Gauß bringt hier keinen naiven Fortschrittsoptimismus zum Ausdruck. Der Figur wird vielmehr die Einsicht in den Mund gelegt, dass man seiner Zeit verhaftet sei und den jeweils vergangenen gegenüber epistemisch privilegiert - aber eben nur diesen, nicht den kommenden. Dazu ließen sich weitere Beobachtungen machen. Humboldt erklärt an einer Stelle: „Die zweitgrößte Beleidigung des Menschen sei die Sklaverei. Die größte jedoch die Idee, der Mensch stamme vom Affen ab.“ (S. 238) Während die erste aus heutiger Sicht unmittelbar einleuchtend ist und die Figur als für ihre Zeit progressiv charakterisiert, erweist sich im selben Atemzug, dass sie Kind ihrer Zeit ist.

Beide werden des Weiteren dabei gezeigt, wie sie verschiedene Prognosen abgeben, die manchmal stimmen, manchmal aber nicht, und in jedem Fall einen Rezipienten von heute voraussetzen, um sie angemessen einschätzen und bewerten zu können. In einem Gedankenbericht über den jungen Gauß heißt es: „Er wußte, daß es bald keine Herzöge mehr geben würde. Dann würde man von absoluten Herrschern nur mehr in Büchern lesen, und der Gedanke, vor einem zu stehen, sich zu verneigen und auf sein Machtwort zu warten, käme jedem Menschen fremd und märchenhaft vor.“ (S. 61) Aus heutiger Perspektive ist einsichtig, dass das stimmt, wobei zu betonen ist, dass es nicht „bald“ geschah, sondern in Deutschland letztlich erst 1918/1919. Humboldt erklärt an einer Stelle: „Die Wissenschaft werde ein Zeitalter der Wohlfahrt herbeiführen, und wer könne wissen, ob sie nicht eines Tages sogar das Problem des Todes lösen werde.“ (S. 238 f.) Diesen Optimismus würde man wohl heute nicht uneingeschränkt teilen, sondern eher eine abwägende Sicht auf wissenschaftlichen Fortschritt einnehmen.

Es kommen ferner bewusst eingesetzte Anachronismen vor. An einer Stelle wird Gauß die Vermutung zugeschrieben, „daß auch die Gesetze der Physik bloß statistisch wirkten, mithin Ausnahmen erlaubten: Gespenster oder die Übertragung der Gedanken“ (S. 13). Anachronistisch ist der Gedanke zum einen, weil er eine Einsicht formuliert, die aus späteren Zeiten stammt, und zum anderen, weil die Einsicht mit voraufklärerischen Vorstellungen über Wunderbares verbunden wird. Ein weiteres Beispiel findet sich an einer Stelle, wo Humboldt 
anscheinend der Sache nach das Echolot entdeckt (vgl. S. 73). Nicht zuletzt auf diese Weise wird hervorgehoben, dass von einem dezidiert heutigen Standpunkt aus erzählt wird.

Belege dieser Art ließen sich in großer Zahl anführen. Es wird also wiederholt und deutlich bewusstgemacht, dass nicht allein der Gegenstand des Erzählens ein historischer ist, sondern Historizität gleichsam den Verstehensrahmen für den Roman bildet. Das Dargestellte ist als Historisches perspektiviert, es ist anders und fremd - und heutige Rezipient/-innen sind allein aufgrund des Umstandes privilegiert, dass sie in späteren Zeiten leben und daher über Erfahrungen und ein Wissen verfügen, welche den Menschen um 1800, selbst den intellektuell herausragenden, nicht zu Gebote stand. Geschichte ist nicht einfach der Stoff für eine zum Beispiel abenteuerliche oder rührende Handlung, die der Unterhaltung dient. Der Roman vermittelt außerdem nicht einfach in ansprechender Form Faktenwissen. Dass es nicht um Tatsachenwissen geht, machen bereits die zahlreichen zum Bereich des Wunderbaren gehörenden Details deutlich, etwa die vermeintliche Sichtung eines Seeungeheuers (vgl. S. 45) und eines UFOs (vgl. S. 135) oder die telepathische Kommunikation von Humboldt und Gauß (vgl. S. 290 f.), daneben die Begegnung mit rätselhaften Figuren sowie Berichte über Ungeheuer und Geistererscheinungen. ${ }^{267}$

$\mathrm{Zu}$ beachten sind ferner die wiederholten Signale der Selbstbezüglichkeit, bei welchen Aussagen der Figurenrede auf den Akt des Erzählens verweisen und somit die Konstruiertheit und Fiktionalität ausgestellt wird, gerade die des historischen Erzählens. Solche Formen der Selbstbezüglichkeit dürften mit hoher Wahrscheinlichkeit auch von nicht-professionellen Rezipient/-innen verstanden werden können, da sie weitverbreitet sind und längst in ,populäre، Literatur und Kunst Eingang gefunden haben. Ein Beispiel findet sich wiederum gleich zu Beginn: „Sogar ein Verstand wie der seine, sagte Gauß, hätte in frühen Menschenaltern oder an den Ufern des Orinoko nichts zu leisten vermocht, wohingegen jeder Dummkopf in zweihundert Jahren sich über ihn lustig machen und absurden Unsinn über seine Person erfinden könne.“ (S. 9) Humboldt nennt es „ein albernes Unterfangen, wenn ein Autor, wie es jetzt Mode werde, eine schon entrückte Vergangenheit zum Schauplatz wähle“ (S. 27), und äußert sich ablehnend $\mathrm{zu}$ „Romane[n], die sich in Lügenmärchen verlören, weil der

267 Vgl. zum magischen Realismus und zu Bezügen auf die lateinamerikanische Literatur Gunther Nickel: Von Beerholms Vorstellung zur Vermessung der Welt. Die Wiedergeburt des magischen Realismus aus dem Geist der modernen Mathematik. In: G. N.: Daniel Kehlmanns Die Vermessung der Welt, S. 151-168; Joachim Rickes: Daniel Kehlmann und die lateinamerikanische Literatur. Würzburg 2012. 
Verfasser seine Flausen an die Namen geschichtlicher Personen binde“ (S. 221). Diese sehr expliziten metafiktionalen Indizien sind nicht allein Teil eines ironischen Spiels, das einen komischen Effekt hat. Sie verdeutlichen vielmehr die Wichtigkeit, den Roman als einen historischen Roman zu lesen, in dem zu bestimmten Zwecken auf Grundlage eines historischen Stoffes eine Handlung konstruiert wird, die über die Darstellung des Tatsächlichen hinausgeht.

In diesem Rahmen eines historischen Erzählens, das historische Bedingtheit und den Akt dieses Erzählens selbst thematisiert, sind all die anderen thematischen Gehalte zu verorten. Das bleibt nicht ohne Konsequenz dafür, was sie aussagen. Ein erstes Beispiel ist Deutschsein und deutsche Identität, die vielfach thematisiert und beschrieben wird. Die satirische Darstellung von Deutschsein und deutscher Identität trägt Züge einer Karikatur und erfolgt ebenfalls aus historischer Perspektive. Wo den Karikaturen ein Wahrheitsgehalt zugewiesen werden kann, verweisen sie nicht auf ahistorische Größen, sondern auf historisch gewordene Mentalitäten und Dispositionen. Über den Vater von Gauß erfährt man:

Sein Vater war Gärtner, hatte meist dreckige Hände, verdiente wenig, und wann immer er sprach, beklagte er sich oder gab Befehle. Ein Deutscher, sagte er immer wieder, während er müde die abendliche Kartoffelsuppe aß, sei jemand, der nie krumm sitze. Einmal fragte Gauß: Nur das? Reiche das denn schon, um ein Deutscher zu sein? Sein Vater überlegte so lange, daß man es kaum mehr glauben konnte. Dann nickte er. (S. 53 f.)

Diese malkontente Haltung mit ihrem zweckfreien Beharren auf Disziplin und der Neigung dazu, Befehle zu geben (und zu empfangen) mag ein Klischee sein, charakterisiert aber wohl zumindest in Teilen zutreffend eine Mentalität, die sich bei manchen Akteuren in der deutschen Geschichte finden lässt (etwa im Kaiserreich). Das Motiv des ,Sich-gerade-Haltens' kommt immer wieder vor, auch bei Humboldt (vgl. S. 35, 55, 60, 194 und 263). Eugen, der Sohn von Gauß, erscheint als deutscher Michel, dessen Freiheitspathos von charakterlichen Unzulänglichkeiten behindert wird, weil ihm letztlich der Mut fehlt. Er kann Russland nicht als „schlimmste Despotie der Welt“ bezeichnen, ohne „rot vor Schreck über sich selbst“ zu werden (S. 218). Wilhelm und Alexander lesen in jungen Jahren auf Empfehlung des mit ihrer Erziehung beauftragten Majordomus Kunth Romane der Schauerromantik, denn: „[W]er die metaphysische Angst nicht kenne, werde nie ein deutscher Mann“ (S. 21). Bei seiner Südamerika-Expedition mit den menschenunwürdigen Bedingungen in einer Silbermine konfrontiert, verweist Humboldt auf Kant, bekommt vom Bergwerksleiter, dem nach eigener Aussage bezeichnender Weise Leibniz näherliege, allerdings die Antwort: „Er habe deutsche Vorfahren, deshalb kenne er all diese schönen 
Phantastereien.“ (S. 199) Auf seiner Russlandreise wird ihm anlässlich einer offenkundigen Falschbehauptung, welcher er widerspricht, bedeutet: „Es gebe eine oberflächliche Wahrheit und eine tiefere, [...] gerade als Deutscher wisse man das.“ (S. 279) Karikiert wird mithin eine Tendenz der deutschen Geistesgeschichte, nach vermeintlich tiefen, metaphysischen Wahrheiten zu suchen, ebenso wie unplausible Weltdeutungen (die bestehende Welt als die beste aller möglichen) oder nur schwer zu realisierende moralische Maximen (der Kantische Imperativ). Außerdem werden an Gauß und Humboldt exemplarisch Indifferenz in nationalen Fragen und auf den landesherrlichen Herrschaftsbereich beschränkter Patriotismus angedeutet. Gauß interessiert sich nicht dafür, ob er seinem braunschweigischen Herzog dient oder Napoleon (vgl. S. 153). Humboldt meint, er könne als „Preuße [...] nicht für ein anderes Land Dienst tun“ (S. 203). Beides kann in gewisser Weise als typisch angesehen werden, ähnlich wie ein (im Roman nur angedeuteter) übersteigerter Nationalismus (vgl. z. B. die unzutreffende Diffamierung Humboldts als „Franzosenknecht“, S. 228).

Wo hingegen vermeintliche Wesenszüge des Deutschen an sich karikiert werden, besitzen sie nur einen geringen Realitätsgehalt. Bonpland zum Beispiel fragt anlässlich des Umstandes, dass Humboldt eine Sonnenfinsternis nicht beobachtet hat, sondern stattdessen mit den Messinstrumenten beschäftigt war, rhetorisch: „Müsse man immer so deutsch sein?“ (S. 80) Solche Zuschreibungen verdanken sich eher der Stereotypen- und Klischeebildung, die ihrerseits historisch geworden ist. Sie sind in etwa so zutreffend, wie die anderen Nationalstereotype, die im Roman vorkommen: frivole Franzosen (am Beispiel Bonplands), despotische Russen und imperialistische Amerikaner. Wenn man nicht zugleich annehmen will, dass diese zutreffen, kann man die deutschen Nationalstereotype ebenso wenig gelten lassen. Sie dienen wohl in erster Linie der Erzeugung von Komik.

Die Aussagen über Deutschsein und deutsche Identität sind, wie bereits deutlich geworden sein dürfte, in zeitgeschichtliche Bezüge eingebunden. Präsentiert wird nicht das deutsche Wesen als solches, sondern seine Bedingtheit durch die deutsche Geschichte. Es wird deutlich, dass Identität historisch bestimmt ist und sich maßgeblich aus der Geschichte speist - und damit wandelbar ist. Auf Absolutismus und Kleinstaaterei eines föderal verfassten, agrarisch geprägten Reiches wird verschiedentlich hingewiesen (vgl. z. B. S. 64 und 194). Das allerdings nicht, ohne anzudeuten, dass dieser „spaßige Fleck“ (S. 181) bei aller Beschränktheit und Skurrilität im Kleinen Überraschendes hervorbringt. Als Landvermesser begegnet Gauß in einer phantastische Züge tragenden Szene dem „Graf Heinrich von der Ohe zur Ohe“, dessen Geschlecht „seit tausend Jahren so [heiße]“ (ebd.). Der provinzielle Duodez-Adlige scheint allerdings 
dessen Disquisitiones Arithmeticae nicht nur gelesen und verstanden zu haben, sondern Gauß in derlei ebenbürtig zu sein (vgl. S. 188 f.). Dennoch werden vor allem Rückständigkeit und Provinzialität verdeutlicht, etwa an Humboldt, der in Südamerika vergeblich versucht, Mitreisenden die Tragweite seiner Widerlegung der neptunistischen Thesen des „großen Abraham Werner“ näherzubringen (S. 208), den dort begreiflicherweise niemand kennt, oder an Goethe, der Humboldt vor seiner Abreise zum „Botschafter“ des kleinen Weimarer MusenHofes zu erklären versucht hatte (S. 37).

Der preußische Militär- und Obrigkeitsstaat wird ebenso karikiert wie die unbeholfenen Versuche, eine freiheitlichere Ordnung einzuführen. Als Humboldt mithilfe Daguerres von seiner Begegnung mit Gauß eine Fotografie machen möchte, spricht ein hinzutretender Polizist von einer „Zusammenrottung“ (S. 16, dazu S. 218 und 228). In Südamerika hatte Humboldt sich auf einer Station zur Weitereise trotz drohenden Unwetters entschlossen, weil man „[d]er Obrigkeit [...] Folge leisten [müsse]“ (S. 139). Eugen nimmt in Berlin an einer konspirativen studentischen Versammlung teil, bei welcher ein sich als Trittbrettfahrer von Turnvater Jahn erweisender Redner spricht, der über Nationalismus, Freiheitspathos und körperliche Ertüchtigung schwadroniert (vgl. S. 230-232). Die ganze Szene offenbart Dilettantismus und wird von eintreffenden Polizisten beendet (vgl. S. 228-234). Eugen bemerkt dazu: „Fünfzig Studenten mit Knotenstöcken [...] und drei Polizisten. Einer mußte angreifen, dann würden die anderen folgen.“ (S. 233) Wenn am Ende der verbannte Eugen nach Amerika auswandert, mag man darin eine Anspielung darauf sehen, dass die maßgeblichen Impulse zur nachhaltigen Etablierung einer freiheitlichen Ordnung auf deutschem Boden von anderen ausgehen werden.

Aufklärerisches Gedankengut, zumal im Bereich der Wissenschaft, wird immer wieder thematisiert und ironisch perspektiviert. Für Humboldt ist Wissen Selbstzweck: „Man wolle wissen, [...] weil man wissen wolle.“ (S. 70) Er schreckt nicht zurück vor schmerzhaften Selbstexperimenten (vgl. z. B. S. 31-34 und 103 f.), fragwürdigen Tierexperimenten (vgl. z. B. S. 165) oder der Störung der Totenruhe im Dienste von „Freiheit und Vernunft“ (S. 121). Die Vernunft stellt er über das Augenscheinliche (vgl. S. 138). Allerdings ist er nicht vor Irrationalem und Wunderbarem gefeit. So zeigt er an einer Stelle eine Neigung zum Animismus („Der Jaguar habe ihn gehen gelassen.“, S. 108) und äußert sich in überraschender Weise abfällig über eine Scéance: „Er sei mit Geistern aufgewachsen und wisse, wie man sich ihnen gegenüber benehme.“ (S. 260) Überhaupt geht es in der Zeit nicht allein rational zu. Georg Forster erzählt „von Drachen und lebenden Toten“ (S. 28), Abraham Werner ist auf der einen Seite Vertreter einer (bald überholten) wissenschaftlichen Theorie und auf der anderen Seite „Ken- 
ner der Zeichen, denen die Dämonen gehorchten“ (S. 29). Humboldts Ansichten zu „natürliche[r] Würde“ wirken unfreiwillig deplatziert (S. 72), sein Beharren auf der „Menschenwürde“ kann bei den Zeitgenossen Unverständnis hervorrufen (S. 165). Seine rastlosen, bei den Zeitgenossen auf Befremden stoßenden und nur unter großen Entbehrungen für sich selbst und andere betriebenen Forschungen, die wieder und wieder beschrieben werden, werden letztlich textintern psychisch motiviert. Dazu ein Beispiel. Marcus Herz, ein Schüler Kants, unterrichtet Wilhelm und Alexander in Physik und Philosophie. Er erklärt: „Wann immer einen die Dinge erschreckten, sei es eine gute Idee, sie zu messen.“ (S. 22) Genau das beherzigt Humboldt sein Leben lang (vgl. z. B. S. 30, $41 \mathrm{f}$. und 50).

Man mag in alledem eine Kritik an der Aufklärung sehen, zumal in dem am Beginn stehenden, explizit als „Experiment“ (S. 20) bezeichneten Versuch, Alexander zu einem Wissenschaftler und Wilhelm zu einem Mann der Kultur zu machen, bei dem Bildung und Pädagogik ins Extrem gesteigert und pervertiert werden. Solches Denken ist allerdings eingebunden in den historischen Rahmen und wird als historisch bedingt und überwunden kenntlich gemacht. Das heißt nicht, dass es nicht negative, kritikwürdige Konsequenzen hatte. Aber das erkennt man vom heutigen Standpunkt eben aufgrund der historischen Erfahrung. Der eigentliche Punkt ist damit kein ideologiekritischer, sondern ein historischer. Es wird nicht noch einmal die ,instrumentelle Vernunft' kritisiert, sondern die (deutsche) Aufklärung historisch verortet und das gezeigt, was aus heutiger Sicht befremden mag.

Gleiches gilt für den Vernunftgebrauch und die Orientierung an Rationalität. Sie werden durchaus von einer komischen Seite gezeigt, etwa wenn Humboldt sagt: „Ein Hügel, von dem man nicht wisse, wie hoch er sei, beleidige die Vernunft und mache ihn unruhig. Ohne stetig die eigene Position $\mathrm{zu}$ bestimmen, könne ein Mensch sich nicht fortbewegen. Ein Rätsel, wie klein auch immer, lasse man nicht am Wegesrand.“ (S. 42) Vor allem aber werden an Gauß Chancen und Folgen des Vernunftgebrauchs deutlich. Er nimmt an, „daß man ein Problem nur ohne Vorurteil und Gewohnheit betrachten müsse, dann zeige sich von selbst seine Lösung“ (S. 57). Auf diese Weise gelangt er, häufig nebenbei, zu bahnbrechenden Erkenntnissen. Er begreift allerdings schon als Kind, „daß niemand den Verstand benutzen wollte“ (S. 55), und wundert sich später, dass seine Mitmenschen das, was ist, unhinterfragt für selbstverständlich halten (vgl.S. 82). Sein überragender Verstand macht ihn abgeklärt: „[E]inmal sprang er grundlos zur Seite und war nicht einmal überrascht, als in derselben Sekunde neben ihm ein Dachziegel zerschellte. Die Zahlen entführten einen nicht aus der Wirklichkeit, sie brachten sie näher heran, machten sie klarer und 
deutlich wie nie.“ (S. 86) Zugleich wird er dadurch melancholisch (vgl. z. B. S. 59 und 87). Die Entdeckungen, die er macht, führen ihm die Unzulänglichkeit der Welt vor, ,als hätte Gott sich Nachlässigkeiten erlaubt und gehofft, keiner würde sie bemerken“ (S. 88, ähnlich z. B. S. 99). Noch der alte Gauß kommt sich „wie eine nicht ganz gelungene Erfindung vor[], wie die Kopie eines ungleich wirklicheren Menschen, von einem schwachen Erfinder in ein seltsam zweitklassiges Universum gestellt“ (S. 282).

So unterschiedlich Gauß und Humboldt in ihren wissenschaftlichen Herangehensweisen und ihrer Forschung sind (vgl. z. B. S. 87, 220, 247 und 272), beide ereilt das Schicksal, dass ihre Leistungen noch zu Lebzeiten von anderen übertroffen werden und manche ihrer Erkenntnisse bereits als überholt gelten. Gerade Humboldt erscheint zum Ende hin als lebende Legende, deren Leistungen aber bereits einer anderen Zeit angehören, weswegen man ihn nicht nur ehren, sondern auch wissenschaftsgeschichtlich kanonisieren kann. Eine Nebenfigur konstatiert anlässlich der mittlerweile veralteten Vorgehensweise Humboldts auf dessen Russlandreise, dies sei, „als erlebe man eine Reise in der Zeit, als wäre man in ein Geschichtsbuch versetzt, so erhaben sei es“ (S. 275). Die Navigation, wie Humboldt sie beherrschte, erweist sich als überholt (vgl. S. 299). Gauß bemerkt am Ende anhand einer Abhandlung seines ehemaligen Lehrers Martin Bartels, dass andere ihn mittlerweile übertroffen haben (vgl. S. 290). Hierin zeigt sich ein letztes Mal die historische Rahmung, in welcher das im Roman Geschilderte steht.

Die vorangehende, aspektbezogene Skizze sollte deutlich machen, dass im Roman eine bestimmte Perspektive entworfen wird auf die deutsche Geschichte um 1800 und darüber hinaus, die genuin historisch ist, ironisch und distanziert. Dazu tragen manche Aspekte der formalen Beschaffenheit bei, etwa die konsequent in den Konjunktiv transponierte Figurenrede oder die Kontrastierung der Figuren Humboldts und Bonplands, oder die als ,allwissend' konzipierte Erzählerinstanz, die Dinge mitteilen kann, welche Humboldt nicht in seine Reisebeschreibungen aufnehmen wollte und die den Figuren entgehen. Außerdem kann er über das Innenleben der Figuren Dinge berichten, welche über die historischen Personen niemand wissen kann. Missstände und problematische Aspekte der deutschen Geschichte werden nicht verschwiegen. Die kulturellen und wissenschaftlichen Leistungen der Zeit werden nicht der Lächerlichkeit preisgegeben, ebenso wenig wie die historischen Personen. Wenn über die Protagonisten und über andere, die als Figuren auftreten, wie Goethe und Kant, Dinge behauptet werden, die in der Fiktion wahr sein mögen, aber nicht den historischen Tatsachen entsprechen, dann dient es dem Zweck, etwas Bestimmtes $\mathrm{zu}$ bewirken, nämlich eine bestimmte Sicht auf und Haltung zu diesen Per- 
sonen und dem, wofür sie in der deutschen Geschichte stehen. Die durch die Darstellung bewirkte Distanz kann zudem einen Verfremdungseffekt haben und dazu führen, Positives und Negatives mit historischem Abstand angemessen zu beurteilen. Die Zeit um 1800 erscheint damit, wie andere Epochen, als Epoche eigenen historischen Rechtes, die man nicht als Vorgeschichte des NS verwerfen muss, sondern deren Leistungen man angemessen würdigen kann, ohne sie in unzulässiger Weise glorifizieren zu müssen.

Sofern die vorangehende Analyse zutreffend ist, stellt sich die Frage, warum dieses Applikationspotenzial dem Anschein nach selten oder kaum realisiert worden ist. Dazu ließen sich verschiedene Hypothesen aufstellen, denen im Rahmen dieser Arbeit allerdings nicht nachgegangen werden kann. Ein Grund könnte in den gewählten Darstellungstechniken zu finden sein. Ironie, Satire und Komik lassen Dargestelltes häufig potenziell mehrdeutig erscheinen. ${ }^{268}$ Ferner könnte bisweilen ein generisches Missverständnis vorliegen. Hier wurde angenommen, dass der Text ein historischer Roman ist. ${ }^{269}$ Der Roman kann jedoch, wie gesehen, anders klassifiziert werden, was dann Folgen für das Textverstehen haben kann. ${ }^{270}$ Nicht zuletzt wäre zu prüfen, ob das identifizierte

268 Zur im Rahmen dieser Arbeit eher behaupteten als belegten These, dass Ironie, Satire und Komik im Roman eine wichtige Rolle spielen, vgl. Stefan Balzter: Wo ist der Witz? Techniken zur Komikerzeugung in Literatur und Musik. Berlin 2013, S. 245-262; Anja Gerigk: Humoristisches Erzählen im 21. Jahrhundert. Gegenwärtige Tradition in Kehlmanns Vermessung der Welt und Krachts Imperium. In: Wirkendes Wort 64 (2014), S. 427-439, hier S. 429-434; Stephanie Catani: Formen und Funktionen des Witzes, der Satire und der Ironie in Die Vermessung der Welt. In: Nickel: Daniel Kehlmanns Die Vermessung der Welt, S. 198-215.

269 In der Forschung wird der Roman bisweilen als (postmoderner) historischer Roman begriffen, vgl. Friedhelm Marx: Die Vermessung der Welt als historischer Roman. In: Nickel: Daniel Kehlmanns Die Vermessung der Welt, S. 169-185; Simone Costagli: Ein postmoderner historischer Roman: Daniel Kehlmanns Die Vermessung der Welt. In: Gegenwartsliteratur. Ein germanistisches Jahrbuch 11 (2012), S. 261-279; Marc Chraplak: Ein postmoderner historischer Roman? Menippeische Satire und karnevaleske Tradition in Daniel Kehlmanns Die Vermessung der Welt (2005). In: Weimarer Beiträge 61 (2015), S. 485-501; Stefan Neuhaus: „Die Fremdheit ist ungeheuer“. Zur Rekonzeptualisierung historischen Erzählens in der Gegenwartsliteratur. In: Carsten Gansel/Elisabeth Herrmann (Hg.): Entwicklungen in der deutschsprachigen Gegenwartsliteratur nach 1989. Göttingen 2013, S. 23-36, zu Kehlmanns Roman S. 30-32; Max Doll: Der Umgang mit Geschichte im historischen Roman der Gegenwart. Am Beispiel von Uwe Timms Halbschatten, Daniel Kehlmanns Vermessung der Welt und Christian Krachts Imperium. Frankfurt a. M. 2017, S. 245-344.

270 Das gilt auch für die Forschung, wo der Roman zur ,neuen deutschen Reiseliteratur` gezählt oder als Genieroman aufgefasst werden kann, vgl. Alexander Honold: Ankunft in der Weltliteratur. Abenteuerliche Geschichtsreisen mit Ilija Trojanow und Daniel Kehlmann. In: Neue Rundschau 118 (2007), S. 82-104, hier S. 92-98; Wieblitz: Geniale Bestseller. Gegen die 
Applikationspotenzial vielleicht relativ komplex ist, da es wohl mitunter eine genauere Lektüre ebenso voraussetzt wie den Versuch, die verschiedenen Teilthemen aufeinander $\mathrm{zu}$ beziehen. Jedenfalls ist es einfacher, einzelne Teilthemen $\mathrm{zu}$ isolieren und $\mathrm{zu}$ applizieren, hinsichtlich von Wissen und Wissenschaft, Aufklärungs- und Vernunftkritik und all den anderen, die in den Rezeptionsdokumenten ausgemacht werden konnten. ${ }^{271}$

Süskinds Das Parfum ist ein Roman, der aufgrund seiner Beschaffenheit eigentlich ein geringes Applikationspotenzial besitzt und sich eher für andere Formen des Umgangs eignet. Vor diesem Hintergrund überrascht es, dass sich in den Rezeptionsdokumenten trotzdem verhältnismäßig viele Versuche ausmachen lassen, Gehalte des Textes zu applizieren. Schlinks Der Vorleser ist ein Roman, der sich relativ gut eignet für Applikationen, zum einen aufgrund der verschiedenen Themen, die im Text angesprochen werden, zum anderen aufgrund formaler Aspekte, etwa der Erzählerfigur, die explizit und wiederholt das Geschehen reflektiert und bewertet, allerdings ohne eine autoritative Deutung anzubieten - und aufgrund der Erzählsituation überhaupt anbieten zu können. Das, was als zentrale Applikationsmöglichkeit des Gesamttextes ausgemacht werden kann, wird durchaus erkannt, allerdings in, verhältnismäßig gesehen, wenigen Quellen. Kehlmanns Die Vermessung der Welt schließlich ist ein Roman, der ebenfalls ein hohes Applikationspotenzial besitzt, das aber nicht in dem zu erwartenden Umfang realisiert zu werden scheint. Während ähnlich wie

\footnotetext{
Auffassung, es handele sich um eine Doppelbiographie, argumentiert Lars Korten: Daniel Kehlmann, Die Vermessung der Welt. In: Mitteilungen des deutschen Germanistenverbandes 57 (2010), S. 197-207. Zum Roman als postmodernem Roman vgl. Joshua Kovaloski: Periodicity and National Identity in Daniel Kehlmann's Die Vermessung der Welt. In: Gegenwartsliteratur. Ein germanistisches Jahrbuch 9 (2010), S. 263-287. Außerdem wurde die Auffassung vertreten, dass der Roman sich nicht genau klassifizieren lasse, vgl. Inka Ulrike Paul: Geschichte und Literatur, Organon der Selbsterkenntnis. Über Daniel Kehlmanns Roman Die Vermessung der Welt (2005). In: I. U. P./Richard Faber (Hg.): Der historische Roman zwischen Kunst, Ideologie und Wissenschaft. Würzburg 2013, S. 159-178, hier S. 161.

271 In der Forschung wurde der Roman als Rationalitäts-, Zivilisations- und Wissenschaftskritik interpretiert, vgl. Márta Horváth: Der Alte und der Greis. Rationalitätskritik in Daniel Kehlmanns Die Vermessung der Welt. In: Attila Bombitz (Hg.): Brüchige Welten. Von Doderer bis Kehlmann. Einzelinterpretationen. Szeged/Wien, S. 251-260; Preußer: Zur Typologie der Zivilisationskritik; Sean Ireton: Lines and Crimes of Demarcation: Mathematizing Nature in Heidegger, Pynchon, and Kehlmann. In: Comparative Literature 63 (2011), S. 142-160. Zur Partizipation des Romans an Wissensbeständen vgl. Christoph Deupmann: Poetik der Indiskretion. Zum Verhältnis von Literatur und Wissen in Daniel Kehlmanns Die Vermessung der Welt. In: Carsten Rohde/Hansgeorg Schmidt-Bergmann (Hg.): Die Unendlichkeit des Erzählens. Der Roman in der deutschsprachigen Gegenwartsliteratur. Bielefeld 2013, S. 237-256.
} 
bei Schlink in der Tendenz vor allem partielle Applikationen einzelner Sachverhalte vorkommen, wird die dem Romanganzen zuzuordnende Applikationsmöglichkeit nicht oder nur sehr bedingt erkannt (oder kommuniziert), soweit es sich auf Grundlage der ausgewerteten Rezeptionszeugnisse sagen lässt. 